\author{
UNIVERSIDADE DE SÃo PAUlo \\ InstituTo DE FísicA DE SÃo CARLOS \\ DEPARTAMENTO DE FísICA E INFORMÁTICA
}

\title{
CARACTERIZAÇÃO DE DESEMPENHO DE UMA REDE ATM
}

\begin{abstract}
André Muezerie
Dissertação apresentada ao Instituto de Física de São Carlos, Universidade de São Paulo, para obtenção do título de Mestre em Física Aplicada.
\end{abstract}

Orientador: Prof. Dr. Jan Frans Willem Slaets

SÃo CARLOS

2001 
Dedico este trabalho à Márcia, que sempre tem me confortado nos momentos difíceis. 


\section{Agradecimentos}

Ao Prof. Dr. Jan F. W. Slaets, por todo apoio e compreensão dispensados durante a orientação deste trabalho.

Ao prof. Dr. Gonzalo Travieso por sua disposição em bem atender a ocasionais pedidos de ajuda, mesmo que não diretamente relacionados ao seu trabalho.

Ao Prof. Dr. Carlos Antônio Ruggiero, pelo empréstimo de material pessoal relacionado ao trabalho.

À minha mãe, que criou-me com muito carinho e educação possibilitando que eu me tornasse o que sou hoje.

Aos colegas do grupo: Bruno, Zem, Paulino, Francisco, Raul, Patrícia, Cláudio, Thaty e especialmente Elô, cuja amizade já vem de longa data. 
Agradeço à FAPESP pelo suporte financeiro. 


\section{Sumário}

1 Introdução 1

2 Conceitos básicos 3

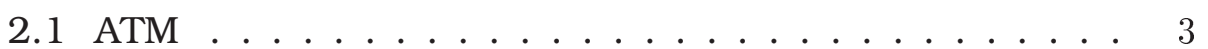

2.2 Camada física da arquitetura ATM . . . . . . . 10

2.3 Camada ATM . . . . . . . . . . . . . . 11

2.4 Camada de adaptação ATM (AAL) . . . . . . . . . 12

2.5 Camada de adaptação AAL5 . . . . . . . . . . . 13

2.6 Protocolo Internet (IP) $\ldots \ldots \ldots$

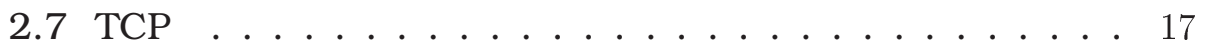

$2.7 .1 \mathrm{MSS} \ldots \ldots \ldots \ldots \ldots$

2.7.2 Mecanismos de controle de fluxo . . . . . . . 21

2.7.3 Fast retransmit e fast recovery . . . . . . . . . 22

2.7.4 Window Scaling . . . . . . . . . . . . 23

2.7.5 Análise do TCP sobre ATM . . . . . . . . . 24

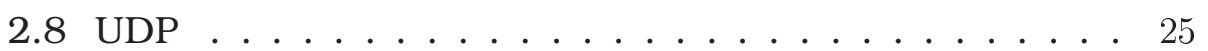

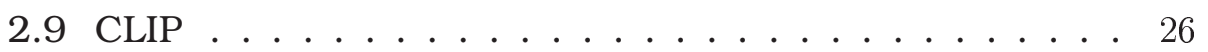

2.9.1 Encapsulamento dos pacotes . . . . . . . 26

2.9 .2 Funcionamento . . . . . . . . . . . 28

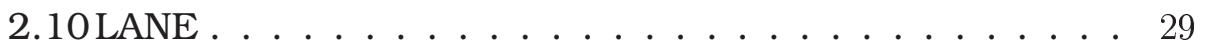

2.10.1 Encapsulamento de dados com LANE . . . . . . . 30 
2.10.2 Componentes e Tipos de Conexões . . . . . . . 31

2.11 Cálculo do throughput . . . . . . . . . . 33

3 Hardware Utilizado 38

3.1 A Interface MultiKron II . . . . . . . . . . . . . 38

3.1 .1 Introdução . . . . . . . . . . . . . 38

3.1.2 Registro de Eventos . . . . . . . . . . . 39

3.2 Interface ATM ForeRunner LE $155 \ldots \ldots$

3.3 Interface Fast EtherLink XL PCI 10/100 . . . . . . 43

3.4 Chave ATM . . . . . . . . . . . . . . . 44

3.5 Chave Fast Ethernet . . . . . . . . . . . . . 44

3.6 Montagem experimental . . . . . . . . . . . . . 44

3.7 Configuração dos computadores . . . . . . . . . . 45

4 Medidas experimentais de throughput 47

4.1 Introdução . . . . . . . . . . . . . . . 47

4.2 Throughput medido com FTP . . . . . . . . . 48

4.3 Throughput medido com Netperf . . . . . . . . 50

4.3.1 Teste de performance da máquina . . . . . . . 52

4.3.2 Throughput TCP sobre CLIP com Netperf . . . . 53

4.3.3 Throughput UDP sobre CLIP com Netperf . . . . 56

4.3.4 Throughput TCP sobre LANE com Netperf . . . . 60

4.3.5 Throughput UDP sobre LANE com Netperf . . . . 61

4.3.6 Throughput TCP sobre Fast Ethernet com Netperf 63

4.3.7 Throughput UDP sobre Fast Ethernet com Net-

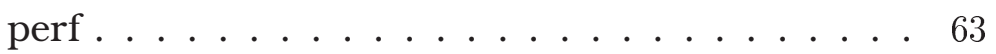

4.4 Resumo dos resultados . . . . . . . . . . . . . 64

5 Medidas experimentais de latência 68

5.1 Latência medida com ping . . . . . . . . . . 68

5.1 .1 Ping sobre CLIP . . . . . . . . . . 68 
5.1 .2 Ping sobre LANE . . . . . . . . . . 70

5.1.3 Ping sobre Fast Ethernet . . . . . . . . . . . 72

5.2 Latência de aplicativo a aplicativo com sockets . . . . 73

5.2.1 Latência do TCP sobre CLIP . . . . . . . . 75

5.2 .2 Latência do UDP sobre CLIP . . . . . . . . . 76

5.2.3 Latência do TCP sobre LANE . . . . . . . . . 76

5.2.4 Latência do UDP sobre LANE . . . . . . . . . 78

5.2.5 Latência do TCP sobre Fast Ethernet . . . . . . . 78

5.2.6 Latência do UDP sobre Fast Ethernet . . . . . . . 79

5.3 Latência de aplicativo a driver e latência no meio físico 81

5.3.1 Uso das interfaces MultiKron no kernel . . . . . 82

5.3.2 Uso de gettimeofday( ) para medida de latência no kernel . . . . . . . . . . . . . . . . 86

5.3.3 Obtenção dos dados experimentais . . . . . . 89

5.3.4 Latência no kernel com TCP sobre CLIP . . . . . 90

5.3.5 Latência no kernel com UDP sobre CLIP . . . . . 91

5.3.6 Latência no kernel com UDP sobre LANE . . . . 92

5.3.7 Latência no kernel com TCP sobre LANE . . . . . 93

5.4 Resumo dos resultados . . . . . . . . . . . . . 93

6 Conclusões $\quad 95$ 


\section{Lista de Figuras}

2.1 Formato de uma célula ATM . . . . . . . . . . 4

2.2 Formato do header das células ATM UNI e NNI . . . . . 4

2.3 Estrutura do campo PT do header da célula ATM . . . . 5

2.4 Hierarquia de canais em uma rede ATM $\ldots \ldots$. . . 7

2.5 Comutação de caminhos e circuitos realizada no interior de uma chave ATM . . . . . . . . . . . 9

2.6 Estrutura da camada AAL5 . . . . . . . . . . . . . 14

2.7 Formato do CPCS-PDU da camada AAL5 . . . . . . . . 15

2.8 Formato do datagrama IP versão $4 \ldots \ldots$. . . . . 17

2.9 Formato do datagrama TCP . . . . . . . . . 20

2.10 Formato do datagrama UDP . . . . . . . . . 26

2.11 Formato do LAN Emulation Data Frame para IEEE 802.3 / Ethernet . . . . . . . . . . . . . 30

2.12 Throughput teórico oferecido às camadas superiores à AAL5 em função do tamanho do PDU . . . . . . . . . . 35

2.13 Throughput teórico oferecido à camada IP em função do tamanho do PDU para CLIP . . . . . . . . . 36

3.1 Interface de rede utilizando o chip NICStAR . . . . . 43

3.2 Montagem experimental utilizada . . . . . . . . 45

4.1 Habilitação do DMA para o disco EIDE e verificação da sua taxa de transferência . . . . . . . . . . . . . 48 
4.2 Exemplo de uso do aplicativo Netperf . . . . . . . . . 51

4.3 Throughput em função do tamanho da mensagem utilizando Netperf com TCP sobre IP tendo localhost como destino para mensagens pequenas . . . . . . . 53

4.4 Throughput em função do tamanho da mensagem utilizando Netperf com TCP sobre CLIP . . . . . . . . . 54

4.5 Throughput para mensagens pequenas em função do tamanho da mensagem utilizando Netperf com TCP sobre CLIP . . . . . . . . . . . . . . . 54

4.6 Throughput em função do tamanho da mensagem utilizando Netperf com TCP sobre CLIP . . . . . . . . 55

4.7 Throughput no lado transmissor em função do tamanho da mensagem utilizando Netperf com UDP sobre CLIP utilizando placa de vídeo externa em donald . . . . . 56

4.8 Throughput no lado receptor em função do tamanho da mensagem utilizando Netperf com UDP sobre CLIP utilizando placa de vídeo externa em donald . . . . . 57

4.9 Throughput em função do tamanho da mensagem no lado transmissor utilizando Netperf com UDP sobre CLIP utilizando placa de vídeo externa em donald . . . 57

4.10 Throughput em função do tamanho da mensagem no lado receptor utilizando Netperf com UDP sobre CLIP utilizando placa de vídeo externa em donald . . . . . 58

4.11 Throughput em função do tamanho da mensagem no lado receptor utilizando Netperf com UDP sobre CLIP utilizando placa de vídeo externa em donald . . . . . 58 4.12 Throughput em função do tamanho da mensagem no lado receptor utilizando Netperf com UDP sobre CLIP utilizando placa de vídeo onboard em donald . . . . . . 59 
4.13 Throughput em função do tamanho da mensagem uti-

lizando Netperf com TCP sobre LANE . . . . . . . . . . 60

4.14 Throughput em função do tamanho da mensagem uti-

lizando Netperf com TCP sobre LANE . . . . . . . . 61

4.15 Throughput em função do tamanho da mensagem no

lado transmissor utilizando Netperf com UDP sobre

LANE . . . . . . . . . . . . . . . . . . 6 62

4.16 Throughput em função do tamanho da mensagem no

lado receptor utilizando Netperf com UDP sobre LANE 62

4.17 Throughput em função do tamanho da mensagem uti-

lizando Netperf com TCP sobre Fast Ethernet . . . . . . 63

4.18 Throughput em função do tamanho da mensagem uti-

lizando Netperf com TCP sobre Fast Ethernet . . . . . . 64

4.19 Throughput em função do tamanho da mensagem no

lado receptor utilizando Netperf com TCP sobre Fast

Ethernet .................... 65

4.20 Throughput em função do tamanho da mensagem no

lado receptor utilizando Netperf com TCP sobre Fast

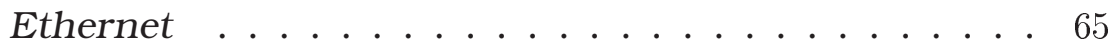

5.1 Saída do aplicativo ping de uma máquina para ela mesma sobre CLIP . . . . . . . . . . . . . 69

5.2 Saída do aplicativo ping de uma máquina para outra sobre CLIP . . . . . . . . . . . . . 70

5.3 Saída do aplicativo ping de uma máquina para a chave ATM sobre CLIP . . . . . . . . . . . . . 71

5.4 Saída do aplicativo ping de uma máquina para ela mesma sobre LANE . . . . . . . . . . . . . 71

5.5 Saída do aplicativo ping de uma máquina a outra sobre LANE . . . . . . . . . . . . . . . . 72 
5.6 Saída do aplicativo ping de uma máquina para a chave ATM sobre LANE . . . . . . . . . . . . . . . . 73

5.7 Saída do aplicativo ping de uma máquina a outra sobre Fast Ethernet . . . . . . . . . . . . . . . . 74

5.8 Latência de aplicativo a aplicativo em função do tamanho da mensagem utilizando sockets TCP sobre CLIP . . . 75

5.9 Latência de aplicativo a aplicativo em função do tamanho da mensagem utilizando sockets TCP sobre CLIP com escala reduzida no eixo vertical . . . . . . . . . 76

5.10 Latência de aplicativo a aplicativo em função do tamanho da mensagem utilizando sockets UDP sobre CLIP . . . 77

5.11 Latência de aplicativo a aplicativo em função do tamanho da mensagem utilizando sockets TCP sobre LANE $\ldots 77$

5.12 Latência de aplicativo a aplicativo em função do tamanho da mensagem utilizando sockets TCP sobre LANE com escala reduzida no eixo vertical . . . . . . . . . 78

5.13 Latência de aplicativo a aplicativo em função do tamanho da mensagem utilizando sockets UDP sobre LANE . . . 79

5.14 Latência de aplicativo a aplicativo em função do tamanho da mensagem utilizando sockets TCP sobre Fast Ethernet .................. 80

5.15Latência de aplicativo a aplicativo em função do tamanho da mensagem utilizando sockets TCP sobre Fast Ethernet com escala reduzida no eixo vertical . . . . . . . . 80

5.16 Latência de aplicativo a aplicativo em função do tamanho da mensagem utilizando sockets UDP sobre Fast Ethernet ..................... 81 
5.17 Latência de aplicativo a aplicativo em função do tamanho da mensagem para mensagens pequenas utilizando sockets UDP sobre Fast Ethernet . . . . . . . . . . . . . 82

5.18 Espaçamento temporal das mensagens enviadas do aplicativo cliente para o servidor utilizadas para determinação da latência de comunicação no kernel . . . . . 90 


\section{Lista de Tabelas}

2.1 Tabela de comutação de caminhos e circuitos virtuais de uma chave ATM . . . . . . . . . . . 8

2.2 Divisão de camadas da arquitetura ATM . . . . . . 9

2.3 Classes de Serviço originais mantidas pela AAL . . . . . 12

3.1 Configuração dos dois computadores utilizados . . . . . 46

4.1 Valores de throughput máximos teóricos e obtidos com a transferência de um arquivo grande via FTP . . . . . . 50

6.1 Tabela comparativa das latências obtidas com o aplicativo ping para LANE, CLIP e Fast Ethernet . . . . . . 96 


\section{Lista de Acrônimos}

AAL ATM Adaptation Layer

ABR Available Bit Rate

AMD Advanced Micro Devices

API Application Program Interface

ARP Address Resolution Protocol

ATM Asynchronous Transfer Mode

ATMARP ATM Address Resolution Protocol

B-ISDN Broadband Integrated Services Digital Network

BUS Broadcast and Unknown Server

CBR Constant Bit Rate

CLIP Classical IP

CLP Cell Loss Priority

CP Common Part

CPCS Common Part Convergence Sublayer

CPI Common Part Indicator 
CPU Central Processing Unit

CRC Cyclic Redundancy Check

CS Convergence Sublayer

DMA Direct Memory Access

EIDE Enhanced IDE

ELAN Emulated LAN

FE Fast Ethernet

FTP File Transfer Protocol

GB $10^{9}$ (Giga) Bytes

Gbps $10^{9}$ (Giga) bits por segundo

GFC Generic Flow Control

HEC Header Error Control, Header Error Check

ICMP Internet Control Message Protocol

IEEE Institute of Electrical and Electronics Engineers

IETF Internet Engineering Task Force

ILMI Interim Local Management Interface

InATMARP Inverse ATM Address Resolution Protocol

IP Internet Protocol

ISDN Integrated Service Digital Network

ISO International Organization for Standardization

ITU International Telecommunication Union 
ITU-T ITU - Telecommunication Standardization Sector

KB $10^{3}$ (Kilo) Bytes

LAN Local Area Network

LANE LAN Emulation

LASER Light Amplification by Stimulated Emission of Radiation

LEC LAN Emulation Client

LECS LAN Emulation Configuration Server

LED Light Emitting Diode

LES LAN Emulation Server

LIS Logical IP Subnetwork

LLC Logical Link Control

MAC Media Access Control

MB $10^{6}$ (Mega) Bytes

Mbps $10^{6}$ (Mega) bits por segundo

MPOA Multi-Protocol over ATM

MTU Maximum Transmission Unit

MSS Maximum Segment Size

NIST National Institute of Standards and Technology

NNI Network to Network Interface

OAM Operation, Administration and Maintenance

OSI Open Systems Interconnection 
PCI Peripheral Component Interconnect

PDU Protocol Data Unit

PT Payload Type

PTI Payload Type Indicator

PVC Permanent Virtual Circuit

QoS Quality of Service

RAM Random Access Memory

RFC Request For Comments

RTT Round Trip Time

SAP Service Access Point

SAR Segmentation And Reassembly

SDH Synchronous Digital Hierarchy

SDU Service Data Unit

SEAL Simple Efficient Adaptation Layer

SNAP SubNetwork Attachment Point

SONET Synchronous Optical NETwork

SRAM Static RAM

SS Service Specific

SSCS Service Specific Convergence Sublayer

STS Syncronous Transport Signal

SVC Switched Virtual Circuit 
TC Transmission Convergence

TCP Transmission Control Protocol

UBR Unspecified Bit Rate

UDP User Datagram Protocol

UNI User to Network Interface

UTOPIA Universal Test and Operations Physical Interface for ATM

UTP Unshielded Twisted Pair

UU User to User

VBR Variable Bit Rate

VC Virtual Circuit, Virtual Channel, Virtual Connection

VCC Virtual Channel Connection

VCI Virtual Channel Identifier

VP Virtual Path

VPC Virtual Path Connection

VPI Virtual Path Identifier

WWW World Wide Web 


\section{Resumo}

Esta presente dissertação descreve métodos e medidas obtidas relativas ao desempenho dos protocolos Classical IP e LAN Emulation na plataforma Linux com conectividade ATM. Medidas comparativas foram realizadas com a tecnologia Fast Ethernet, que possui uma capacidade de transmissão relativamente próxima da ATM de $155 \mathrm{Mbps}$, mas uma forma de funcionamento bastante diferente. As características avaliadas na comunicação entre os computadores foram a taxa de transmissão, a latência e o jitter. A interface MultiKron II foi utilizada para a obtenção de sincronismo nas medidas de tempo efetuadas nos computadores para a determinação da latência. Maior enfoque foi dado às medidas de aplicativo a aplicativo, mas foram também realizadas medidas de tempo no interior do kernel do Linux para a determinação das latências de transmissão dos equipamentos de rede e do overhead imposto pelas diversas camadas de protocolos. Dificuldades de realização de medidas no kernel assim como a dependência do desempenho do sistema com relação à sua configuração são também descritas. 


\section{Abstract}

The present dissertation describes methods and measurements used to evaluate the performance of Classical IP and LAN Emulation network protocols. The data was collected on PCs with ATM 155Mbps interfaces using the Linux operating system. Comparative data with Fast Ethernet technology was also collected. The observed features of the communication between the computers were throughput, latency and jitter. To determine the latency of the network, MultiKron II interfaces driven by a shared clock were used on both computers to synchronize the data collections. Since most of the traffic consists of application to application communication this topic is treated in detail. Latencies due to the protocol overhead in the Linux kernel as well as those produced by the network were determined. Solutions used to bypass the limitations of the MultiKron software needed to determine the latency produced by the Linux kernel are also discussed. Finally the experimentally observed relation between network performance and hardware configuration is discussed. 


\section{Capítulo 1}

\section{Introdução}

Historicamente o volume de transmissões de dados vem aumentando muito mais que a transmissão tradicional de voz. Este fato, aliado à implantação em larga escala de fibras ópticas e ao desenvolvimento da arquitetura dos equipamentos comutadores de dados, contribuiu para a criação da tecnologia ATM, que visava a utilização da nova infra-estrutura digital também para a transmissão de dados. Ela foi rapidamente vista como uma substituta a todas as outras tecnologias de redes utilizadas até então [ATMO1], trazendo consigo uma filosofia revolucionária de comutação de células de tamanho fixo através de canais virtuais estabelecidos através de uma estrutura de rede física (serviço orientado à conexão), enquanto que tradicionalmente as grandes redes de computadores realizavam roteamento de datagramas, fazendo intensivo uso do protocolo IP, com a intenção de fazer o melhor possível para que o datagrama chegasse ao destino [Com95b]. Uma vez que o ATM foi criado a partir de uma tecnologia perfeitamente adequada à transmissão de voz mas totalmente nova no mundo das redes de computadores, fica no ar a questão do seu desempenho frente às diferentes necessidades dos aplicativos. 
Este trabalho se dedica à análise de desempenho do protocolo IP sobre uma rede ATM, tanto do tipo Classical IP quanto do tipo LAN Emulation. As características estudadas foram throughput, latência de comunicação de aplicativo a aplicativo, latência de comunicação de aplicativo a nível físico e jitter.

O capítulo 2 descreve brevemente a tecnologia ATM, assim como os protocolos de rede envolvidos. É feita ainda uma análise do throughput teórico alcançável pela rede em função do tamanho dos pacotes que por ela trafegam.

A seguir, no capítulo 3 é feito um levantamento do hardware utilizado no trabalho e é também descrita a montagem dos equipamentos com as respectivas topologias de rede.

Nos capítulos 4 e 5 são apresentados os resultados experimentais obtidos para throughput e latência, respectivamente, assim como a metodologia adotada para sua obtenção.

As conclusões do trabalho são apresentadas no capítulo 6 . 


\section{Capítulo 2}

\section{Conceitos básicos}

\section{$2.1 \quad$ ATM}

O Asynchronous Transfer Mode (ATM) é uma tecnologia de rede que se localiza nos níveis de enlace e físico do modelo Open Systems Interconnection (OSI), baseada na transmissão de pequenas unidades de informação de tamanho fixo e formato padronizado denominadas células. Foi desenvolvida para ser uma única rede de transporte para diversos serviços, tanto para redes locais como de longa distância, devendo ser muito escalável e apresentar baixos atrasos de comutação. Sua grande promessa é a integração eficiente de dados e tráfego multimídia com voz e vídeo através da garantia de qualidade de serviço (QoS).

O tamanho das células é pequeno e fixo para facilitar a multiplexação de diferentes fluxos de informação através da rede. Isto permite que uma informação de maior importância possa ser priorizada em relação a uma informação de menor relevância sem a necessidade de remanejamentos complexos das unidades de informação.

Toda célula precisa possuir uma certa quantidade de informa- 


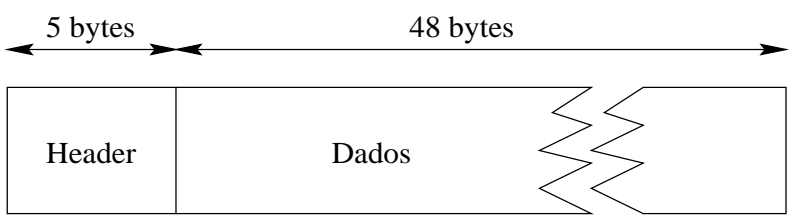

Figura 2.1: Formato de uma célula ATM.

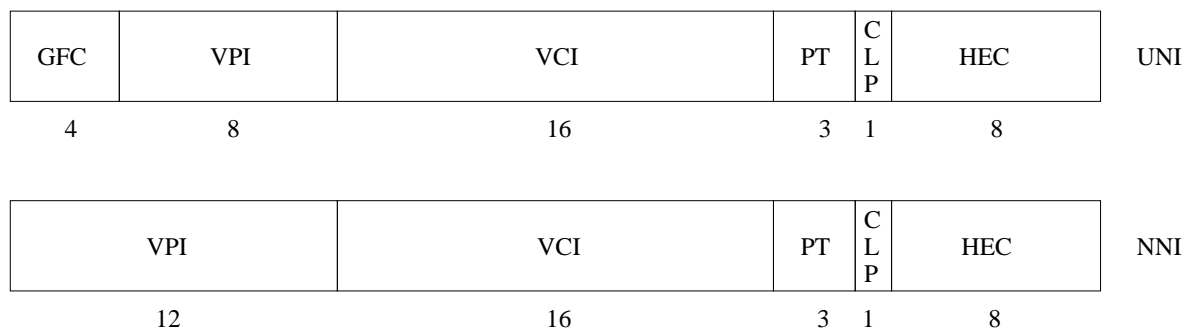

Figura 2.2: Formato do header das células ATM UNI e NNI.

ção para indicar onde ela deve ir, além de algumas informações adicionais descritas logo a seguir. Tais informações ficam armazenadas no cabeçalho (header), sendo que a informação de interesse a ser transmitida fica armazenada no restante da célula, chamado de payload. Entretanto, geralmente os dados do usuário são ainda encapsulados por outros protocolos, alguns dos quais serão descritos futuramente, fazendo com que nem sempre uma célula carregue 48 bytes de dados do usuário. O formato de uma célula ATM é mostrado na figura 2.1 e o dos cabeçalhos das células para as interfaces User to Network Interface (UNI) e Network to Network Interface (NNI) são apresentados na figura 2.2. É notável que um header de 5 bytes impõe um overhead bastante considerável para um payload de 48 bytes, porém, um payload maior por célula dificultaria a multiplexação eficiente de dados com conexões de voz.

As seguintes informações fazem parte dos cabeçalhos de uma célula ATM:

GFC (controle de fluxo genérico, do inglês Generic Flow Control): 


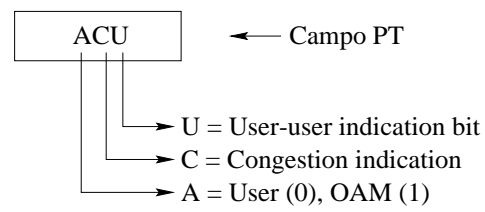

Figura 2.3: Estrutura do campo PT do header da célula ATM.

somente presente nas células UNI, sua função é controlar a quantidade de dados que entra na rede para evitar congestionamentos. Entretanto, essa funcionalidade está no campo PT, não sendo o campo GFC usado na prática.

VPI (identificador de caminho virtual, do inglês Virtual Path Identifier): identifica o caminho virtual que a célula deve seguir até o próximo elemento comutador da rede. Representa um mecanismo para direcionar um feixe de canais virtuais através da rede com um mínimo de processamento. Este campo apresenta tamanhos diferentes na UNI e NNI.

VCI (identificador de canal virtual, do inglês Virtual Channel Identifier): identifica o canal virtual que a célula deve seguir até o próximo elemento comutador da rede.

PT (tipo de dados, do inglês Payload Type): também conhecido por PTI (identificador do tipo de dado, do inglês Payload Type Indicator). A estrutura de três bits deste campo está ilustrada na figura 2.3. O bit A serve para indicar se a célula em questão é uma célula de usuário, transportando um payload que precisa ser chaveado adiante através da rede, ou uma célula de gerenciamento (célula OAM), que pode parar em uma chave ou outro tipo de dispositivo dependendo do tipo da célula de gerenciamento.

O bit de indicação de congestão é utilizado no mecanismo de 
controle de fluxo de conexões com qualidade de serviço do tipo Available Bit Rate (ABR). O User-user indication bit é utilizado para indicar que a célula em questão corresponde à última unidade de informação de um CPCS-PDU. Chaves ATM com um algoritmo de descarte de células um pouco mais elaborado (também chamado de Packet Level Discard), ao descartar uma célula, descartam também as células seguintes que vêm pelo mesmo VPI:VCI (já que nas camadas superiores do receptor o PDU não poderá mesmo ser corretamente remontado), até encontrar por este caminho uma célula que esteja com este bit setado, indicando que as próximas células pertencem a outro CPCS-PDU.

CLP (prioridade de perda de célula, do inglês Cell Loss Priority): este bit, quando setado, indica que a célula tem prioridade para descarte em caso de congestionamento e significa que esta célula quebra o contrato estabelecido com a rede. Células com este bit setado são transmitidas pela rede apenas se houver disponibilidade de recursos. Mecanismos de policiamento de tráfego fazem uso deste bit.

HEC (verificação de erro no cabeçalho, do inglês Header Error Check): este campo armazena o resultado de uma geração polinomial com os dados do cabeçalho. Desta forma é possivel detectar e corrigir um erro de um único bit e detectar um erro de múltiplos bits. Vale a pena enfatizar que ele não verifica os 48 bytes de payload da célula.

O envio de dados em uma rede ATM ocorre sobre circuitos virtuais estabelecidos através da estrutura física da rede, conforme mostrado na figura 2.4. A cada canal virtual (VC) é atribuído um 


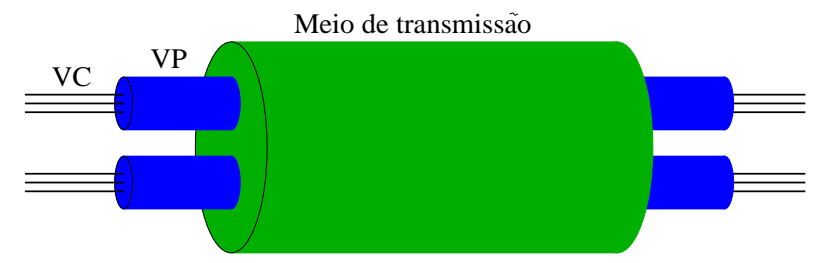

Figura 2.4: Hierarquia de canais em uma rede ATM.

Virtual Channel Identifier (VCI) e uma determinada qualidade de serviço. Desta maneira, um único computador conectado diretamente a uma rede ATM através de um cabo do tipo Unshielded Twisted Pair (UTP), por exemplo, pode estabelecer vários circuitos virtuais, direcionados a um mesmo destino ou não, cada um com sua respectiva qualidade de serviço. Suponhamos que alguns circuitos sejam estabelecidos com qualidade de serviço do tipo Unspecified Bit Rate (UBR) e outros do tipo Constant Bit Rate (CBR). Em caso de congestionamento na rede, os circuitos do tipo UBR podem ser prejudicados enquanto que os circuitos do tipo CBR não serão influenciados pelo congestionamento, uma vez que sua largura de banda é garantida.

Canais virtuais são unidirecionais e portanto quando uma aplicação nativa em ATM ${ }^{1}$ em um computador ATM deseja estabelecer uma comunicação bidirecional com outra aplicação em outro ponto da rede, é necessária a criação de dois canais virtuais, um em cada sentido.

Percebe-se que em uso normal, facilmente um único equipamento ATM pode criar diversos canais simultaneamente. Para facilitar o gerenciamento nas chaves ATM foi criado o conceito de Virtual Path (VP), que agrupa diversos canais virtuais com mesmo ponto

\footnotetext{
${ }^{1}$ É dito que uma aplicação é nativa em ATM quando ela faz uso direto da camada de adaptação AAL, especificando qual o par VPI/VCI a ser utilizado, sem fazer uso dos protocolos TCP/IP
} 
Tabela 2.1: Tabela de comutação de caminhos e circuitos virtuais de uma chave ATM.

\begin{tabular}{|c|c||c|c|}
\hline \multicolumn{2}{|c||}{ Entrada } & \multicolumn{2}{c|}{ Saída } \\
\hline VPI & VCI & VPI & VCI \\
\hline 2 & 3 & 7 & 6 \\
\hline 2 & 9 & 2 & 11 \\
\hline 2 & 7 & 7 & 8 \\
\hline 4 & 5 & 12 & 5 \\
\hline 4 & 6 & 12 & 6 \\
\hline
\end{tabular}

de terminação, como indicado na figura 2.4. Cada caminho virtual possui um Virtual Path Identifier (VPI), que é atribuído assim que o caminho virtual é estabelecido. Todos os circuitos virtuais que dividem o mesmo caminho virtual possuem o mesmo VPI.

A cada célula que alcança o porto de uma chave é verificada uma tabela de comutação, como a tabela 2.1, que para todas as conexões de entrada (par VPI/VCI) identifica por qual porto a célula deve sair e com quais valores para os campos VPI/VCI, indicando a conexão virtual à qual a célula pertence. Na figura 2.5 é ilustrada a comutação de caminhos e circuitos realizada no interior de uma chave.

O VPI presente no cabeçalho das células pode ser modificado pelas chaves ATM, sem necessariamente alterar o VCI destas, processo chamado de comutação de caminhos ou VP switching. A comutação dos caminhos virtuais não implica na comutação dos circuitos virtuais. Assim, comutadores de circuito virtual também são comutadores de caminhos virtuais, mas o contrário não é sempre verdade. 


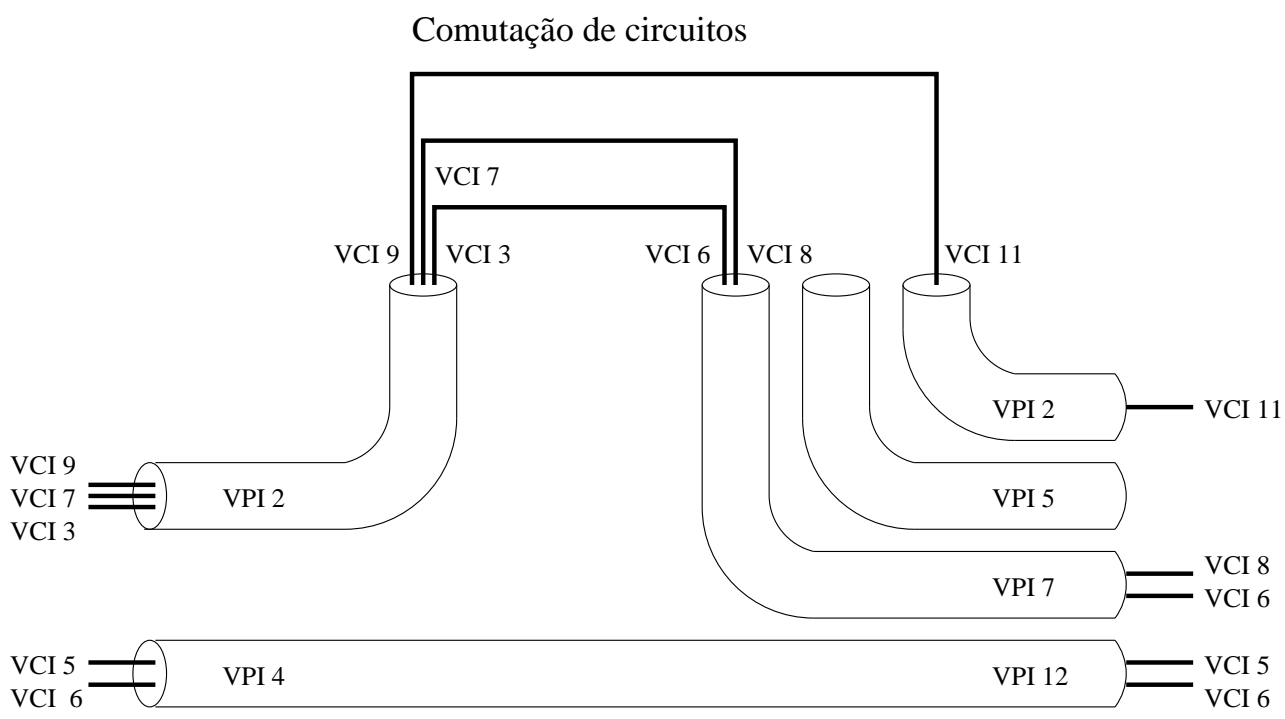

Comutação de caminhos

Figura 2.5: Comutação de caminhos e circuitos realizada no interior de uma chave ATM.

Tabela 2.2: Divisão de camadas da arquitetura ATM.

\begin{tabular}{|c|c|c|c|}
\hline Modelo OSI & Camadas ATM & Subcamadas ATM & Funções das camadas \\
\hline \multirow{3}{*}{$\begin{array}{c}\text { Camada } \\
\text { de } \\
\text { Enlace }\end{array}$} & \multirow{2}{*}{$\begin{array}{l}\text { Camada } \\
\text { de } \\
\text { Adaptação } \\
\text { ATM }\end{array}$} & $\begin{array}{l}\text { Subcamada de } \\
\text { convergência }\end{array}$ & $\begin{array}{l}\text { Convergência } \\
\text { da mensagem }\end{array}$ \\
\hline & & $\begin{array}{l}\text { Subcamada de } \\
\text { Segmenteção }\end{array}$ & $\begin{array}{l}\text { Segmentação e } \\
\text { remontagem }\end{array}$ \\
\hline & $\begin{array}{l}\text { Camada } \\
\text { ATM }\end{array}$ & $\begin{array}{l}\text { Camada } \\
\text { ATM }\end{array}$ & $\begin{array}{l}\text { Controle de fluxo } \\
\text { Proc. cabeçalhos } \\
\text { Translação VPI/VCI } \\
\text { Multiplex. de células }\end{array}$ \\
\hline \multirow[t]{2}{*}{$\begin{array}{l}\text { Camada } \\
\text { Física }\end{array}$} & \multirow[t]{2}{*}{$\begin{array}{l}\text { Camada } \\
\text { Física }\end{array}$} & $\begin{array}{l}\text { Subcamada } \\
\text { de } \\
\text { convergência } \\
\text { de } \\
\text { transmissão }\end{array}$ & $\begin{array}{l}\text { Desacoplamento de } \\
\text { taxa de células } \\
\text { HEC geração/check } \\
\text { Delineamento de células } \\
\text { Adaptação de frame } \\
\text { Geração e rec. de frame }\end{array}$ \\
\hline & & $\begin{array}{c}\text { Subcamada } \\
\text { do meio físico }\end{array}$ & $\begin{array}{l}\text { Sincronização de bits } \\
\text { Transmissão física }\end{array}$ \\
\hline
\end{tabular}




\subsection{Camada física da arquitetura ATM}

A camada física compreende duas sub-camadas: a sub-camada do meio físico e a sub-camada de convergência de transmissão (TC), conforme ilustrado na tabela 2.2.

A primeira delas diz respeito à transmissão de sinais sobre o meio, envolvendo alinhamento de bits e geração e recuperação de sincronismo, seja o meio composto de fios metálicos trançados (cabo UTP) ou fibra óptica. O tipo do meio físico determina o modo de operação desta sub-camada.

A subcamada TC é independente do meio físico empregado. Sua principal tarefa é adaptar as células ATM à capacidade de transmissão do meio físico. Isso é realizado com o auxílio de 5 funções:

1. Geração e recuperação do quadro de transmissão: responsável pela geração dos quadros físicos.

2. Adaptação do quadro de transmissão: responsável pelas ações necessárias para combinar o fluxo de células ATM com o quadro utilizado pelo meio físico. No sentido contrário ela extrai as células do quadro recebido.

3. Delineamento de células: permite recuperar os limites de cada célula dentro da cadeia binária recebida.

4. Geração do Header Error Check (HEC): mecanismo polinomial para detecção e correção de erros nos cabeçalhos das células.

5. Desacoplamento da taxa de células: permite à camada física inserir células vazias no fluxo de células enviadas pela camada superior. Isto pode ser importante para manter a operação da camada física sob uma taxa constante de quadros transmitidos. No receptor as células vazias são descartadas. 


\subsection{Camada ATM}

A principal função da camada ATM é enviar e receber células, independentemente de como estas células são tratadas pela camada física. Ela implementa 4 funções:

1. Multiplexação de células: agrupa as células de todas as conexões virtuais em um único feixe de células.

2. Demultiplexação de células: separa as células recebidas de acordo com as conexões virtuais às quais pertencem.

3. Translação de VPI/VCI: realiza a comutação de células propriamente dita. Em comutadores VP apenas o VPI é modificado, enquanto que em comutadores VC são modificados tanto o VPI quanto o VCI do header das células.

4. Geração e extração de cabeçalho: insere o cabeçalho de célula nos dados que são passados para a camada ATM pelo seu usuário (a camada AAL). O par VPI/VCI é obtido através de um mapeamento do Service Access Point (SAP) utilizado pela camada usuária para transmissão de células e, na recepção, o par VPI/VCI indica o SAP para o qual os dados devem ser entregues. Observa-se que as informações do cabeçalho ATM não são passadas para a camada AAL.

A camada ATM pode ainda realizar a função Generic Flow Control (GFC) para controle de fluxo. Ela é independente do circuito virtual e permite a uma estação marcar as células que excedem a taxa contratada com a rede. 
Tabela 2.3: Classes de Serviço originais mantidas pela AAL.

\begin{tabular}{|c|c|c|c|c|c|c|c|c|}
\cline { 2 - 8 } \multicolumn{1}{c|}{} & $\mathrm{A}$ & & $\mathrm{B}$ & $\mathrm{C}$ & & & & $\mathrm{D}$ \\
\hline $\begin{array}{c}\text { Tempo- } \\
\text { rização }\end{array}$ & $\begin{array}{c}\text { tempo } \\
\text { real }\end{array}$ & $\begin{array}{c}\text { nenhu- } \\
\text { ma }\end{array}$ & $\begin{array}{c}\text { tempo } \\
\text { real }\end{array}$ & $\begin{array}{c}\text { nenhu- } \\
\text { ma }\end{array}$ & $\begin{array}{c}\text { tempo } \\
\text { real }\end{array}$ & $\begin{array}{c}\text { nenhu- } \\
\text { ma }\end{array}$ & $\begin{array}{c}\text { tempo } \\
\text { real }\end{array}$ & $\begin{array}{c}\text { nenhu- } \\
\text { ma }\end{array}$ \\
\hline $\begin{array}{c}\text { Taxa } \\
\text { de bits }\end{array}$ & \multicolumn{3}{c|}{ constante } & \multicolumn{2}{c|}{ variável } & \multicolumn{2}{c|}{ constante } & \multicolumn{2}{c|}{ variável } \\
\hline Modo & \multicolumn{3}{c|}{ Orientado à conexão } & \multicolumn{3}{c}{ Sem conexão } \\
\hline
\end{tabular}

\subsection{Camada de adaptação ATM (AAL)}

Para unificar os diversos tipos de serviços, o ATM utiliza a ATM Adaptation Layer (AAL), que se localiza na parte superior do nível de enlace e efetua a adaptação dos diversos tipos de tráfego que os serviços necessitam. Isto é necessário pois os serviços têm diferentes necessidades. Por exemplo, aplicações multimídia suportam perdas relativamente pequenas nos dados, enquanto que transmissões de dados não, porém, transmissões de dados são tolerantes a atrasos relativamente grandes, sendo que o mesmo não ocorre com transmissões de vídeo ou voz em tempo real.

Pode-se dividir as aplicações de acordo com suas necessidades, diferenciando-as pelas características mencionadas na tabela 2.3, obtendo-se oito serviços distintos.

A ITU-T considerou que somente quatro dos oito serviços eram realmente úteis, e os chamou de classes A, B, C e D. Para especificar cada um destes serviços, a ITU definiu os protocolos AAL1 a AAL4 na recomendação I.363 [ITU93]. Posteriormente, o ITU decidiu que as diferenças entre as AALs 3 e 4 não justificavam a existência de dois protocolos independentes, fundindo-os em um único protocolo, que passou a ser chamado AAL 3/4. Passado algum tempo, o proto- 
colo AAL 3/4 foi considerado complexo e inadequado à transmissão eficiente de dados por redes ATM pelos fabricantes de equipamentos. Foi então proposta pelo ATM Forum a criação de um protocolo mais simples, chamado inicialmente de Simple Efficient Adaptation Layer (SEAL), que foi adotado pelo ITU com o nome de AAL5. Os protocolos Classical IP e LAN Emulation utilizam o protocolo AAL5 e portanto somente ele será descrito com maiores detalhes a seguir. Os demais tipos de AAL estão detalhados na literatura especializada.

A função básica da camada AAL é preparar os dados das camadas superiores para transmissão sobre a rede ATM. Os PDUs a serem transmitidos devem ser segmentados e arranjados nas células ATM de acordo com os requisitos de desempenho de cada aplicação. Este processo de particionamento ocorre na subcamada de segmentação e remontagem (SAR). Outra subcamada da AAL é a subcamada de convergência (CS), que localiza-se logo acima da subcamada SAR, e sua função é adicionar mensagens de controle aos PDUs.

\subsection{Camada de adaptação AAL5}

O protocolo AAL5 é um protocolo simples idealizado para ser utilizado na transmissão de dados sem conexão. Ele não permite multiplexação de mensagens em uma mesma conexão virtual, nem a reordenação de células, pois ele admite que elas são entregues sem erros e sem alteração de ordem. A perda de uma célula ATM pertencente a um PDU AAL5 é detectada por um CRC de 32 bits e pode implicar no descarte de todo o PDU.

A estrutura da camada AAL5 é mostrada na figura 2.6. 


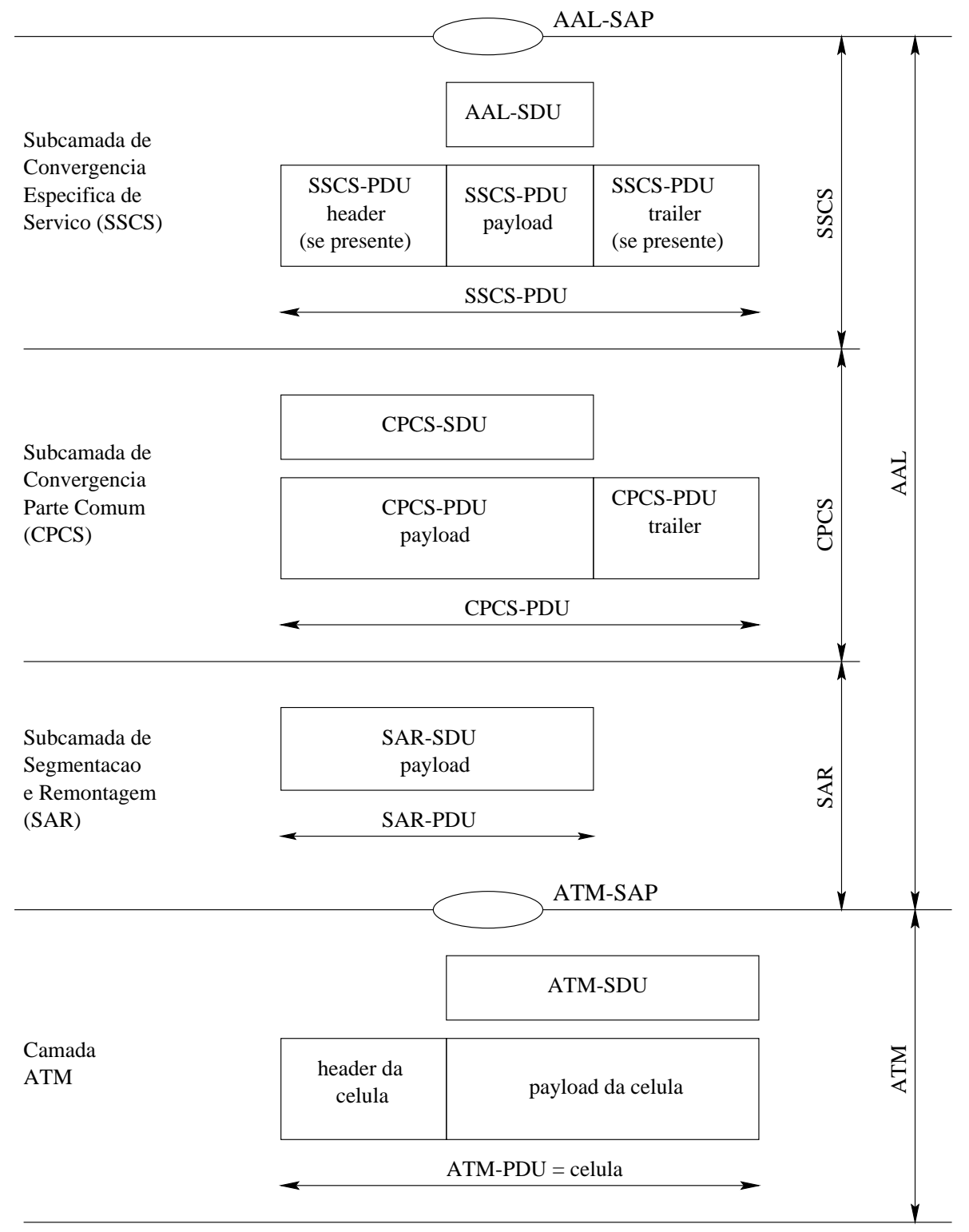

Figura 2.6: Estrutura da camada AAL5. 


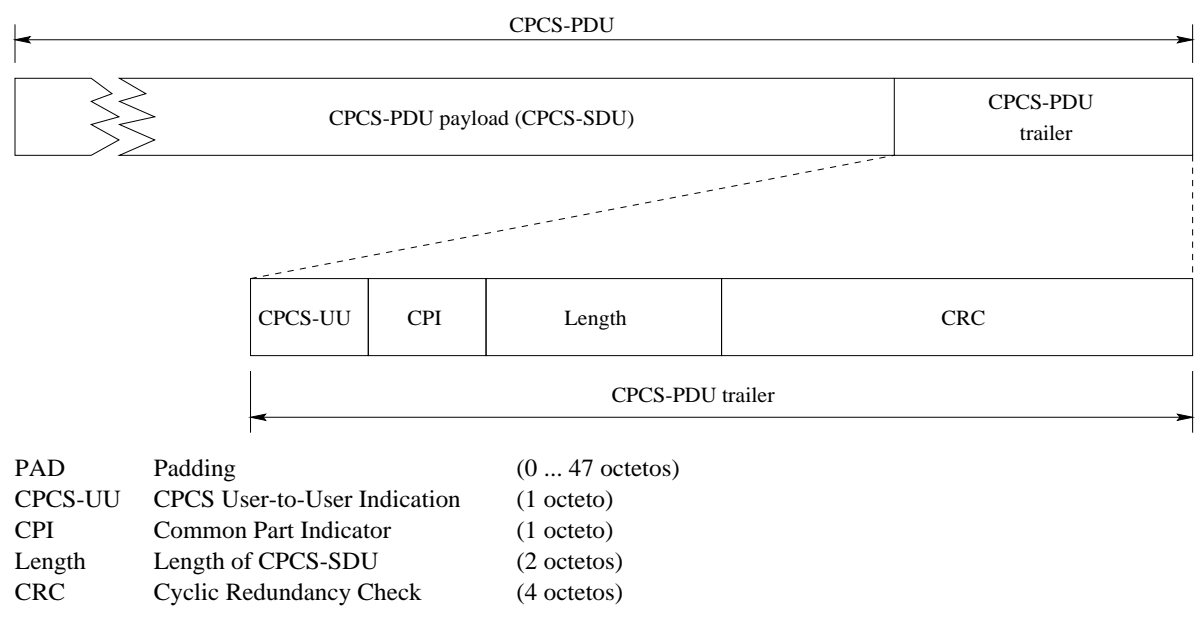

Figura 2.7: Formato do CPCS-PDU da camada AAL5.

O CPCS-PDU da camada AAL5 é ajustado de tal forma que o seu tamanho total (incluindo payload e trailer) seja múltiplo de 48 bytes, permitindo facilmente sua segmentação em um número inteiro de SAR-PDUs. Seu formato é mostrado na figura 2.7, cuja descrição dos campos segue a seguir:

CPCS-PDU payload: é utilizado para transportar o CPCS-SDU e pode ter qualquer tamanho entre 1 e 65535 bytes, sendo que o overhead devido ao encapsulamento é relativamente maior para mensagens pequenas.

UU: é utilizado para transferir informações de usuário para usuário de maneira transparente.

CPI: tem a única função de alinhar o trailer em 64 bits, sendo que futuras funções deste campo estão em estudo. Quando ele é utilizado exclusivamente como padding seu valor deve ser nulo.

Length: armazena o comprimento útil da mensagem e com ele é possível a separação da mensagem do padding. 
$C R C$ : é usado para verificar a integridade da mensagem, detectando eventuais perdas de células que compõem a mensagem. Seu algoritmo está bem descrito em [ITU96]. Vale a pena lembrar que o CRC realizado na camada ATM é feito apenas sobre o cabeçalho das células ATM, e não sobre o seu payload. Certamente o cálculo do CRC representa um overhead no processamento, podendo influenciar na latência de uma transmissão em AAL5. A montagem da SAR-PDU é obtida dividindo-se o CPCS-PDU (que é sempre múltiplo de 48 bytes graças ao padding) em blocos de 48 bytes. O campo payload type é utilizado para indicar qual a última célula pertencente a um PDU AAL5, para que no receptor o PDU possa ser corretamente remontado e seu trailer identificado.

Há ineficiências significativas em mensagens pequenas (de aproximadamente 48 bytes) devido à introdução do padding para tornar a CPCS múltipla de 48 bytes.

A AAL5 é incapaz de multiplexar partes de mensagens em uma mesma conexão virtual, já que seria impossível separá-las na remontagem no lado receptor. As mensagens são enviadas seqüencialmente uma a uma, através de uma conexão virtual. Em conexões vituais distintas não há restrições para o envio de mensagens em paralelo.

\subsection{Protocolo Internet (IP)}

O IP foi inicialmente projetado para permitir a interconexão de redes de computadores que utilizavam tecnologia de comutação de pacotes. O protocolo IP é dito sem conexão, o que significa que cada datagrama é tratado como uma unidade independente, que não 


\begin{tabular}{|c|c|c|c|c|}
\hline \multicolumn{1}{|c|}{4} & \multicolumn{1}{c|}{16} & 24 \\
\hline VERS & HLEN & TOS & \multicolumn{2}{|c|}{ COMPRIMENTO TOTAL } \\
\hline \multicolumn{3}{|c|}{ IDENTIFICACAO } & FLAGS & FRAGMENT OFFSET \\
\hline TTL & PROTOCOLO & HEADER CHECKSUM \\
\hline \multicolumn{4}{|c|}{ ENDERECO IP FONTE } \\
\hline \multicolumn{4}{|c|}{ ENDERECO IP DESTINO } \\
\hline \multicolumn{3}{|c|}{ OPCOES IP (SE HOUVER) } \\
\hline \multicolumn{3}{|c|}{ DADOS } \\
\hline
\end{tabular}

Figura 2.8: Formato do datagrama IP versão 4.

possui relação nenhuma com qualquer outro datagrama.

A versão do protocolo IP discutida aqui é a IPv4 (quarta versão), que foi a utilizada no trabalho.

Cada datagrama IP contém um cabeçalho fixo (header) e um campo de dados (payload), conforme pode ser visto na figura 2.8. As informações contidas no cabeçalho identificam, entre outras coisas, os computadores de origem e destino, o tipo de serviço, o protocolo superior e o comprimento do pacote.

Em datagramas IPv4 sem opções especiais o cabeçalho ocupa 20 bytes.

\subsection{TCP}

Graças ao advento da Internet, o protocolo TCP tornou-se o protocolo de transporte mais utilizado.

Ele é usado como complemento do mecanismo de endereçamento proporcionado pelo protocolo IP (permitindo multiplexar / demultiplexar fluxos TCP sobre IP), que manipula datagramas. O TCP proporciona um serviço de transporte confiável, orientado à conexão, que além de garantir a integridade e o ordenamento dos dados assegura também o controle de fluxo às conexões. Isto é consegui- 
do recorrendo a uma complexa interação entre vários algoritmos e estruturas de dados [Com95a].

Como protocolo confiável, o TCP baseia-se na técnica positive acknowledgement with retransmission, segundo a qual o receptor notifica a fonte, através de uma mensagem de ACKNOWLEDGE, de que recebeu um ou mais pacotes em sequência. Para tal, a fonte guarda um registro de cada pacote que envia, e aguarda uma mensagem de notificação para cada registro. Simultaneamente, é iniciado um temporizador de retransmissão para cada pacote enviado. Quando este temporizador expira, devido a um pacote perdido, uma mensagem de notificação perdida ou um congestionamento na rede, o pacote é retransmitido.

A quantidade de dados que o TCP pode enviar através de uma determinada conexão é limitada por uma janela anunciada pelo receptor e por uma janela de congestionamento, controlada pelo emissor, que varia de acordo com o estado de congestionamento da rede. O TCP guarda o registro dos dados transferidos em bytes apesar de os enviar em pacotes. Cada pacote consiste em um cabeçalho seguido dos dados. O cabeçalho contém informações de controle e identificação das máquinas (endereço IP e número do porto TCP). No cabeçalho consta ainda informação relativa ao número do primeiro byte do próximo pacote que a fonte espera receber (relativamente ao tráfego em sentido oposto). A janela anunciada pelo receptor é transportada no cabeçalho das mensagens dirigidas à fonte, indicando a quantidade de dados que está disposto a aceitar.

Alguns pacotes transportam apenas informações de controle, para pedido de estabelecimento ou encerramento de conexões.

Os mecanismos iniciais de controle de janela e de congestionamento sofreram várias evoluções, principalmente devido ao advento 
de aplicações multimídia e tráfego WWW.

Redes de grandes dimensões geográficas ou com grande largura de banda forçaram a criação de extensões no TCP, como são os mecanismos de Window Scaling [Fox89] e Fast Retransmit/Fast Recovery [Ste01]. Porém, tudo isto não foi ainda de encontro a algumas particularidades lesivas do TCP nestes novos cenários. O mecanismo de slow start em determinadas situações não se justifica [Ste01], sendo desejável um mecanismo que permita recuperar rapidamente de situações resultantes da expiração de temporizadores de retransmissão ou de congestionamento da rede, para melhor aproveitamento da largura de banda disponível. Em [JK88] chamase, no entanto, a atenção para o perigo de afetar a estabilidade da rede com um algoritmo mais agressivo no caso de ter havido de fato congestionamento da rede.

O fato do protocolo TCP ter sido concebido para funcionar sobre qualquer tecnologia de suporte tem constituído um importante fator de inércia na sua adaptação a tecnologias como o ATM que, na eventualidade de perder uma única célula na transmissão, pode potencialmente desencadear o mecanismo de slow start.

Os mecanismos de controle de fluxo e de erros foram concebidos para redes que fornecem um serviço best-effort. Assim, não há reserva de recursos para as conexões TCP, o que representa potenciais situações de congestionamento e conseqüentes perdas de pacotes. A recuperação dos pacotes perdidos realiza-se por meio de retransmissão e durante a recuperação devem ser usadas técnicas de controle de congestionamento com o objetivo de prevenir situações graves que poderiam resultar de retransmissões sucessivas. As redes ATM proporcionam controle de tráfego e mecanismos de atribuição prévia de recursos com várias classes de tráfego, sub- 


\begin{tabular}{|c|c|c|c|}
\hline \multicolumn{1}{|c|}{4} & 10 & 16 \\
\hline \multicolumn{3}{|c|}{ PORTO TCP DE ORIGEM } & PORTO TCP DE DESTINO \\
\hline \multicolumn{3}{|c|}{ NUMERO DE SEQUENCIA } \\
\hline \multicolumn{3}{|c|}{ NUMERO DE ACKNOWLEDGEMENT } \\
\hline HLEN & RESERV. & CODE BITS & JANELA \\
\hline \multicolumn{3}{|c|}{ CHECKSUM } & PONTEIRO URGENTE \\
\hline \multicolumn{3}{|c|}{ OPCOES (OPCIONAL) } \\
\hline \multicolumn{3}{|c|}{ DADOS } \\
\hline \multicolumn{3}{|c}{$\bullet$} \\
\hline
\end{tabular}

Figura 2.9: Formato do datagrama TCP.

aproveitados com o uso do TCP.

\subsubsection{MSS}

No protocolo TCP a informação é enviada em pacotes que, neste contexto, recebem a designação de segmentos. O valor máximo do tamanho dos segmentos (MSS, do inglês Maximum Segment Size), é previamente negociado entre os pares envolvidos na conexão. Os segmentos enviados através de uma conexão não têm necessariamente o mesmo tamanho.

O correto dimensionamento do MSS é importante devido à sua influência no desempenho do TCP. Se sub-dimensionado, a utilização efetiva da rede é reduzida (só o cabeçalho introduzido pelo TCP/IP é de 40 bytes, conforme pode ser observado na figura 2.9), se por outro lado, o valor do MSS for demasiado elevado, pode conduzir a fenômenos de fragmentação de pacotes ao longo das subredes percorridas e o processo de reconstrução da informação na recepção pode ser seriamente prejudicado pois a simples perda de um fragmento implica na retransmissão do pacote inteiro. Em redes com velocidades de transmissão elevadas, o processo de reconstrução da informação pode tornar-se o fator limitante do desempenho. 


\subsubsection{Mecanismos de controle de fluxo}

O controle de fluxo no TCP recorre a um mecanismo de janela deslizante que permite a transmissão de pacotes enquanto se aguarda a notificação relativa a outros já transmitidos. O número de bytes transmitidos nestas condições é limitado pelo tamanho da janela anunciada pelo receptor que dispõe assim de um mecanismo de controle de fluxo ao anunciar a capacidade, em termos de buffers, disponivel para a conexão TCP. A fonte também impõe controle de fluxo através da janela de congestionamento que reflete a percepção da fonte com relação ao estado de congestionamento da rede.

Os dados são enviados considerando a janela de congestionamento, na qual o emissor guarda informações sobre congestionamentos, e a janela anunciada pelo receptor. Para efeitos de transmissão é usado o menor destes.

Em certos pontos da rede, a carga pode eventualmente exceder a largura de banda disponível conduzindo a perdas por congestionamento. Os atrasos aumentam podendo implicar na expiração dos temporizadores correspondentes nas fontes, levando a retransmissões. Estas por sua vez podem aumentar ainda mais o congestionamento, fenômeno chamado de congestion collapse. Como método preventivo, quando ocorrem perdas ou atrasos, o TCP recorre às estratégias de slow start e congestion avoidance.

A estratégia de congestion avoidance baseia-se no pressuposto de que as perdas ocorrem sobretudo devido a congestionamento. Mediante a perda de um segmento, a janela de congestionamento é reduzida para a metade (até um mínimo de um segmento). Para os segmentos que permanecem na janela, o temporizador de retransmissão aumenta exponencialmente.

A estratégia slow start permite a recuperação de situações de 
congestionamento e evita que elas surjam novamente devido à criação de novas conexões. Sempre que se aumenta o tráfego após um período de congestionamento ou se inicia uma conexão, a janela de congestionamento é inicializada com o valor um e aumentada de um segmento por cada notificação recebida pela fonte. A fonte começa assim por transmitir apenas um segmento. Após a recepção da notificação, a janela de congestionamento é incrementada de um para dois segmentos. O envio de dois segmentos implica na recepção de duas notificações implicando, cada uma, no incremento da janela de congestionamento que ficará com o valor quatro. A abertura da janela de congestionamento é desta forma exponencial.

Para impedir que a janela aumente muito rapidamente, conduzindo eventualmente a um novo congestionamento, assim que a janela atinge metade do tamanho que possuía no instante em que se verificou a situação de congestionamento (slow start threshold size), a velocidade de crescimento da janela é reduzida, aumentando de apenas um segmento quando para todos os segmentos na janela for recebida uma notificação (fase de congestion avoidance do TCP).

\subsubsection{Fast retransmit e fast recovery}

Uma vez que o TCP não consegue distinguir se a recepção de várias mensagens de notificação para o mesmo segmento é causada pela perda desse segmento ou apenas devido ao reordenamento dos segmentos, o algoritmo fast retransmit assume que um segmento se perdeu ao receber três ou mais mensagens de notificação para o mesmo segmento (duplicated ACKNOWLEDGE). Sem esperar que o temporizador de retransmissão expire, é retransmitido o segmento completo que supostamente se perdeu.

O algoritmo fast recovery possibilita throughput elevado sob con- 
dições de congestionamento moderado, especialmente com valores de janelas elevados. Após o fast retransmit enviar o segmento supostamente perdido, o algoritmo de congestion avoidance é executado mas o de slow start não, ou seja, com o fast retransmit a janela de congestionamento é reduzida para a metade do valor que possuía quando ocorreu a suposta perda e o incremento de um segmento é feito apenas quando, para todos os segmentos da janela, for recebida uma mensagem de notificação.

Sem estes mecanismos que tipicamente são implementados em conjunto, qualquer perda de pacotes obrigaria ao escoamento dos dados no interior da rede seguido de um slow start. Ao invés disso, a perda de um pacote por janela pode ser recuperada de forma eficiente com estes algoritmos.

\subsubsection{Window Scaling}

Um parâmetro de grande importância no TCP é o produto largura de banda $\times$ Round Trip Time (RTT) da rede, que corresponde aos dados em trânsito na rede (data in flight).

O valor deste produto condiciona o dimensionamento dos buffers na fonte e na recepção pois, para optimizar o throughput da conexão TCP, tem de se considerar a quantidade de dados sem notificação a manipular para que a rede permaneça ocupada. O dimensionamento dos buffers deve ser criterioso. Feito de forma inadequada pode resultar na perda de pacotes devido simplesmente a picos de tráfego (burstiness) bastante abaixo, eventualmente, do congestionamento da rede.

Para se atingir a utilização máxima da rede, o tamanho da janela deve pelo menos corresponder ao produto largura de banda $\times$ RTT. Este produto é elevado para redes com atrasos significativos, como 
conexões via satélite, ou com largura de banda elevada, como redes ATM. Surgiu então o mecanismo Window Scaling [JBB92], permitindo tamanhos de janela superiores ao máximo original de 65535 bytes. Todavia, o recurso de janelas muito grandes tem como efeito colateral o aumento da probabilidade de perda de mais de um pacote por janela. Isto implica em uma queda drástica no throughput pois, enquanto o temporizador de retransmissão não expira, a conexão não é utilizada. Esta é uma das causas principais do mau desempenho que o TCP apresenta em redes como ATM.

\subsubsection{Análise do TCP sobre ATM}

As redes ATM são caracterizadas por uma largura de banda elevada. Como tal, o produto largura de banda $\times$ RTT tem um valor elevado. Para que a utilização da rede seja optimizada a janela de congestionamento usada pelo TCP terá de ter pelo menos este valor, conduzindo ao aumento da probabilidade de perda de mais que um pacote para uma mesma janela.

Os parâmetros de uma conexão TCP - tamanho de janela, MSS e RTT não têm correspondência com os parâmetros de qualidade de serviço negociados para uma conexão ATM. Além disso, o tráfego TCP varia significativamente implicando em uma variação dinâmica dos parâmetros associados enquanto que os parâmetros negociados para uma conexão ATM se mantêm fixos até o fim.

O tráfego TCP tende a apresentar rajadas (burstiness), ou seja, o TCP transmite os pacotes de uma janela tão rápido quanto possível. Ele pode, no entanto, ser suavizado por mecanismos implementados na fonte (traffic shaping). A variabilidade do tráfego TCP aliada à granularidade insuficiente para assegurar um bom desempenho em presença de perdas (se a chave ficar sob congestionamento, o 
tempo que se aguarda para a retransmissão ao nível do TCP pode ir de 200 a 500 ms), podem conduzir a situações de baixo desempenho.

O TCP foi originalmente concebido para operar sobre redes besteffort que comutavam pacotes. O fato do ATM comutar células constitui um grande entrave ao desempenho do TCP sobre ATM. A comparação do desempenho do TCP sobre redes ATM (sem o controle de congestionamento efetuado pelo ATM) é comparado em [RF95] com o desempenho do TCP sobre redes de pacotes. A primeira conclusão é que o desempenho pode ser drasticamente comprometido pela perda de células em uma chave ATM sob congestionamento. O baixo throughput obtido deve-se sobretudo à largura de banda desperdiçada na transmissão de células relativas a pacotes já corrompidos (pacotes dos quais a chave já perdeu pelo menos uma célula). Os buffers são também utilizados de forma ineficiente.

\section{$2.8 \mathrm{UDP}$}

O protocolo UDP provê um mecanismo que aplicativos utilizam para enviar datagramas a outros aplicativos. O UDP utiliza portos para distinguir entre os vários programas sendo executados em uma máquina. Além dos dados sendo transmitidos, cada datagrama UDP contém o número dos portos de destino e origem, tornando possível ao aplicativo no destino enviar uma mensagem de resposta ao aplicativo transmissor correto.

Para o transporte de uma mensagem de uma máquina a outra o UDP faz uso do IP e fornece um envio de datagramas de maneira não orientada a conexão (não garantido). Ele não usa acknowledgements para certificar-se de que a mensagem foi recebida, não 


\begin{tabular}{|c|c|}
\hline PORTO UDP DE ORIGEM & PORTO UDP DE DESTINO \\
\hline COMPRIMENTO DA MENSAGEM & CHECKSUM UDP \\
\hline \multicolumn{2}{|c|}{ DADOS } \\
\hline \multicolumn{2}{|c|}{} \\
\hline
\end{tabular}

Figura 2.10: Formato do datagrama UDP.

garante a ordem de entrega dos datagramas e nem fornece feedback para controlar a taxa à qual a informação flui entre as máquinas, podendo levar à perda de pacotes no lado receptor.

Toda a responsabilidade pela entrega não garantida, incluindo perda, duplicação, atraso e entrega de mensagens fora de ordem fica a cargo da aplicação.

O formato do datagrama UDP é mostrado na figura 2.10. Maiores detalhes podem ser encontrados em [Com95a].

\subsection{CLIP}

O Classical IP (CLIP) foi idealizado pelo IETF e é especificado no RFC 2225 [LH98], que torna mais claros e detalhados os RFCs 1626 [Atk94] e 1577 [Lau93], agora considerados obsoletos.

\subsubsection{Encapsulamento dos pacotes}

O IETF trabalhou para definir um modo para transportar diversos tipos de pacotes de rede ou camada de enlace através de uma conexão ATM (AAL 5) e também para multiplexar diversos tipos de pacotes pela mesma conexão. Assim como no LANE, houve esforço em fazer reuso de uma mesma conexão para todas as transferências de dados entre dois nós, já que isto conserva os recursos de rede e diminui a latência de criação de canais depois que a primeira conexão é criada. Isto só é possível, entretanto, enquanto são usadas 
apenas conexões UBR ou ABR. Se as camadas de rede requererem garantias de QoS então cada fluxo distinto irá tipicamente requerer sua própria conexão (VBR).

Para permitir reutilização de conexões, deve haver meios de um nó que recebe um pacote de camada de rede ou de uma conexão ATM saber que tipo de pacote acaba de receber e a qual aplicação ou entidade de nível superior passar o pacote. Para isto o pacote deve vir precedido de um campo de multiplexação. Dois métodos foram definidos no RFC 1483 [Hei93] para prover multiplexação / demultiplexação:

- Encapsulamento LLC/SNAP: neste método, vários tipos de protocolos podem ser transportados através de uma única conexão com o tipo de pacote encapsulado sendo identificado por um cabeçalho LLC/SNAP padrão. Uma implicação conseqüente do encapsulamento LLC/SNAP, entretanto, é que todas as conexões utilizando tal encapsulamento terminam na camada LLC, já que é lá que ocorre a multiplexação.

- Multiplexação de VCs: no método VC muxing, apenas um tipo de protocolo é transportado através uma conexão ATM, com o tipo de protocolo implicitamente identificado na criação do canal. Conseqüentemente, não é necessário um campo identificador de tipo de pacote nem nenhuma forma de multiplexação.

O encapsulamento LLC/SNAP é o encapsulamento mais comumente utilizado com IP sobre ATM. O ITU-T adotou-o como o encapsulamento default para transporte de multiprotocolos sobre ATM, assim como o fez o grupo ATM Forum. 


\subsubsection{Funcionamento}

O CLIP utiliza o conceito de Logical IP Subnetwork (LIS) que, para funcionar, depende de um servidor ARP (do inglês Address Resolution Protocol), que é responsável por manter uma tabela com os IPs de todas as máquinas da subrede lógica que estão ativas no momento e relacionar estes IPs com seus respectivos endereços ATM definidos de acordo com a recomendação E.164 ou com o formato NSAP definido pelo ATM Forum. As entradas desta tabela ficam armazenadas temporariamente, tendo que ser realimentadas para não serem excluídas. É interessante mencionar que uma chave ATM pode ser configurada para atuar como servidor ARP assim como um computador também pode. A centralização do servidor ARP em um único equipamento representa um ponto fraco, e às vezes é preferida a utilização de uma chave ATM como servidora ARP, pois caso uma chave ATM, responsável pela conectividade de vários computadores, fique fora de operação, os computadores dela dependentes já ficam sem conectividade com o restante da rede e portanto não há comprometimento adicional com relação a estes computadores se esta mesma chave for responsável pelo servidor ARP. Já o mesmo não ocorre quando um computador é configurado para atuar como servidor ARP, sendo que sua parada representaria a queda desnecessária de toda a rede lógica.

A cada LIS corresponde um servidor ARP. Desta maneira é possivel ter mais de uma rede lógica sobre uma mesma estrutura física. Todas as máquinas de uma rede do tipo Classical IP são consideradas clientes do servidor ARP que provê o funcionamento desta rede e todos os clientes mantêm um canal permanentemente aberto ao servidor ARP. Quando um cliente CLIP deseja enviar um pacote IP a outro cujo endereço ATM ele desconhece (o endereço pode ser co- 
nhecido por ainda estar na tabela ARP temporária da máquina ou podem estar sendo utilizados PVCs), ele deve fazer uma requisição ARP ao ARP server. Ao ser informado do endereço ATM ele cria um canal ATM ao outro cliente para só então poder enviar o pacote IP diretamente ao outro. Quando clientes de duas redes lógicas distintas desejam se comunicar eles precisam fazer isto através de um roteador, que é uma máquina cliente das duas redes lógicas e é configurada para atuar como roteadora entre elas.

CLIP por si só não suporta o envio simultâneo de mensagens a um grupo de IPs (multicast) assim como o envio simultâneo de mensagens a todos os clientes de uma LAN (broadcast). Para ter suporte multicast a aplicações IP é necessário instalar o MARS [Arm96] (do inglês Multicast Address Resolution Server), que permite multicast IP sobre conexões ATM do tipo ponto-multiponto.

A unidade de transmissão máxima default (MTU, do inglês Maximum Transmission Unit) para o CLIP é de 9180 bytes. Entretanto, o MTU de um VC ponto-a-ponto pode ser negociado na inicialização da conexão.

\subsection{LANE}

O protocolo LAN Emulation [ATM95] define mecanismos para emular uma rede local do tipo Ethernet ou Token Ring sobre ATM. De acordo com a versão 1.0 da especificação LANE, desenvolvido pelo ATM Forum e aprovado em fevereiro de 1995, o principal objetivo do LAN Emulation é permitir aplicações existentes acessarem uma rede ATM de modo transparente, como se estivessem rodando em redes tradicionais. LANE permite máquinas com interfaces 802.3 Ethernet e 802.5 Token Ring comunicarem-se com máquinas ATM 


\begin{tabular}{|l|l|}
\hline \multicolumn{1}{|c|}{16} \\
\hline LE HEADER & ENDER DEST. \\
\hline \multicolumn{3}{|c|}{ ENDER DEST. } \\
\hline \multicolumn{3}{|c|}{ ENDER ORIGEM } \\
\hline ENDER ORIGEM & TIPO / COMPRIMENTO \\
\hline \multicolumn{2}{|c|}{ DADOS } \\
\hline \multicolumn{3}{|c}{} \\
\hline
\end{tabular}

Figura 2.11: Formato do LAN Emulation Data Frame para IEEE 802.3/ Ethernet.

sem modificações nas aplicações, nos sistemas operacionais ou nas interfaces de rede.

O protocolo LANE define uma interface de serviços para protocolos de camadas mais altas (de camada de rede) igual à interface de LANs existentes e transmite os dados através da rede ATM encapsulados em frames de formato adequado. Isto significa que os protocolos LANE fazem uma rede ATM parecer e se comportar como uma LAN Token Ring ou Ethernet.

A função básica do protocolo LANE é resolver endereços MAC em endereços ATM para que clientes LANE possam abrir canais para a transmissão de dados.

\subsubsection{Encapsulamento de dados com LANE}

O datagrama para transmissão de dados em LANE recebe também o nome de LE Data Frame. Ele deve ter um comprimento mínimo de 62 bytes, pois assim, retirando o campo LE Header ( 2 bytes) e incluindo o CRC (4 bytes) restaura-se o comprimento mínimo de 64 bytes exigido pelo padrão Ethernet. O formato do LE Data Frame para IEEE 802.3 / Ethernet está ilustrado na figura 2.11. 


\subsubsection{Componentes e Tipos de Conexões}

Uma Emulated LAN (ELAN) emula uma rede Ethernet ou Token

Ring, e consiste dos seguintes elementos:

LAN Emulation Client (LEC): é a entidade em um sistema final que realiza envio de dados, resolução de endereços e outras funções de controle para um único sistema final dentro de uma ELAN. O LEC também provê uma interface de serviço de LAN a qualquer entidade superiora que interaja com o LEC. Uma placa de rede ou uma chave interagindo com uma ELAN suporta um único LEC para cada ELAN ao qual ele está conectado. Um sistema final que conecta a várias ELANs terá um LEC por ELAN.

Cada LEC é identificado por um único endereço ATM, e é associado a um ou mais endereços MAC alcançáveis através deste endereço ATM. No caso de uma placa de rede, por exemplo, o LEC pode ser associado com apenas um endereço MAC, enquanto que no caso de uma chave, o LEC seria associado a todos os endereços MAC alcançáveis através dos portos desta chave que são atribuídos à particular ELAN. Note que no último caso o conjunto de endereços pode mudar à medida que máquinas são ligadas e desligadas.

LAN Emulation Server (LES): implementa a função de controle para uma particular ELAN. Só há um LES lógico por ELAN, e pertencer a uma particular ELAN significa manter um relacionamento de controle com o LES desta ELAN. Cada LES é identificado por um endereço ATM único.

Broadcast and Unknown Server (BUS): é o servidor multicast que espalha tráfego para endereços de destino desconhecidos e re- 
passa tráfego multicast e broadcast a clientes dentro de uma particular ELAN. Cada LEC é associado a somente um BUS por ELAN, mas pode haver múltiplos BUS dentro de uma particular ELAN que se comunicam e coordenam de alguma maneira proprietária. O BUS ao qual um LEC conecta é identificado por um endereço ATM único. No LES, ele é associado com o endereço MAC de broadcast e este mapeamento é normalmente configurado no LES.

LAN Emulation Configuration Server (LECS): é uma entidade que atribui clientes LANE individualmente a ELANs particulares redirecionando-os ao LES que corresponde à ELAN. Há um LECS por domínio administrativo, e ele serve todas as ELANs dentro deste domínio.

O protocolo LANE não especifica onde cada um dos componentes do servidor devem ser colocados; qualquer dispositivo ou dipositivos com conectividade ATM podem servir. Porém, por questões de segurança e confiabilidade, a maioria dos fabricantes implementa estes componentes em equipamentos de rede como chaves ATM ou roteadores.

As entidades comunicam-se entre si usando uma série de conexões ATM. LECs mantêm conexões separadas para transmissão de dados e controle de tráfego.

As conexões de controle são:

- Configuration Direct VCC: este é um VCC ponto-a-ponto bidirecional criado pelo LEC ao LECS.

- Control Direct VCC: este é um VCC bidirecional criado pelo LEC ao LES. 
- Control Distribute VCC: este é um VCC unidirecional criado pelo LES de volta ao LEC; ele é tipicamente uma conexão ponto-a-multiponto.

As conexões de dados são:

- Data Direct VCC: este é um VCC bidirecional ponto-a-ponto criado entre dois LECs que desejam trocar dados. Dois LECs irão tipicamente usar o mesmo direct data VCC para transportar todos os pacotes entre eles, ao invés de abrir um novo VCC, para conservar recursos de conexão e latência de conexão. Já que LANE emula LANs existentes, incluindo sua falta de suporte a GoS, conexões do tipo data direct serão tipicamente conexões UBR ou ABR, não oferecendo qualquer tipo de garantia de QoS.

- Multicast Send VCC: este é um VCC bidirecional ponto-a-ponto criado pelo LEC ao BUS.

- Multicast Forward VCC: este é um VCC unidirecional criado do BUS ao LEC. Ele é tipicamente uma conexão ponto-amultiponto, com cada LEC como uma folha.

\subsection{Cálculo do throughput}

O quadro básico do Synchronous Optical NETwork (SONET) é transmitido a cada $125 \mu \mathrm{s}$, resultando em uma taxa de 8000 quadros/s, que corresponde exatamente à taxa de amostragem dos canais PCM usados nos sistemas de telefonia digital, fornecendo uma taxa bruta de 51,84Mbps. Este é o canal básico do SONET, também chamado de STS-1 (Syncronous Transport Signal-1). Todos os troncos do SONET são múltiplos do STS-1. 
O quadro STS- 1 pode ser representado por 9 linhas de 90 colunas de 1 byte, onde as 3 primeiras colunas de cada quadro representam o overhead do SONET. Dessa forma, o quadro OC-3/STS-3, cuja taxa bruta é $3 \times 51,84 \mathrm{Mbps}=155,52 \mathrm{Mbps}$ possui $3 \times 9 \times 810=$ 2430 bytes, sendo que destes, 90 correspondem ao overhead. Desta forma, a largura de banda disponível para a camada ATM é:

$$
\begin{gathered}
B W_{A T M}=\frac{\text { payload }}{\text { tamanho_quadro }} \times \text { taxa_bruta } \\
B W_{A T M}=\frac{2430-90}{2430} \times 155,52 \\
B W_{A T M}=149,46 \mathrm{Mbps}
\end{gathered}
$$

O overhead do ATM é de 5 bytes para cada 48 bytes de payload, deixando a seguinte largura de banda para a camada AAL:

$$
B W_{A A L}=\frac{\text { payload }}{\text { tamanho_celula }} \times B W_{A T M}=\frac{53-5}{53} \times 149,46=135,63 \mathrm{Mbps}
$$

A camada AAL5 possui um overhead fixo de 8 bytes de trailer e um overhead variável devido ao padding. A largura de banda que a camada AAL5 disponibiliza às camadas superiores está ilustrada na figura 2.12. Abaixo calculamos a largura de banda para um datagrama de 9976 bytes. Para este datagrama não é necessário padding pois após serem adicionados os 8 bytes de trailer da AAL5 o PDU fica múltiplo de 48 bytes. Além disso, os 8 bytes de trailer não são representativos perante o tamanho do datagrama e portanto esperamos encontrar um valor muito próximo da largura de banda máxima atingivel:

$$
\begin{gathered}
B W_{L L C / S N A P}=\frac{\text { payload }}{\text { tamanho_CPCS_PDU }} \times B W_{A A L} \\
B W_{L L C / S N A P}=\frac{9976}{9976+0+8} \times 135,63
\end{gathered}
$$




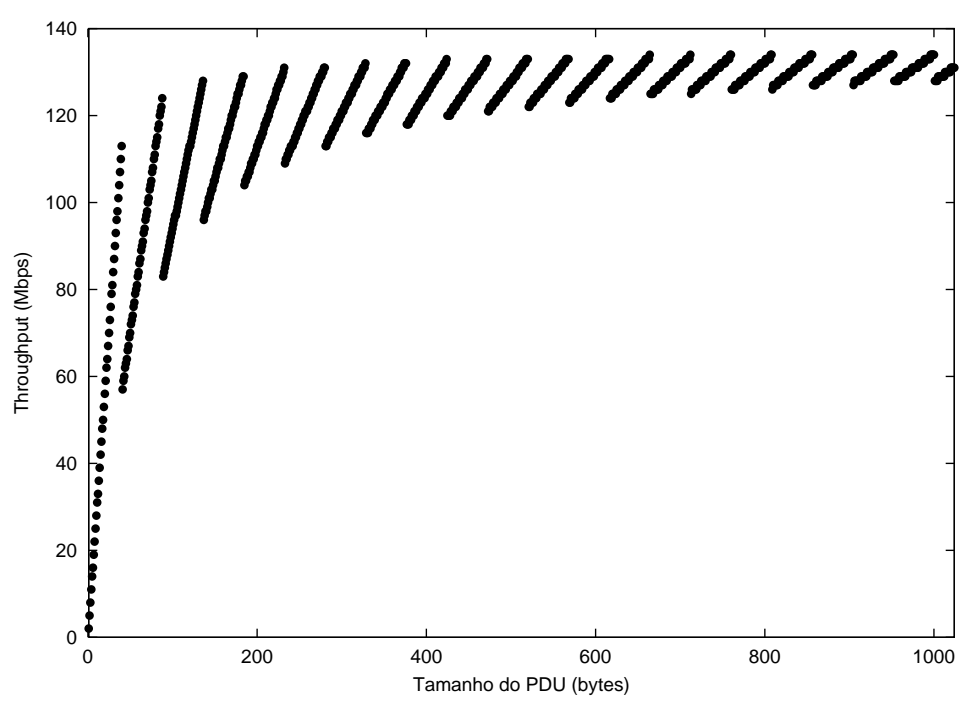

Figura 2.12: Throughput oferecido às camadas superiores à AAL5 em função do tamanho do PDU.

$$
B W_{L L C / S N A P}=135,52 M b p s
$$

Em CLIP, devido ao encapsulamento LLC/SNAP, a largura de banda disponível para a camada IP é ainda mais reduzida, conforme mostrado na figura 2.13.

Calculando a largura de banda disponível para a camada IP para o mesmo datagrama anterior que fornece uma boa aproximação da largura de banda máxima obtemos:

$$
\begin{gathered}
B W_{I P \_C L I P}=\frac{\text { payload }}{\text { tamanho_PDU }} \times B W_{A A L} \\
B W_{I P \_C L I P}=\frac{9976-8}{9976+0+8} \times 135,63 \\
B W_{I P \_C L I P}=135,41 \mathrm{Mbps}
\end{gathered}
$$

A largura de banda que sobra para uma aplicação que utiliza TCP sobre CLIP fica portanto restrita a:

$$
B W_{A P \_T C P \_C L I P}=\frac{P D U_{-} I P-H e a d e r_{-} I P-H e a d e r \_T C P}{P D U_{-} I P} \times B W_{I P \_C L I P}
$$




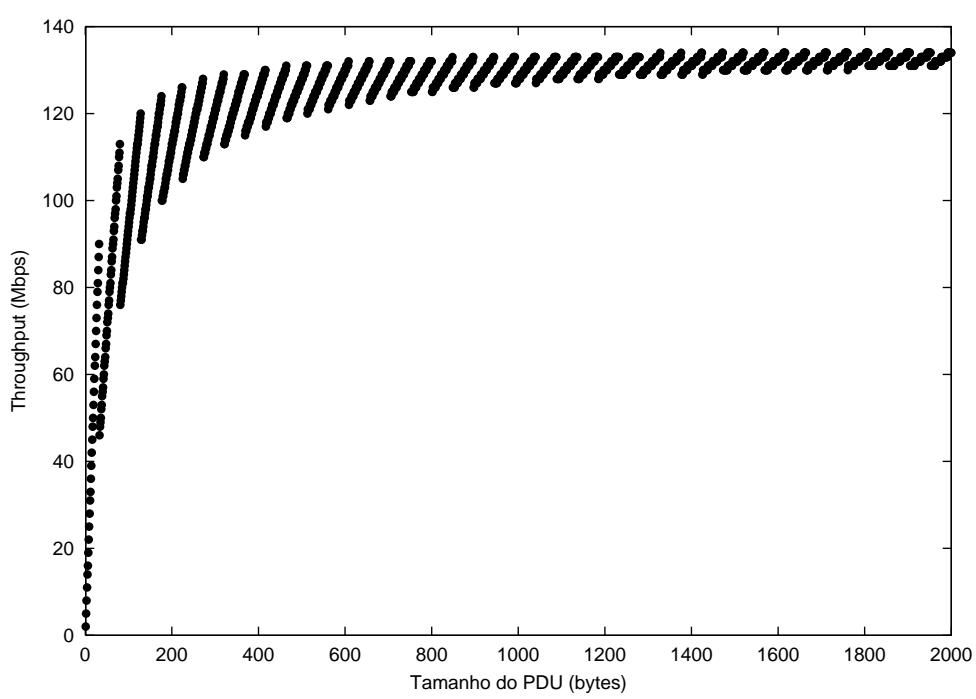

Figura 2.13: Throughput oferecido à camada IP em função do tamanho do PDU para CLIP.

$$
\begin{gathered}
B W_{A P \_T C P \_C L I P}=\frac{9968-20-20}{9968} \times 135,41 \\
B W_{A P \_T C P \_C L I P}=134,87 \mathrm{Mbps}
\end{gathered}
$$

Para aplicações que utilizam UDP sobre CLIP, a largura de banda a esperar é um pouco mais alta devido ao fato do cabeçalho UDP ser de apenas 8 bytes, contra 20 bytes do cabeçalho TCP:

$$
\begin{gathered}
B W_{A P \_U D P \_C L I P}=\frac{P D U_{-} I P-H e a d e r_{-} I P-H e a d e r \_U D P}{P D U_{-} I P} \times B W_{I P \_C L I P} \\
B W_{A P \_U D P \_C L I P}=\frac{9968-20-8}{9968} \times 135,41 \\
B W_{A P \_U D P \_C L I P}=135,03 \mathrm{Mbps}
\end{gathered}
$$

O MTU do LANE é por default 1500 bytes, então para uma mensagem de 1440 bytes temos que a largura de banda que sobra para a camada IP em LANE, considerando um padding nulo, 8 bytes de 
trailer AAL5, 16 bytes de cabeçalho LANE e 8 bytes devido ao encapsulamento LLC/SNAP é:

$$
\begin{gathered}
B W_{I P_{-} L A N E}=\frac{\text { payload }}{P D U_{-} I P+0+8+16+8} \times B W_{A A L} \\
B W_{I P \_L A N E}=\frac{1440}{1440+0+8+16+8} \times 135,65 \\
B W_{I P \_L A N E}=132,70 \mathrm{Mbps}
\end{gathered}
$$

Para uma aplicação que utiliza TCP sobre LANE temos:

$$
\begin{gathered}
B W_{A P \_T C P \_L A N E}=\frac{\text { payload }}{\text { payload }+ \text { Header_IP+Header_TCP}} \times B W_{I P \_L A N E} \\
B W_{A P \_T C P \_L A N E}=\frac{1440}{1440+20+20} \times 132,70 \\
B W_{A P \_T C P \_L A N E}=129,11 \mathrm{Mbps}
\end{gathered}
$$

Para uma aplicação que utiliza UDP sobre LANE temos:

$$
\begin{gathered}
B W_{A P \_U D P \_L A N E}=\frac{\text { payload }}{\text { payload }+ \text { Header_IP }+ \text { Header_UDP }} \times B W_{I P \_L A N E} \\
B W_{A P_{-} U D P_{-} L A N E}=\frac{1440}{1440+20+8} \times 132,70 \\
B W_{A P_{-} U D P_{-} L A N E}=130,19 \mathrm{Mbps}
\end{gathered}
$$




\section{Capítulo 3}

\section{Hardware Utilizado}

\subsection{A Interface MultiKron II}

\subsubsection{Introdução}

Produzida pelo Instituto Nacional de Padrões e Tecnologia americano (NIST), a MultiKron II consiste de uma placa de computador que permite medidas de tempo em computadores de multiprocessadores ou de um único processador. Em versões para barramentos VME, Sbus e PCI, há suporte para sistemas Solaris 2.x, SunOS 4.1.x, DEC - ALPHA, Windows NT, BSDI, FreeBSD e Linux. Apesar do seu principal chip, o MultiKron II ser um dispositivo de 64 bits, a interface se configura de maneira automática e transparente para funcionar em modo de 32 ou 64 bits através do protocolo PCI.

A meta do NIST ao produzir esta interface era prover a preço acessivel suporte de hardware para medições de performance com perturbação tolerável tanto para a aplicação sendo executada quanto para a arquitetura na qual ela é executada ${ }^{1}$. A interface Multikron II alcança estes objetivos sendo mapeada na memória do com-

\footnotetext{
${ }^{1}$ Perturbação tolerável refere-se à não introdução de distorções significativas no ato da medida.
} 
putador. Desta maneira todas as interações são leituras e escritas em endereços específicos de memória [Min94].

O software necessário à operação da interface MultiKron pode ser encontrado no website do NIST [NIS99, Min97], consistindo basicamente do driver e do software de captura de amostras armazenadas na memória da placa MultiKron (mk_rdsample.c) e outro de geração de uma tabela das amostras capturadas (mk_expand.c). O script de instalação do driver cria o arquivo especial /dev/mk0, usado para acessar o dispositivo. O software mk_rdsample.c lê o conteúdo da memória da interface MultiKron e gera um arquivo binário a partir destes dados, já mk_expand.c utiliza este arquivo binário como entrada para gerar uma tabela legível que lista os eventos registrados pela interface.

\subsubsection{Registro de Eventos}

O registro preciso dos instantes de tempo de ocorrência de vários eventos na execução de um processo de computador pode ser usado para calcular com precisão o tempo transcorrido e a latência, entre outras coisas. Aos dados necessários para especificar um registro de evento chamamos de trace sample. Monitoramento passivo de endereços de instruções buscadas externamente para determinar a ocorrência de um evento é insuficiente, já que caches internos mascaram as instruções executadas e além disso endereços externos são endereços físicos, enquanto que os compiladores produzem código em termos de endereços virtuais. Devido a estes problemas, uma visão interna da atividade do programa é necessária para determinar quando um evento ocorre de maneira que dados de medida para um trace sample possam ser coletados. Para perturbação mínima do programa sendo executado uma solução 
híbrida para registro de eventos foi empregada pelo NIST na qual pouco código é adicionado ao software para sinalizar ao hardware quando registrar um evento. Ao construir o hardware de captura como um dispositivo mapeado na memória, este código pode ser tão pequeno quanto uma única operação de escrita na memória por evento. A execução deste código informa ao hardware de medição da ocorrência de um evento e ainda informa os dados especificados pelo usuário, que podem ser armazenados como parte de um trace sample, fornecendo meios de identificar um evento, ou mais precisamente, onde na execução do programa o evento ocorreu. A identificação de um evento, por exemplo, pode ser especificada por um número que tem significado apenas para a pessoa que realiza a medida, como "27", que poderia indicar a posição no código onde uma mensagem proveniente de outro aplicativo acaba de ser recebida.

Tempo instantâneo é um dado importante a coletar na ocorrência de um evento. É necessário para isso um contador de tempo (Timestamp Counter) que tenha uma resolução de tempo compatível com a velocidade de execução do computador e precisão suficiente para que ele não recomece a contagem em zero durante o experimento a ser realizado. A MultiKron II é dotada de um contador de 56 bits e todos eles são incluídos em um trace sample.

Para permitir correlação das amostras tomadas por várias interfaces MultiKron os contadores devem estar todos sincronizados. O método de sincronização utilizado emprega um relógio e um sinal de reset (que inicializa o contador de tempo em zero) comum a todas as interfaces. 


\subsection{Interface ATM ForeRunner LE 155}

Fabricada pela Marconi (antiga Fore Systems), a interface PCI ForeRunner LE obedece ao padrão ATM sendo capaz de operar a uma taxa sustentada full-duplex de 155 Mbps wire-speed. Sua implementação é baseada no chip IDT77211 NICStAR ${ }^{T M}$, sendo que este chip é responsável pela camada de adaptação AAL, pela camada de segmentação e remontagem (SAR) e pela camada ATM, sem a necessidade de um processador acoplado. São suportadas pelo hardware as classes de serviço CBR, VBR e UBR assim como células de operação e manutenção (células OAM).

Sua arquitetura foi desenvolvida de maneira a manter os PDUs da subcamada de convergência (CS) na memória do próprio computador ao invés de armazená-los em uma memória localizada na interface com o objetivo principal de reduzir custos. Os dados são acessados pelo barramento PCI através de bus master para reduzir a utilização de CPU no computador. O NICStAR controla todas as operações das camadas AAL, SAR e ATM e também as transferências de dados com a memória do computador como um PCI bus master. Ao driver da placa fica a responsabilidade de alocar e gerenciar espaços de memória destinados aos buffers a serem utilizados pela placa. Estruturas com ponteiros para estes buffers são fornecidas pelo driver à placa durante a utilização da mesma, na medida em que ela faz tais solicitações, através de interrupções.

$\mathrm{O}$ fato dos PDUs serem armazenados diretamente na memória do computador, além da redução de custo, traz também uma redução na latência de comunicação pois é evitada uma cópia dos dados de uma memória local da placa para a memória do computador. A técnica de armazenar os PDUs em uma memória próxima à camada SAR é mais utilizada em sistemas que têm um barramento 
com menor largura de banda sustentada que a conexão ATM. Assim, os CS-PDUs são transferidos a uma taxa pequena através do barramento para então serem transmitidos em uma rajada através da rede. Quando os PDUs são armazenados na memória local da placa, há uma limitação física (sem usar um algoritmo complexo) no número de PDUs que podem ser manipulados simultaneamente [Alm95].

O NICStAR possui uma FIFO para receber células ATM com capacidade para 315 células. Ao receber uma célula ATM, o NICStAR realiza um processo lookup table utilizando o identificador de conexão presente no header da célula para determinar onde na memória do computador colocar o payload da célula. Desta maneira, os payloads das células ATM são colocados diretamente na memória do computador para formar os CS-PDUs.

$\mathrm{Na}$ transmissão, os CS-PDUs são enfileirados na memória do computador pelo driver da placa ATM. O próprio NICStAR, ao realizar a segmentação dos CS-PDUs em payloads de células ATM, adiciona os respectivos headers para criar as células de 53 bytes. O byte do campo HEC é inserido pelo NICStAR apenas como um padding. As células são então transmitidas ao dispositivo PHY, através de um barramento chamado Universal Test and Operations Physical Interface for ATM (UTOPIA), de acordo com uma tabela de escalonamento, como ilustrado na figura 3.1. O dispositivo PHY calcula e substitui o byte do Header Error Check (HEC) para formar uma célula ATM de 53 bytes completa. É ele também que na recepção faz a verificação do HEC, descartando a célula em caso de erro. 


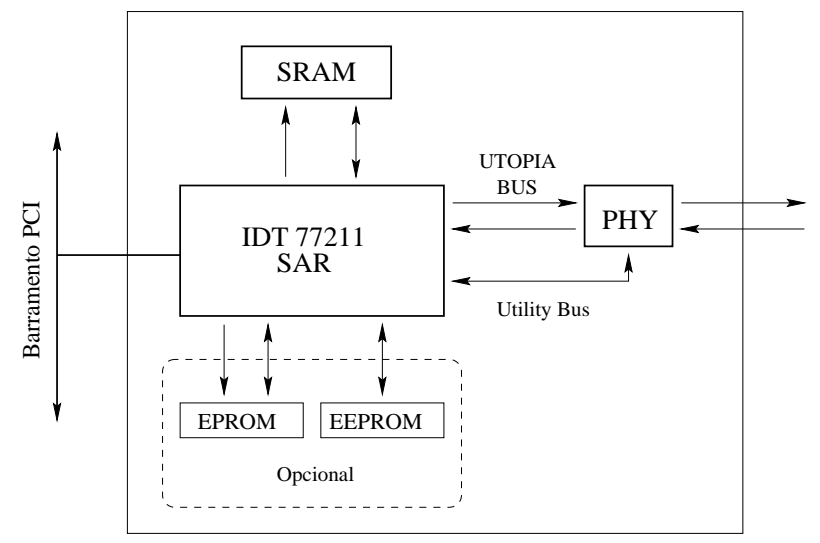

Figura 3.1: Interface de rede utilizando o chip NICStAR.

\subsection{Interface Fast EtherLink XL PCI 10/100}

Foram utilizadas duas interfaces 10/100 modelo 3C905B-TX-NM fabricadas pela $3 \mathrm{Com}$ para medidas comparativas às realizadas com as interfaces ATM. Em condições normais estas interfaces Fast Ethernet ficavam ligadas ao hub do laboratório para conexão dos micros à Internet, mas durante as medidas eram ligadas à chave 3Com mencionada a seguir para não sofrer com colisões ou outras interferências externas.

A placa 3C905B-TX foi construída para barramentos PCI de 32 bits. É dotada de 8 KBytes de memória destinada aos buffers de transmissão e recepção, que podem ser particionados respectivamente como $6: 2,5: 3,4: 4,3: 5$ ou 2:6. Nos sistemas utilizados ela foi particionada com $3 \mathrm{~KB}$ para o buffer de transmissão e $5 \mathrm{~KB}$ para o buffer de recepção.

A interface se configura automaticamente para operar em 10 ou 100 Mbps modo full-duplex, conforme a capacidade da rede.

Uma placa de rede Ethernet comum é limitada a transferir 64 bytes pelo barramento PCI por operação de bus master, necessitando de 24 operações para a transferência de um pacote de 1514 bytes. 
A interface 3C905B-TX possui uma implementação chamada Parallel Tasking II que a permite transferir um pacote Ethernet inteiro pelo barramento PCI em uma única operação bus master, aumentando a eficiência do barramento PCI e o throughput da rede.

\subsection{Chave ATM}

Foi utilizada no trabalho uma chave ATM modelo ForeRunner LE 155, produzida pela empresa Marconi (antiga Fore Systems). Ela possui 14 portos ATM para cabo UTP de $155 \mathrm{Mbps}$ e 2 portos ATM para fibra multimodo de $155 \mathrm{Mbps}$, além de um porto serial utilizado para configuração inicial da chave e atribuição de número IP. Configurações adicionais podem posteriormente ser feitas pela rede ATM.

\subsection{Chave Fast Ethernet}

Foi utilizada para fins comparativos uma chave Fast Ethernet Super Stack II da 3Com (modelo 3C16465A) presente no laboratório, parte integrante de um cluster de computadores. Esta chave possui 24 portos 10/100, sendo que apenas 16 são utilizados normalmente.

\subsection{Montagem experimental}

Na figura 3.2 é apresentada a montagem experimental utilizada para a realização das medidas. Ela consistuiu-se basicamente de dois computadores $\mathrm{K} 6$ III com clock de $450 \mathrm{MHz}$ interligados por uma chave ATM modelo ForeRunner LE 155. Sobre esta rede ATM física foram configuradas uma rede CLIP e outra LANE. Testes comparativos de desempenho destas duas redes foram feitas com Fast Eth- 


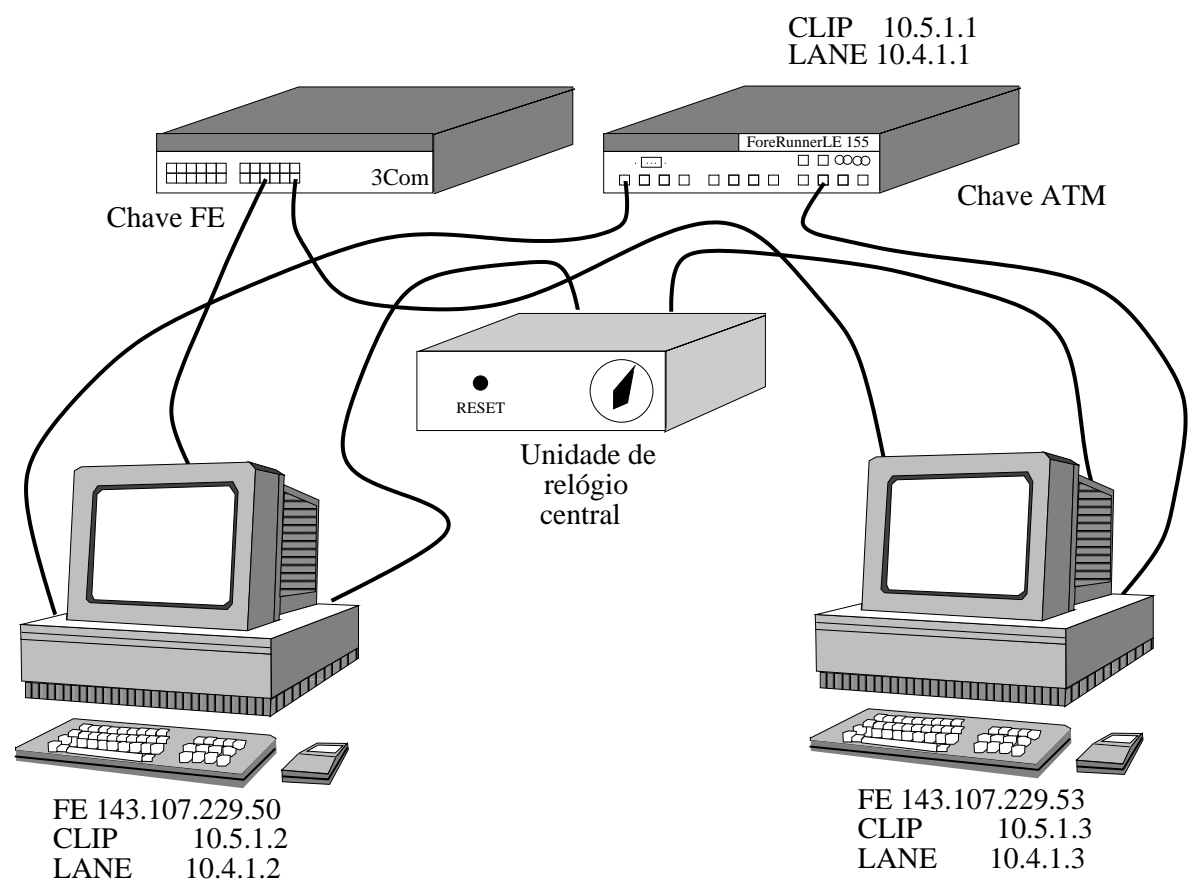

Figura 3.2: Montagem experimental utilizada, com dois micros K6 III $450 \mathrm{MHz}$, chave Fast Ethernet, chave ATM e unidade de relógio central da MultiKron.

ernet, através das interfaces Fast Ethernet modelo 3C905B-TX-NM instaladas nos dois computadores e ligadas à chave Super Stack II da 3Com. Uma unidade de relógio central foi conectada aos dois micros para prover uma mesma fonte de tempo às interfaces MultiKron instaladas em ambas as máquinas, assim como um mecanismo de sincronismo através do botão de reset presente no painel frontal do relógio.

\subsection{Configuração dos computadores}

Na tabela 3.1 é apresentada a configuração inicial dos computadores utilizados nas medidas experimentais. Após constatada a degradação no desempenho do sistema causada pela placa de vídeo onboard na donald, descrita na seção 4.3.3, a placa onboard foi 
Tabela 3.1: Configuração dos dois computadores utilizados.

\begin{tabular}{|l|l|l|}
\hline \hline Nome do computador & \multicolumn{1}{|c|}{ jan4 } & \multicolumn{1}{c|}{ donald } \\
\hline \hline CPU & AMD K6-III 450 MHz & AMD K6-III 450 MHz \\
\hline Memória RAM (MB) & 256 & 128 \\
\hline Motherboard & ASUS P5S-B & ASUS P5S-B \\
\hline Disco rígido & Quantum 8 GB & Quantum 8 GB \\
\hline Placa de vídeo & Diamond 64 MB (PCI) & onboard SiS 6326 \\
\hline Interface ATM & ForeRunner 155 (PCI) & ForeRunner 155 (PCI) \\
\hline Interface Fast Ethernet & 3C905B-TX-NM (PCI) & 3C905B-TX-NM (PCI) \\
\hline IP FE & 143.107 .229 .50 & 143.107 .229 .53 \\
\hline IP CLIP & 10.5 .1 .2 & 10.5 .1 .3 \\
\hline IP LANE & 10.4 .1 .2 & 10.4 .1 .3 \\
\hline & Interface MultiKron II & Interface MultiKron II \\
\hline
\end{tabular}

desabilitada e passou a ser utilizada uma placa de vídeo externa, como na jan4. 


\section{Capítulo 4}

\section{Medidas experimentais de throughput}

\subsection{Introdução}

A quantidade de dados que é possivel transmitir em um dado intervalo de tempo (throughput) é um dos parâmetros mais relevantes na caracterização de uma rede. Foram utilizados neste trabalho dois métodos para sua determinação:

- Transferência de um grande arquivo por FTP

- Sobrecarga da rede pelo envio sucessivo de pacotes de tamanhos variados com Netperf

Com ambos os métodos foram determinados os limites do próprio sistema e a seguir realizados testes sobre TCP e UDP sobre

- CLIP

- LANE

- Fast Ethernet 


\subsection{Throughput medido com FTP}

A transferência de um arquivo grande por FTP representa uma maneira simples e prática de se determinar o throughput de uma rede. Porém, cuidados devem ser tomados para que o valor medido corresponda realmente ao valor máximo de throughput da rede, e não do hardware ou do software que compõem os microcomputadores. É portanto necessário conhecer os limites de desempenho do sistema antes de efetuar medidas na rede. O elemento mais crítico em uma transferência via FTP (além da rede, é claro) é a velocidade do disco onde o arquivo está armazenado e a velocidade do disco para onde ele será copiado. O Linux por default não habilita o DMA para o disco rígido, limitando sua velocidade em um patamar bem abaixo do limite no qual ele é capaz de trabalhar. Habilitando as tranferências via DMA para o disco EIDE utilizado e verificando sua taxa de transferência em uma situação de utilização mínima de $\mathrm{CPU}^{1}$ obtivemos $106 \mathrm{Mbps}$, como ilustrado na figura 4.1, o que não é suficiente para saturar uma rede ATM de 155 Mbps.

Foi então criado um RAMDisk no lado transmissor para armaze-

\footnotetext{
${ }^{1}$ A taxa de transferência para discos EIDE cai proporcionalmente à utilização de CPU.
}

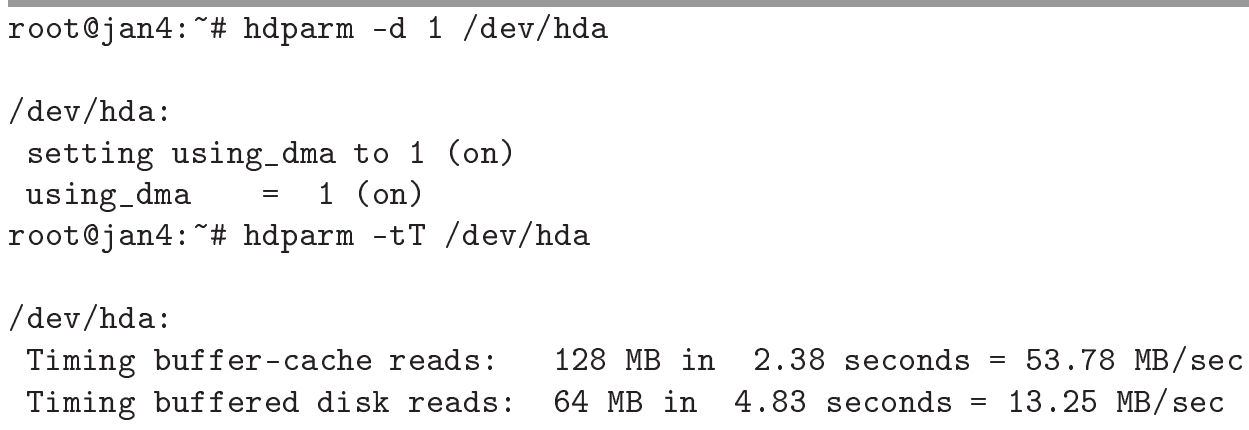

Figura 4.1: Habilitação do DMA para o disco EIDE e verificação da sua taxa de transferência. 
namento em memóra RAM do arquivo a ser transferido e no receptor direcionamos o arquivo para o dispositivo /dev/null, eliminando assim o gargalo representado pelo disco rígido em ambas as pontas.

Medimos então a taxa de transferência por FTP na mesma máquina com RAMDisk, obtendo taxas por volta de $477 M b p s$. Pudemos assim concluir que o limite de velocidade imposto pelo sistema com RAMDisk estava bastante acima da capacidade máxima das redes.

Por fim, os resultados obtidos com a transferência de um grande arquivo por FTP sobre CLIP, LANE e Fast Ethernet estão listados na tabela 4.1, assim como os valores máximos teóricos. Para o cálculo do máximo teórico do FTP sobre Ethernet foram considerados payloads de 1440 bytes e um overhead de 18 bytes devido ao frame Ethernet, 3 bytes devido ao LLC e 20 bytes devido ao TCP. Pelo fato do FTP utilizar pacotes grandes para maximização da eficiência da rede, o throughput alcançado nos três casos é bastante próximo ao máximo teórico possível. O Fast Ethernet obteve o menor desvio padrão, mostrando o comportamento mais estável dentre os três casos estudados. Já o CLIP aproximou-se mais do valor máximo teórico possivel, com um desvio padrão pequeno em relação ao valor alcançado, mostrando um desempenho muito bom. Por fim, o LANE apresentou um desvio padrão maior que o Fast Ethernet e CLIP, indicando maior necessidade de uso de CPU ou acessos à memória, levando a uma maior flutuação em relação ao valor médio. Tal flutuação pode, entretanto, ser considerada tolerável levando em conta as vantagens que LANE apresenta com relação à integração com outras tecnologias. 
Tabela 4.1: Valores de throughput máximos teóricos e obtidos com a transferência de um arquivo grande via FTP, com uso de RAMDisk no lado transmissor e direcionamento para / dev/null no lado receptor.

\begin{tabular}{|c|c|c|}
\hline \hline \multirow{2}{*}{ Tecnologia } & \multicolumn{2}{|c|}{ Throughput (Mbps) } \\
\cline { 2 - 3 } & medido com FTP & máximo teórico \\
\hline \hline CLIP/ATM & $133,8 \pm 0,8$ & 134,9 \\
\hline LANE/ATM & $125 \pm 3$ & 129,1 \\
\hline Fast Ethernet & $93,7 \pm 0,1$ & 97,2 \\
\hline
\end{tabular}

\subsection{Throughput medido com Netperf}

Medidas de throughput foram também realizadas com o auxílio do software Netperf [Jon00] que além do throughput permite a quantificação de vários outros aspectos da performance das redes. Nos testes realizados ele foi unicamente utilizado para medir throughput através de TCP e UDP sobre CLIP, IP sobre LANE e IP sobre Fast Ethernet.

Ele é baseado no modelo cliente-servidor, sendo que em uma máquina ele é instalado como servidor e em outra como cliente. Na configuração de servidor ele corresponde a um daemon que fica aguardando uma solicitação de um cliente através de um porto específico conhecido pelos dois.

Assim que o Netperf é executado é estabelecida uma conexão de controle com o sistema remoto. Esta conexão é do tipo TCP (para garantir a entrega) e é utilizada para a passagem de informações de controle e resultados das medidas.

Uma vez que a conexão de controle esteja funcional e as informações tenham sido transmitidas, uma conexão adicional é aberta para a medida a ser realizada utilizando a API e o protocolo apro- 


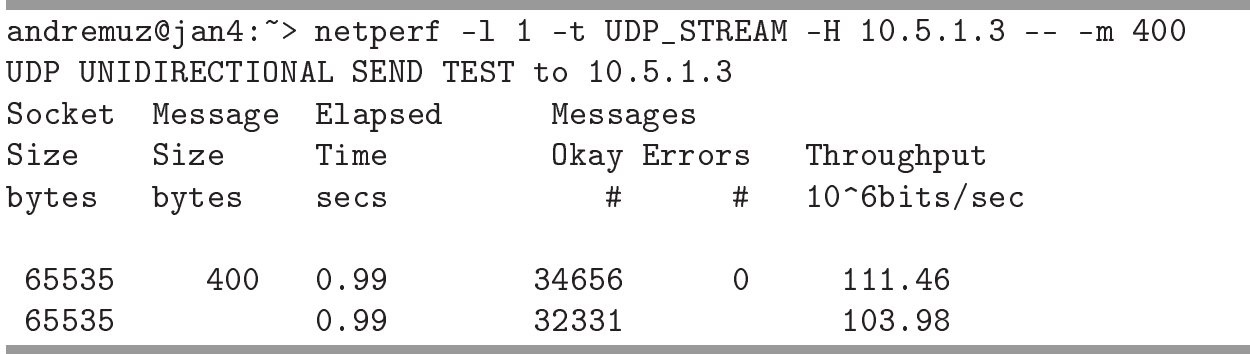

Figura 4.2: Exemplo de uso do aplicativo Netperf. O tempo tomado pela medida é de um segundo (-1 1), o protocolo de camada 4 utilizado é o UDP (-t UDP_STREAM), o tamanho da mensagem transmitida é 400 bytes (-m 400) e o endereço IP da máquina destino é 10.5.1.3, que por fazer parte da rede CLIP faz com que seja medido o throughput do CLIP sobre ATM. A saída indica que o throughput no lado transmissor foi de 111,46Mbps e de 103, 98Mbps no lado receptor.

priados ao teste. Durante a realização da medida não é transmitido nada pelo canal de controle para não haver interferência.

Os aspectos explorados foram:

- Endereço IP da máquina destino, através do qual selecionamos o trecho de rede a ser avaliado. Passado como parâmetro ao Netperf.

- Nivel físico (Fast Ethernet ou ATM) ou protocolos ATM (CLIP ou LANE). Selecionados indiretamente através do endereço da máquina no item acima.

- Protocolo da camada 4 do modelo OSI (UDP ou TCP). Selecionado diretamente através de um parâmetro passado ao Netperf.

- Tamanho da mensagem a ser transmitida.

Um exemplo de uso está ilustrado na figura 4.2, no qual o tempo tomado pela medida é de um segundo (-1 1), o protocolo de camada 
4 utilizado é o UDP (-t UDP_STREAM), o tamanho da mensagem transmitida é 400 bytes (-m 400) e o endereço IP da máquina destino é 10.5.1.3, que por fazer parte da rede CLIP faz com que seja medido o throughput do CLIP sobre ATM. A saída indica que o throughput no lado transmissor foi de $111,46 \mathrm{Mbps}$ e de 103,98Mbps no lado receptor, indicando a perda de pacotes permitida pelo protocolo UDP.

Para a tomada subsequente de várias medidas para diferentes tamanhos de mensagem foram criados shell-scripts, cuja saída foi redirecionada para um arquivo. Posteriormente, scripts em linguagem Perl foram utilizados para extrair destes arquivos os dados de interesse a serem colocados em gráficos através do software Gnuplot, apresentados nas seções a seguir.

\subsubsection{Teste de performance da máquina}

Foi executado Netperf em uma das máquinas para medir o throughput para ela mesma. Desta forma, os pacotes representando as mensagens só descem até a camada IP, onde é percebido que a própria máquina é também destinatária destes pacotes e assim eles são enviados para cima novamente até chegar na camada de aplicação. Não há portanto limite imposto pela capacidade máxima da rede nem do barramento PCI, e sim da capacidade de processamento e manipulação de dados da memória. O gráfico da figura 4.3 mostra o throughput para a própria máquina com a utilização do protocolo TCP, para mensagens de 1 a 500 bytes. Conforme pode ser observado, a máquina é capaz de saturar uma interface de rede de 155 Mbps com mensagens maiores que 200 bytes no pior caso. Em condições favoráveis, a saturação já pode ocorrer para mensagens maiores que 70 bytes. 


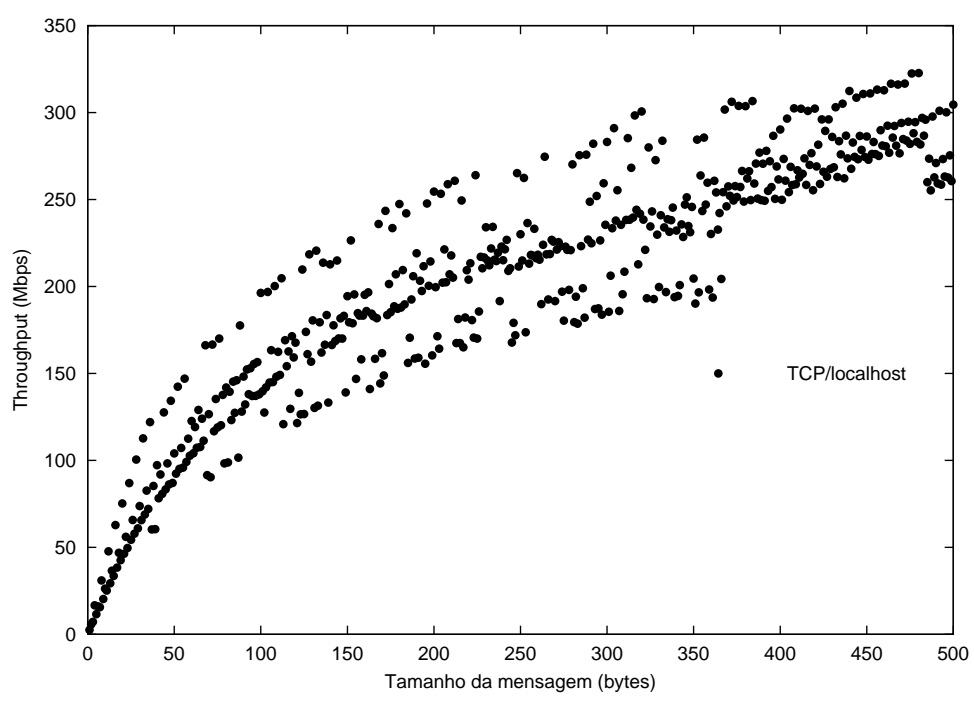

Figura 4.3: Throughput em função do tamanho da mensagem utilizando Netperf com TCP sobre IP tendo localhost como destino para mensagens pequenas com $1 s$ para cada medida.

\subsubsection{Throughput TCP sobre CLIP com Netperf}

Na figura 4.4 é apresentado o throughput do TCP sobre CLIP para mensagens de 1 a 64 KBytes. Para a realização de cada medida foi utilizado $1 s$, tempo que mostrou-se ser suficiente para obtenção de um valor médio estável em CLIP.

Para visualizar melhor o comportamento do sistema para pacotes pequenos foi gerado o gráfico da figura 4.5, que detalha melhor o throughput para mensagens menores que 1 Kbyte e revela que para mensagens maiores que 250 bytes o limite máximo teórico da rede, conforme calculado em (2.1), é alcançado.

Observa-se que apesar do gráfico da figura 4.5 corresponder a apenas um conjunto de dados, ele aparenta representar quatro curvas diferentes para mensagens menores que 150 bytes. Isto fica ainda mais evidente observando a figura 4.6, que representa o mesmo gráfico da figura 4.5 mas que distingue as mensagens de acordo 


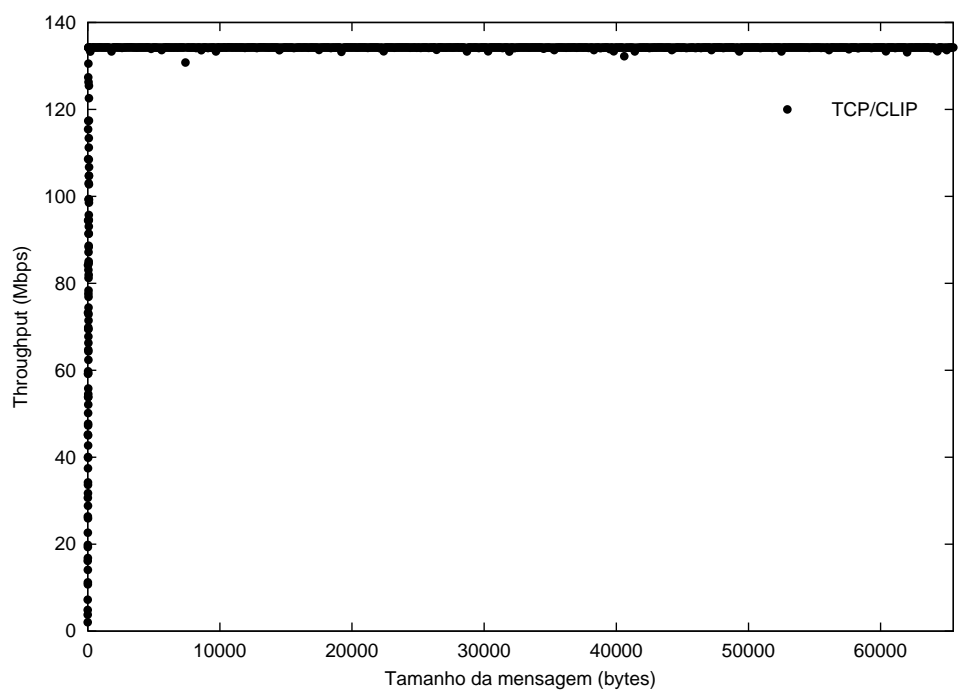

Figura 4.4: Throughput em função do tamanho da mensagem utilizando Netperf com TCP sobre CLIP e $1 s$ para cada medida.

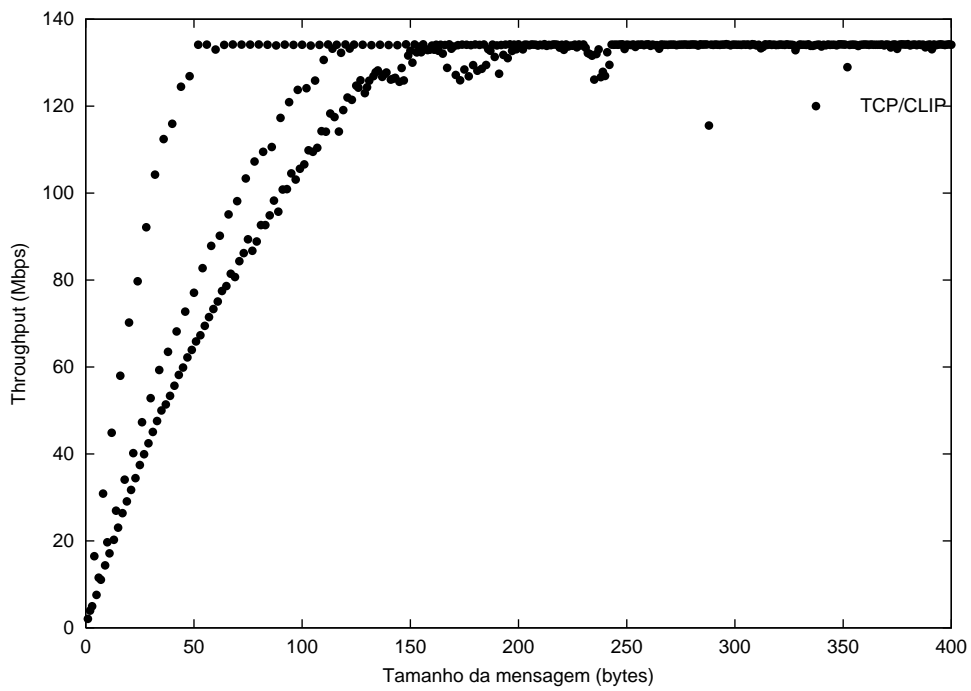

Figura 4.5: Throughput para mensagens pequenas em função do tamanho da mensagem utilizando Netperf com TCP sobre CLIP com 1s para cada medida. 


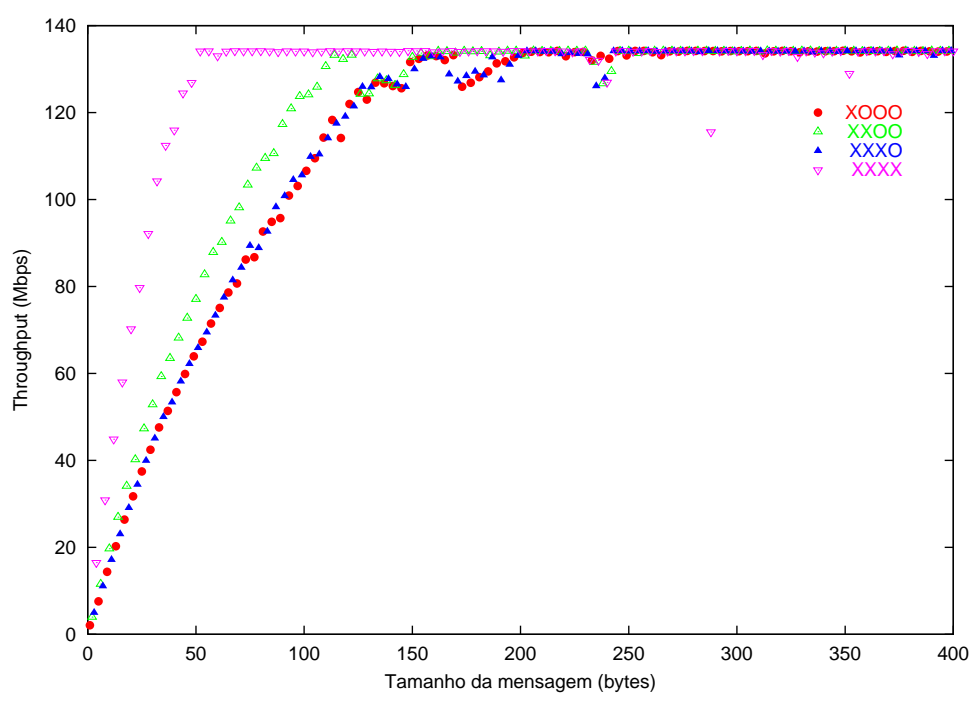

Figura 4.6: Throughput em função do tamanho da mensagem utilizando Netperf com TCP sobre CLIP e $1 s$ para cada medida. A legenda distingue as mensagens de acordo com seu alinhamento final. Por exemplo, XXXO indica que apenas os três primeiros bytes da última palavra de 32 bits são ocupados pela mensagem.

com seu alinhamento final: mensagens que na última palavra de 32 bits ocupam apenas o primeiro byte, mensagens que ocupam apenas os dois primeiros, outras que ocupam os três primeiros e por fim as mensagens que ocupam todos os quatro bytes da última palavra de 32 bits, por serem múltiplas de 32 bits. Isto se deve provavelmente ao fato da arquitetura do computador utilizado ser de 32 bits, uma vez que o efeito é também visível na figura 4.3 que mede o throughput para o localhost, não sofrendo influência do barramento PCI, que poderia ser um fator limitante do desempenho no caso de uma implementação ruim [Cor97] na placa de rede. Conclui-se que seria interessante sempre enviar mensagens múltiplas de 32 bits em arquiteturas de 32 bits e assim extrair maior desempenho da máquina. 


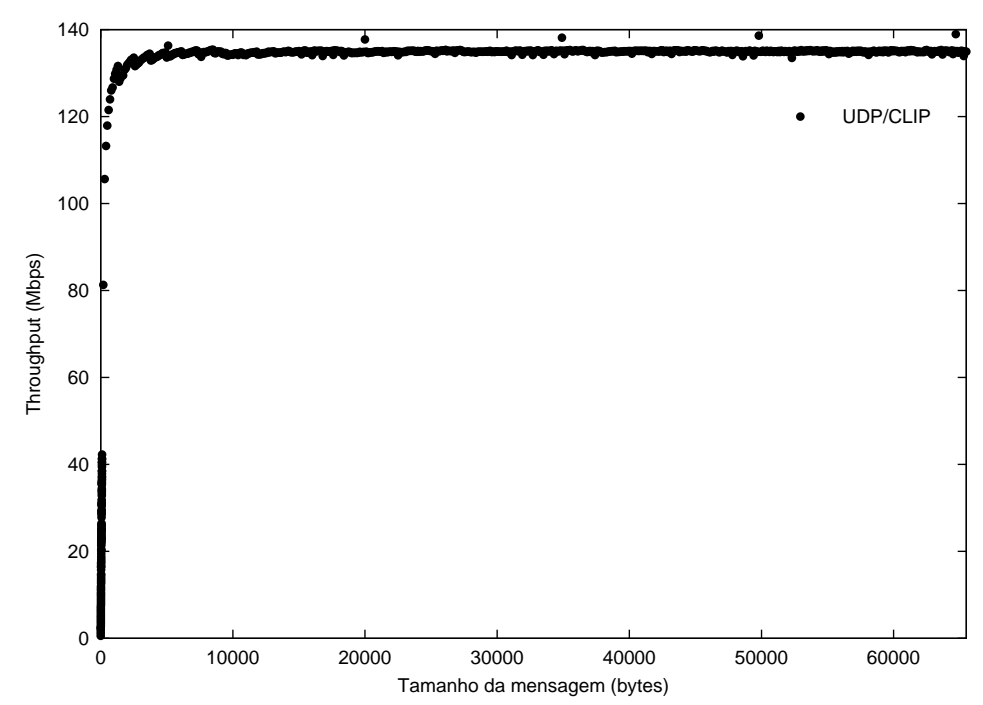

Figura 4.7: Throughput no lado transmissor em função do tamanho da mensagem utilizando Netperf com UDP sobre CLIP e $1 s$ para cada medida utilizando placa de vídeo externa em donald.

\subsubsection{Throughput UDP sobre CLIP com Netperf}

Na figura 4.7 é apresentado o throughput no lado transmissor em função do tamanho das mensagens para o protocolo UDP sobre CLIP, para mensagens de 1 a 64 KBytes. Porém, como o UDP é um protocolo sem conexão (cuja entrega não é garantida), é necessário verificar o throughput no lado receptor também, que é apresentado na figura 4.8.

Não há diferenças visíveis entre as figuras 4.7 e 4.8, mas uma observação melhor no comportamento do throughput para mensagens pequenas tanto no lado transmissor quanto no receptor através das figuras $4.9,4.10$ e 4.11 revela que apesar do throughput no receptor crescer quase que linearmente para mensagens de 1 a 100 bytes, ele cai inesperadamente a praticamente zero e depois cresce novamente por volta de 400 bytes para rapidamente atingir a capacidade máxima da rede. 


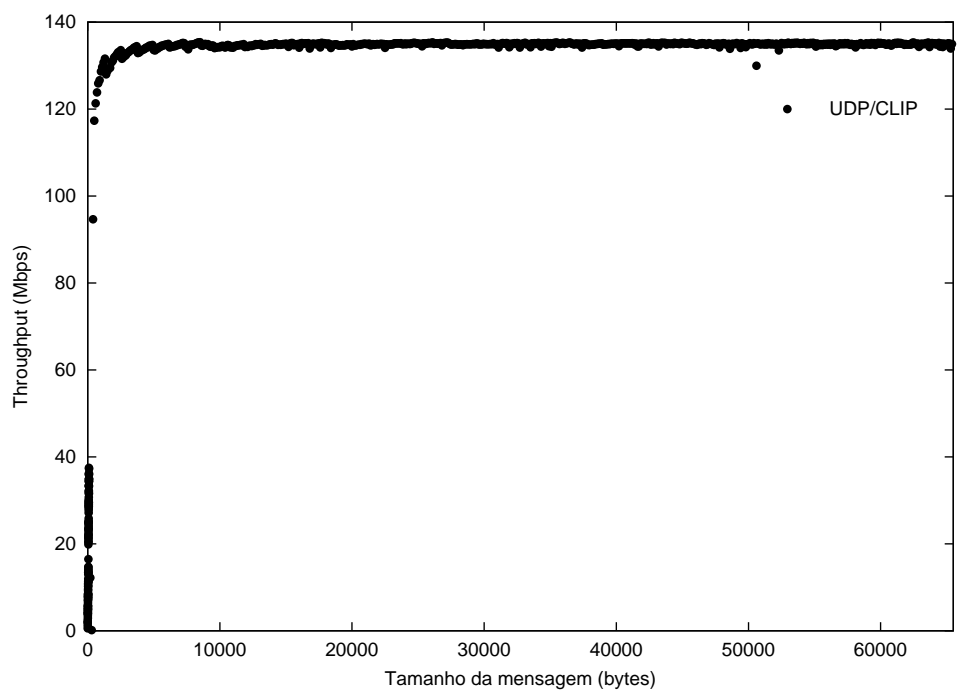

Figura 4.8: Throughput no lado receptor em função do tamanho da mensagem utilizando Netperf com UDP sobre CLIP e $1 s$ para cada medida utilizando placa de vídeo externa em donald.

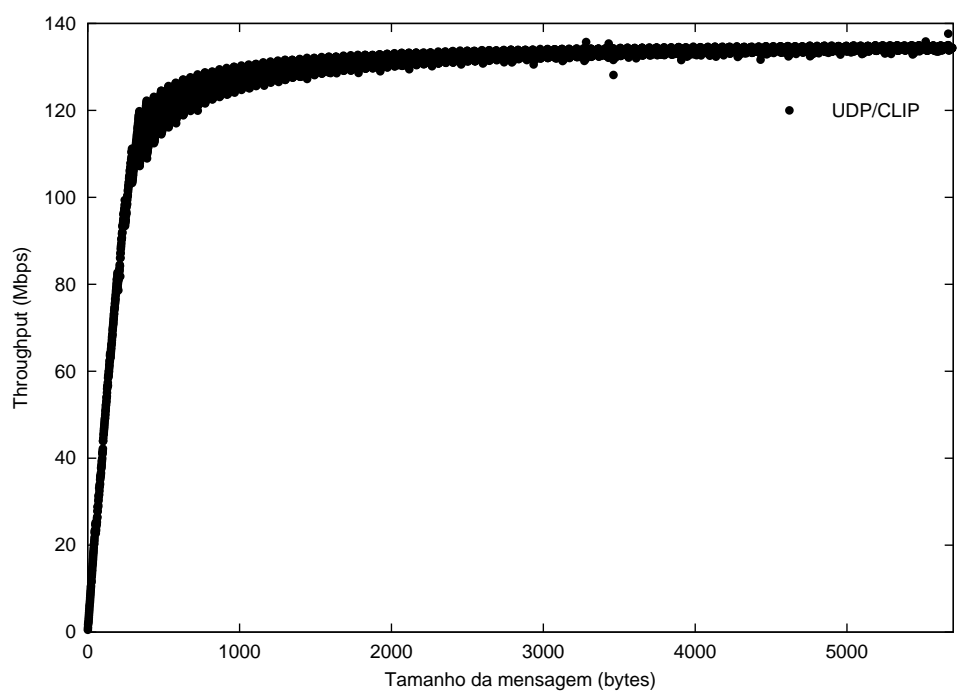

Figura 4.9: Throughput em função do tamanho da mensagem no lado transmissor utilizando Netperf com UDP sobre CLIP e $1 s$ para cada medida utilizando placa de vídeo externa em donald. 


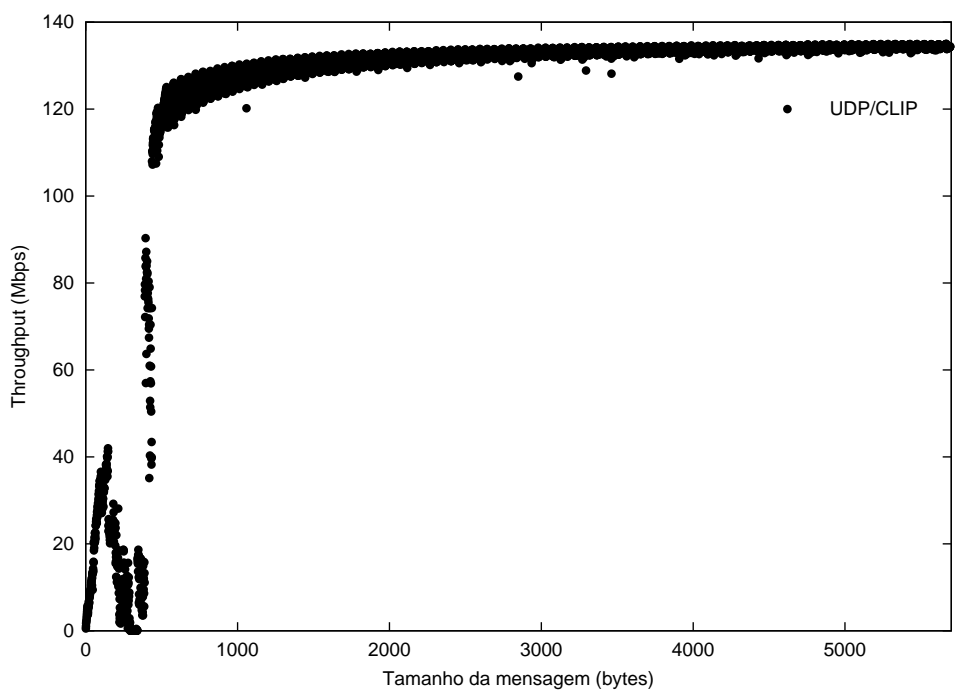

Figura 4.10: Throughput em função do tamanho da mensagem no lado receptor utilizando Netperf com UDP sobre CLIP e $1 s$ para cada medida utilizando placa de vídeo externa em donald.

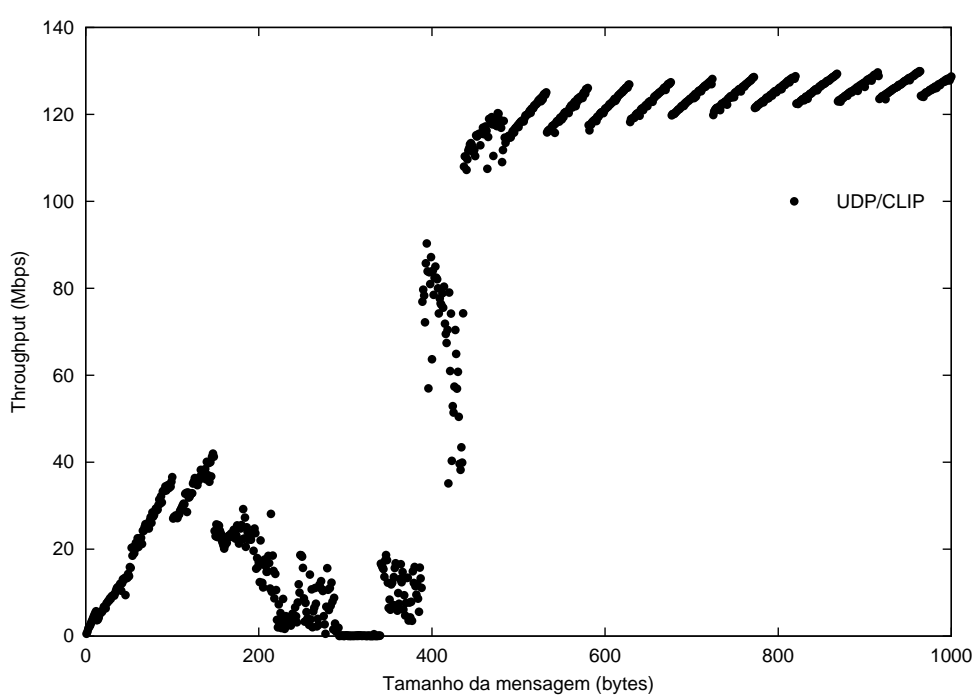

Figura 4.11: Throughput em função do tamanho da mensagem no lado receptor utilizando Netperf com UDP sobre CLIP e $1 s$ para cada medida utilizando placa de vídeo externa em donald. 


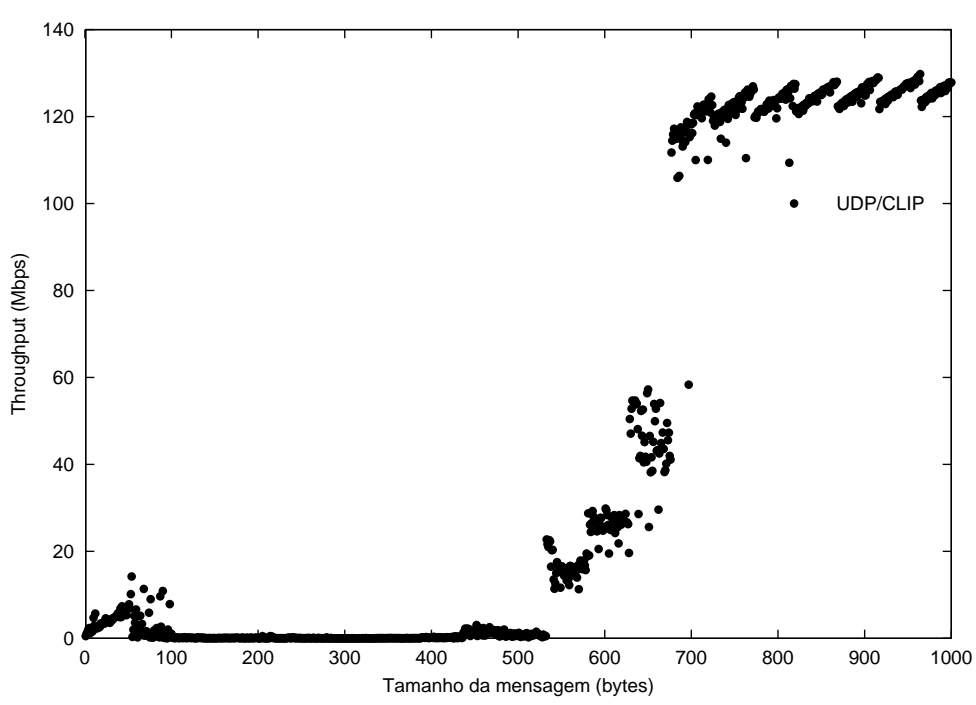

Figura 4.12: Throughput em função do tamanho da mensagem no lado receptor utilizando Netperf com UDP sobre CLIP e $1 s$ para cada medida utilizando placa de vídeo onboard em donald.

O gráfico da figura 4.12 também representa o throughput no lado receptor em função do tamanho da mensagem para UDP sobre CLIP, com a diferença que neste gráfico foi utilizada a placa de vídeo onboard no computador donald, de maneira que 4 MB da memória do sistema são compartilhados com a parte de vídeo, trazendo prejuízos visiveis no throughput para pequenas mensagens. Isto na verdade foi descoberto ao perceber-se que rodando Netperf de jan4 para donald o throughput era muito baixo (quase nulo) para mensagens de 500 bytes, e no sentido inverso, de donald para jan4, ele ficava acima de 100Mbps. Constatou-se que isto era causado exclusivamente devido à utilização de uma placa de vídeo externa em jan4 e de uma onboard em donald. Medidas posteriores foram realizadas com placas de vídeo externas em ambos os micros. 


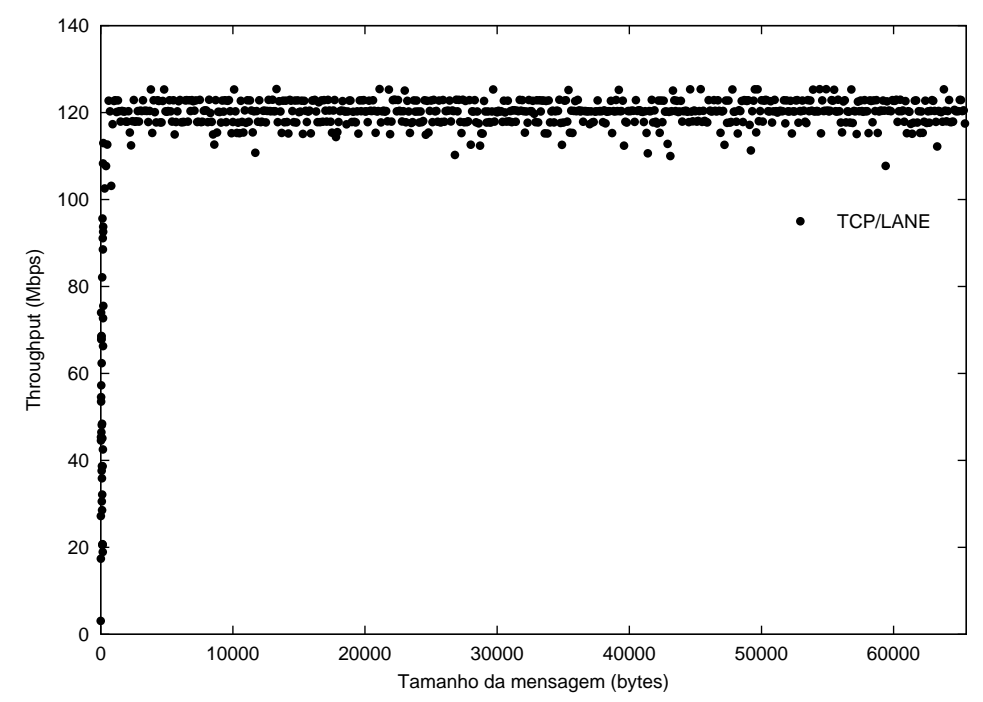

Figura 4.13: Throughput em função do tamanho da mensagem utilizando Netperf e $60 s$ para cada medida para TCP sobre LANE.

\subsubsection{Throughput TCP sobre LANE com Netperf}

Na figura 4.13 é apresentado o throughput do TCP sobre LANE para mensagens de 1 a 64 KBytes. Para a realização de cada medida foram utilizados $60 \mathrm{~s}$, tempo que se mostrou ser necessário para a obtenção de uma medida estável em LANE.

Uma visualização melhor para mensagens pequenas é oferecida pela figura 4.14, que assim como no caso do receptor UDP sobre CLIP mostra problemas para mensagens na faixa de 100 a 400 bytes.

Pode ser observado que há uma queda do throughput para mensagens entre 100 e 200 bytes e que para mensagens um pouco maiores que 200 bytes ele sobe até atingir a capacidade máxima da rede. Uma observação um pouco mais detalhada revela que o throughput sobe de modo diferente de acordo com o alinhamento final da mensagem. Para as mensagens que ocupam todos os bytes da última palavra de 32 bits, o throughput sobe o mais rápido possivel após a queda. Logo a seguir alcançam o throughput máximo as mensa- 


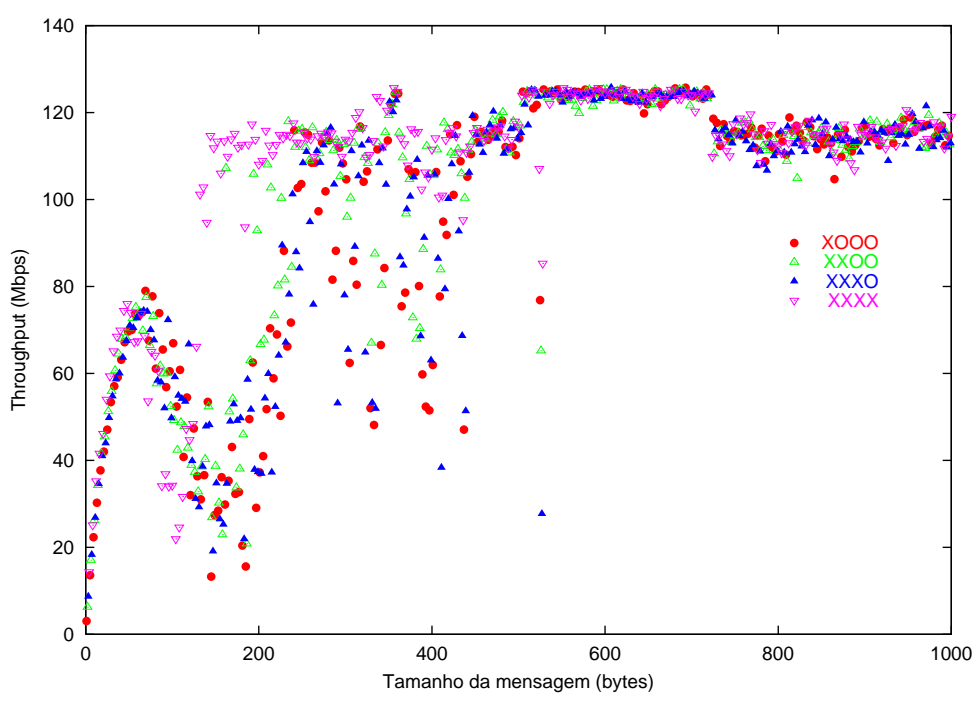

Figura 4.14: Throughput em função do tamanho da mensagem utilizando Netperf e $60 s$ para cada medida para TCP sobre LANE. A legenda distingue as mensagens de acordo com seu alinhamento final. Por exemplo, XXXO indica que apenas os três primeiros bytes da última palavra de 32 bits são ocupados pela mensagem.

gens que ocupam apenas dois bytes da última palavra de 32 bits e por fim temos os outros dois casos.

\subsubsection{Throughput UDP sobre LANE com Netperf}

Na figura 4.15 é mostrado o throughput para UDP sobre LANE para o lado transmissor e na figura 4.16 o throughput para o lado receptor. Novamente para mensagens de 100 a 400 bytes há uma queda acentuada do throughput no lado receptor. Podemos observar uma ligeira queda do throughput para mensagens por volta de 1500 bytes. Isto se deve ao tamanho do MTU do LANE ser de 1500 bytes, sendo necessário o envio de dois ou mais pacotes para mensagens maiores. Isto se repete periodicamente para mensagens de 3000, 4500 bytes, etc. 


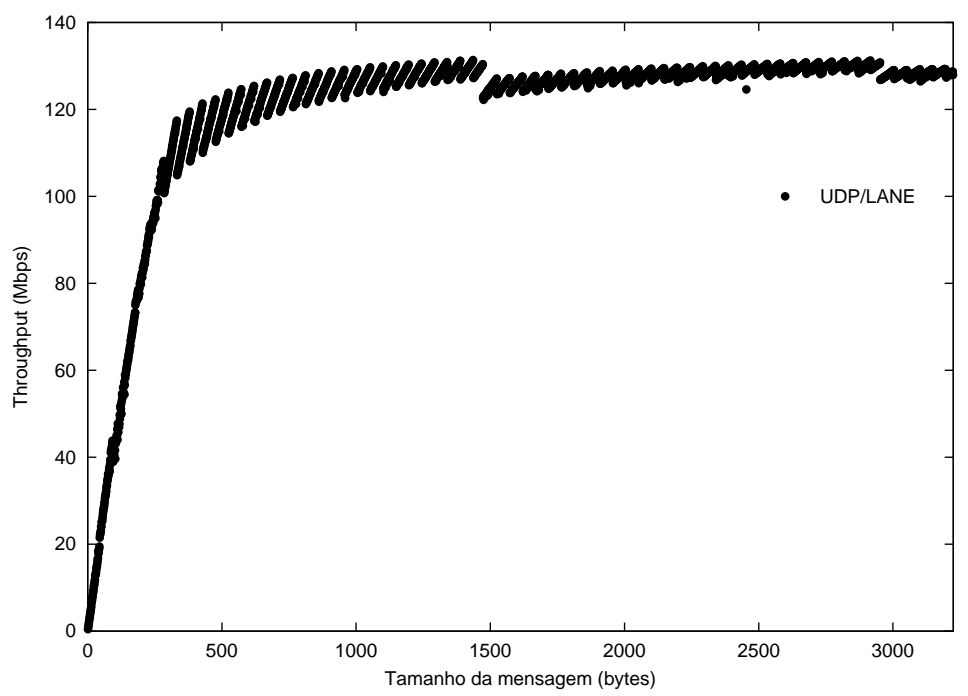

Figura 4.15: Throughput em função do tamanho da mensagem no lado transmissor utilizando Netperf com UDP sobre LANE e $60 s$ para cada medida.

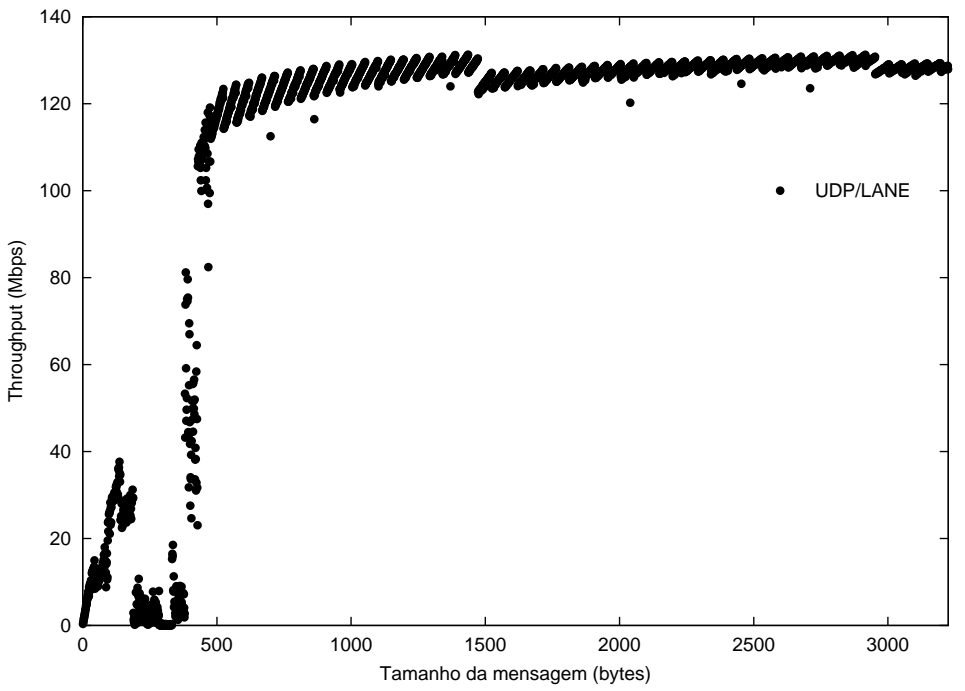

Figura 4.16: Throughput em função do tamanho da mensagem no lado receptor utilizando Netperf com UDP sobre LANE e $60 s$ para cada medida. 


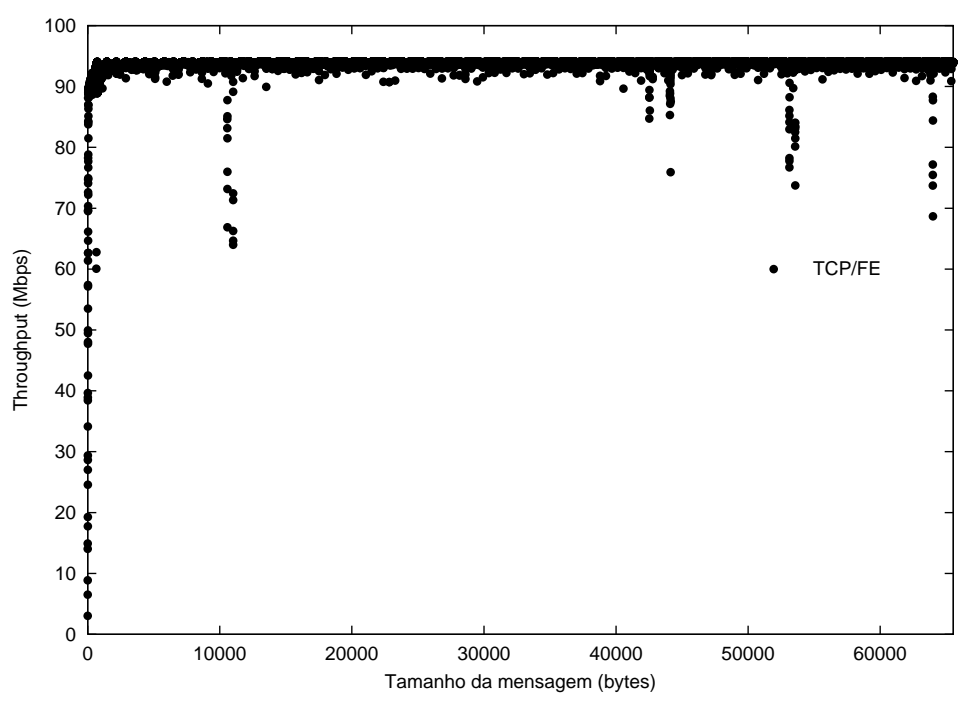

Figura 4.17: Throughput em função do tamanho da mensagem utilizando Netperf com TCP sobre Fast Ethernet e 1s para cada medida.

\subsubsection{Throughput TCP sobre Fast Ethernet com Netperf}

Medidas sobre Fast Ethernet foram realizadas para servirem de comparação. Na figura 4.17 temos o throughput em função do tamanho da mensagem para TCP sobre Fast Ethernet. Para a realização de cada medida foi utilizado apenas $1 s$, tempo que se mostrou ser mais do que suficiente para a obtenção de um valor médio estável em Fast Ethernet.

Na figura 4.18 é dado ênfase nas mensagens pequenas. Observase que o throughput inicialmente cresce muito rápido e para mensagens de 50 bytes ele já alcança a capacidade máxima da rede, ficando estável por volta de $90 \mathrm{Mbps}$ para mensagens maiores.

\subsubsection{Throughput UDP sobre Fast Ethernet com Netperf}

Nas figuras 4.19 e 4.20 temos o throughput em função do tamanho da mensagem para UDP sobre Fast Ethernet para o lado receptor. Para a realização de cada medida foi utilizado apenas $1 s$, tempo que 


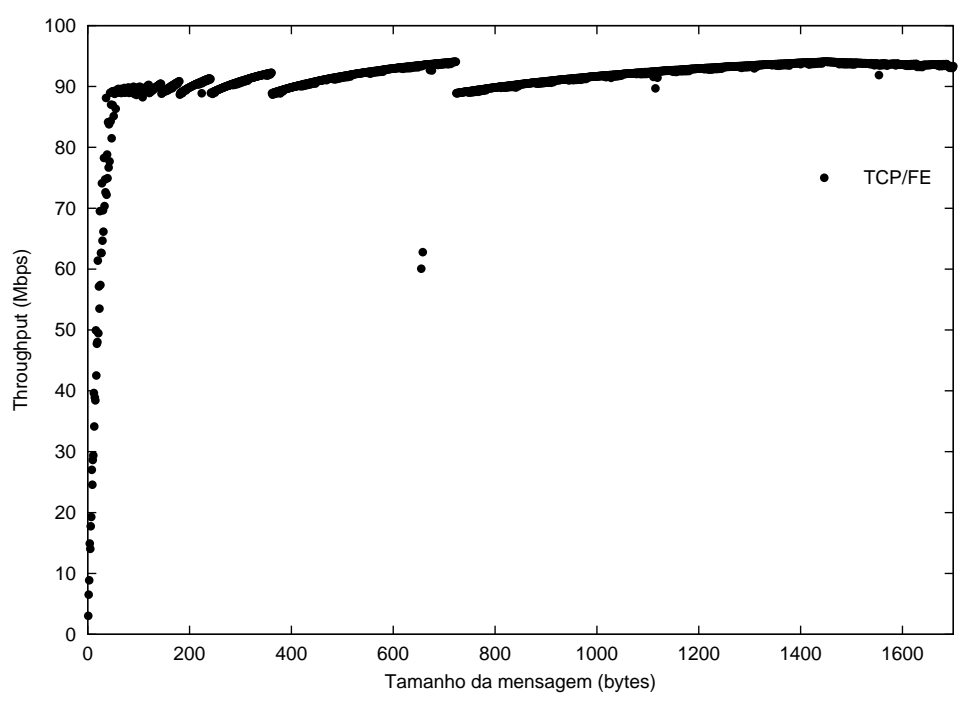

Figura 4.18: Throughput em função do tamanho da mensagem utilizando Netperf com TCP sobre Fast Ethernet e $1 s$ para cada medida.

se mostrou ser mais do que suficiente para a obtenção de um valor médio estável em Fast Ethernet. Observa-se que para mensagens de aproximadamente 200 bytes houve uma pequena perda de pacotes na rede, como havia sido constatado com maior intensidade nos casos com UDP sobre CLIP e LANE.

\subsection{Resumo dos resultados}

Para a medida do throughput com FTP houve necessidade de usar RAMDisk na máquina transmissora e direcionamento do arquivo para o dispositivo /dev/null na máquina receptora para alcance do desempenho máximo da rede. Devido à utilização de grandes datagramas pelo FTP, o throughput alcançado com FTP sobre CLIP, LANE e Fast Ethernet foi muito próximo do máximo teórico possível. O Fast Ethernet obteve o menor desvio padrão, mostrando o comportamento mais estável dentre os três casos estudados. Já o CLIP aproximou-se mais do valor máximo teórico possível, com um 


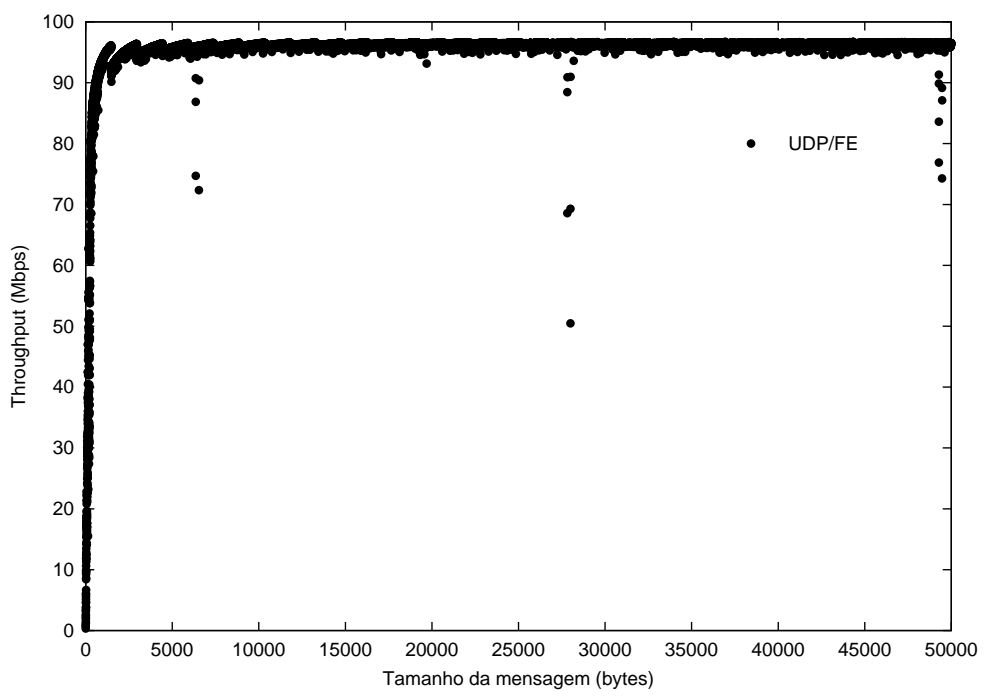

Figura 4.19: Throughput em função do tamanho da mensagem no lado receptor utilizando Netperf com UDP sobre Fast Ethernet e 1s para cada medida.

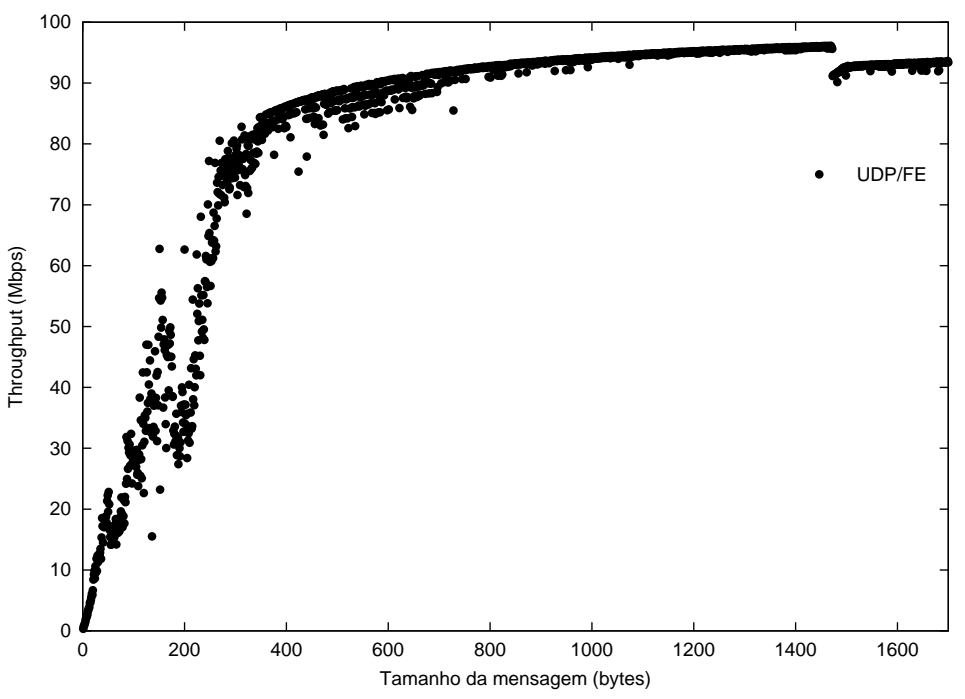

Figura 4.20: Throughput em função do tamanho da mensagem no lado receptor utilizando Netperf com UDP sobre Fast Ethernet e $1 s$ para cada medida. 
desvio padrão pequeno em relação ao valor alcançado, mostrando um desempenho muito bom, tanto pela eficiência quanto pela estabilidade. Por fim, o LANE apresentou um desvio padrão maior que o Fast Ethernet e CLIP, indicando maior necessidade de uso de CPU ou acessos à memória, levando a uma maior flutuação em relação ao valor médio.

Com Netperf foi possível uma análise mais detalhada do comportamento do TCP, assim como do UDP, sobre CLIP, LANE e Fast Ethernet. Em geral, para mensagens grandes (maiores que 700 bytes) o comportamento de todos os protocolos foi muito semelhante, sendo medidas taxas de transferência muito próximas do máximo teórico de cada um.

O CLIP com TCP apresentou um bom comportamento, com rápido crescimento do throughput, alcançando a saturação para mensagens de 50 a 150 bytes, dependendo do seu alinhamento final. Com UDP o crescimento também foi muito rápido no lado transmissor, mas grande parte das mensagens de 1 a 600 bytes foram perdidas no lado receptor, reduzindo o throughput nesta faixa. Constatouse maior degradação com uso da placa de vídeo onboard que com uma placa de vídeo externa, caso em que a faixa de baixo throughput se restringiu de 100 a 400 bytes, e com menor perda.

O LANE necessitou de um tempo maior por medida que o CLIP e Fast Ethernet para a obtenção de um valor médio estável. Apesar do throughput para mensagens de 1 a 50 bytes sobre TCP indicar crescimento, logo após há um declínio e um comportamento instável, que mostra forte influência da placa de vídeo e do alinhamento final das mensagens. Com UDP, assim como no caso do CLIP sobre LANE, houve grande perda de mensagens na faixa de 100 a 400 bytes no lado receptor. 
O Fast Ethernet mostrou-se muito estável, tanto com TCP como UDP. Uma perda perceptivel de pacotes ocorreu para mensagens por volta de 200 bytes, porém, menos significativa que nos casos CLIP e LANE.

Vale a pena ainda ressaltar que a comparação de desempenho das placas ATM e Ethernet utilizadas pode ser considerada desleal não apenas por se tratar de duas tecnologias bastante diferentes, mas também pelo fato das placas se enquadrarem em categorias de preço diferentes dentro de sua categoria: a placa ATM ForeRunner LE 155 é considerada uma das mais baratas no segmento de interfaces ATM de 155Mbps, enquanto que a placa Fast Ethernet, além de trazer recursos que a maioria das placas Fast Ethernet não dispõe, é de uma marca das mais prestigiadas na área de equipamentos para redes de computadores. 


\section{Capítulo 5}

\section{Medidas experimentais de}

\section{latência}

\subsection{Latência medida com ping}

Uma maneira fácil e comum de se medir a latência de comunicação por uma rede é através do uso do aplicativo ping.

\subsubsection{Ping sobre CLIP}

"Pingando" o IP configurado em CLIP na interface ATM da própria máquina, como mostrado na listagem da figura 5.1, observamos que os tempos de resposta são tão pequenos que são arredondados para zero devido à precisão utilizada. A magnitude dos tempos de resposta é tão pequena porque o pacote de rede com a requisição ping gerado pela camada Internet Control Message Protocol (ICMP) nem chega a descer abaixo da camada IP pois ela mesma percebe que a requisição é para a própria máquina e devolve um pacote ICMP de resposta. O tempo fica portanto apenas limitado pela capacidade de processamento da máquina e pela manipulação de dados 


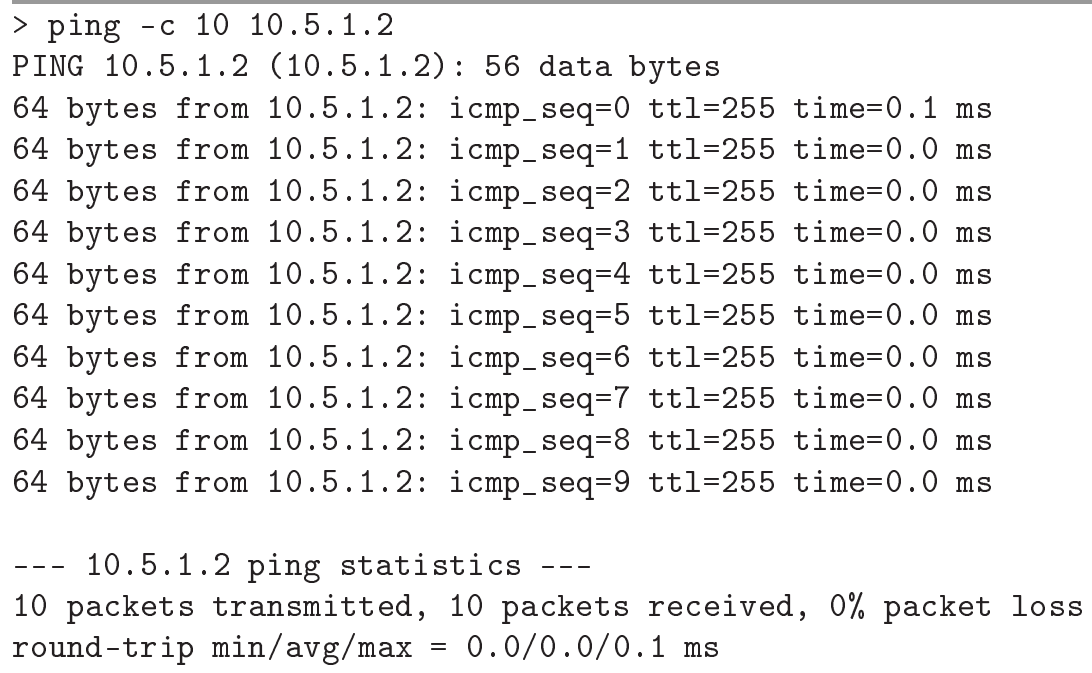

Figura 5.1: Saída do aplicativo ping de uma máquina para ela mesma sobre CLIP.

na memória.

Para pings de máquina a máquina em CLIP sobre ATM, temos que o primeiro pacote leva consideravelmente mais tempo para voltar que os demais que o sucedem. O primeiro levou aproximadamente $24 \mathrm{~ms}$ para voltar, o que se deve à necessidade de consultar o ARP Server para descobrir o endereço ATM correspondente ao IP destino e em seguida abrir um canal ATM à máquina destino, enquanto que para os demais o canal permanece aberto e pronto para uso, resultando em tempos por volta de $0,4 \mathrm{~ms}$, conforme mostrado na figura 5.2 .

Realizando a mesma medida com a chave ATM como destino obtivemos tempos que permanecem por volta de $2 m s$, do primeiro ao último, como mostrado na figura 5.3. Isto ocorre pois como explicado na seção 2.9, cada cliente de uma LIS mantém um PVC permanentemente aberto com o ARP Server, que neste caso é a própria chave que estamos a testar. O tempo de resposta a cada ping também é maior com a chave do que com outro computador. Isto vem a 


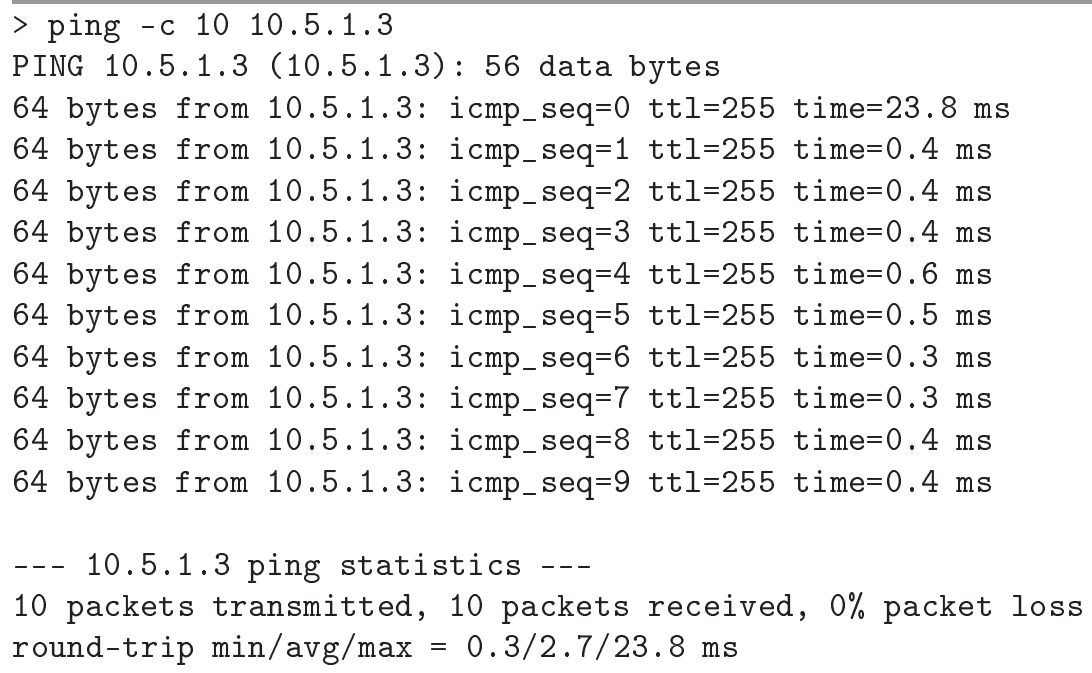

Figura 5.2: Saída do aplicativo ping de uma máquina para outra sobre CLIP.

mostrar que a capacidade de processamento disponível ou dedicada ao processamento da resposta ICMP influencia na latência obtida.

\subsubsection{Ping sobre LANE}

"Pingando" o IP configurado em LANE na interface ATM da própria máquina, observamos que os tempos de resposta são tão pequenos quanto no caso com CLIP, conforme ilustrado na listagem da figura 5.4 .

Pings de máquina a máquina em LANE sobre ATM mostram que o primeiro pacote leva quase $1 s$ para voltar, sendo que os demais levam aproximadamente $0,4 \mathrm{~ms}$, como no caso do CLIP, conforme mostrado na figura 5.5. Isto ocorre porque o primeiro pacote destinado à outra ponta não tem um canal aberto para utilizar. Ele é então enviado ao BUS, que o repassará a todos os clientes da LAN emulada ao mesmo tempo que é feita a consulta do endereço ATM do destino e a conseqüente abertura do canal, como discutido na seção 2.10. Os demais pacotes têm um canal já aberto para ser uti- 


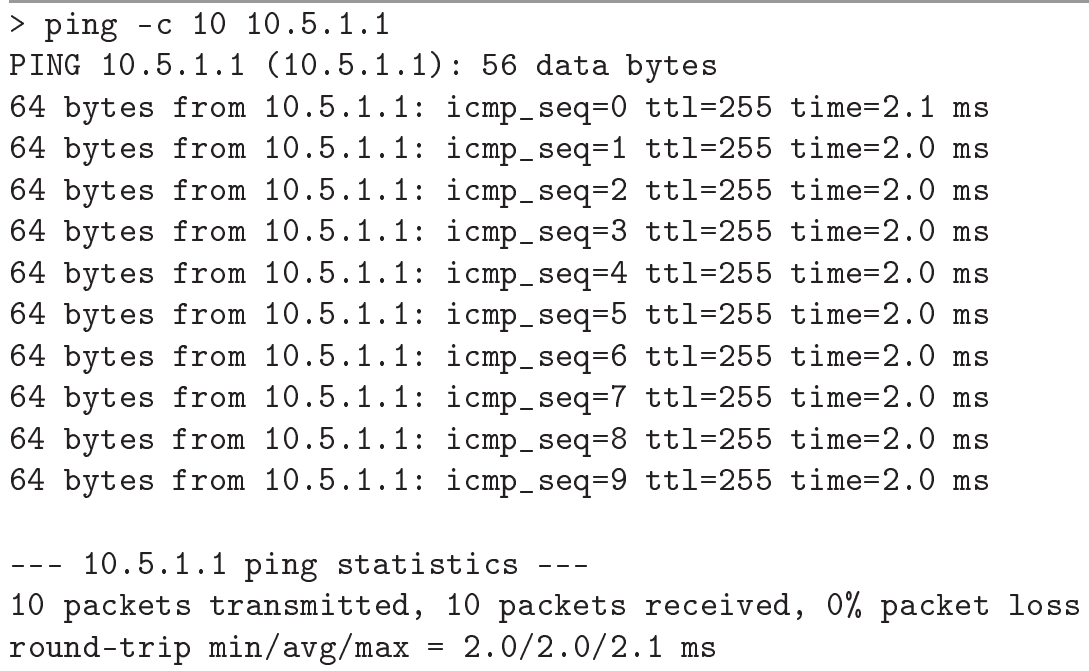

Figura 5.3: Saída do aplicativo ping de uma máquina para a chave ATM sobre CLIP.

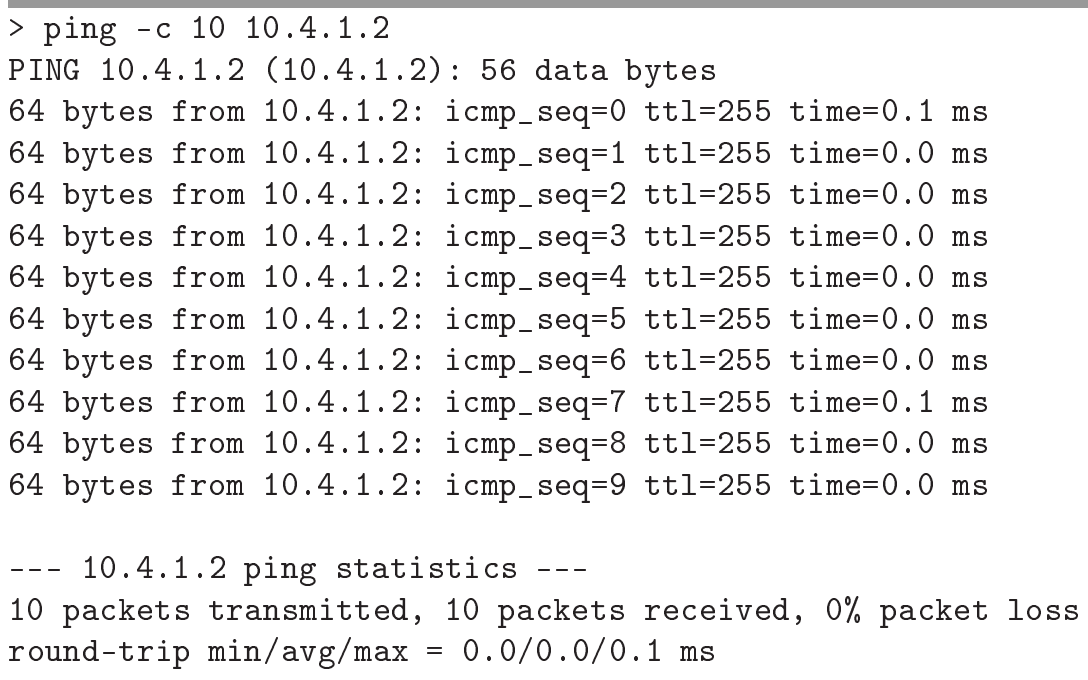

Figura 5.4: Saída do aplicativo ping de uma máquina para ela mesma sobre LANE. 


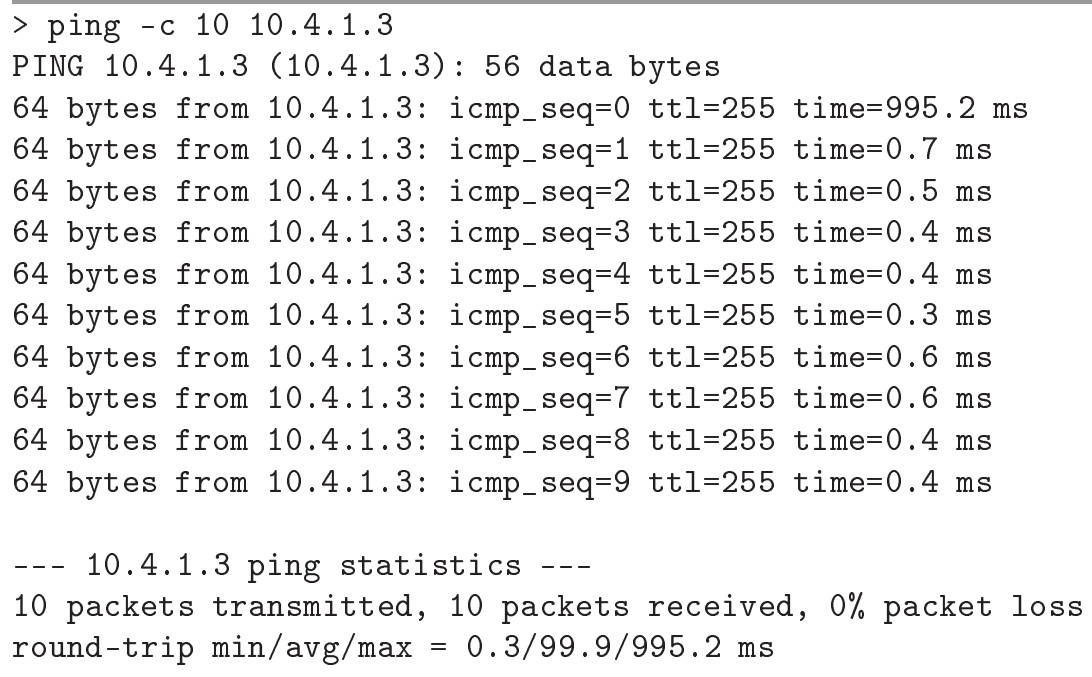

Figura 5.5: Saída do aplicativo ping de uma máquina a outra sobre LANE.

lizado, resultando em um tempo de tráfego muito menor. Nota-se ainda que há um desvio em relação ao tempo médio maior em LANE que em CLIP para o segundo pacote em diante, indicando um maior overhead de processamento ou dependência de fatores externos do LANE.

Por fim, com a chave ATM como destino temos que o primeiro pacote também leva aproximadamente $1 s$ para voltar e que os demais levam aproximadamente $3 \mathrm{~ms}$, conforme mostrado na figura 5.6, novamente indicando uma menor capacidade de processamento na chave destinada ao processamento de uma resposta ICMP e um maior overhead de processamento do protocolo LANE em relação ao CLIP, uma vez que o tempo normal de resposta da chave sobre CLIP foi de $2 \mathrm{~ms}$.

\subsubsection{Ping sobre Fast Ethernet}

O ping sobre Fast Ethernet de uma máquina a outra através da chave 3 Com forneceu $0,4 \mathrm{~ms}$ para o primeiro pacote e $0,1 \mathrm{~ms}$ para 


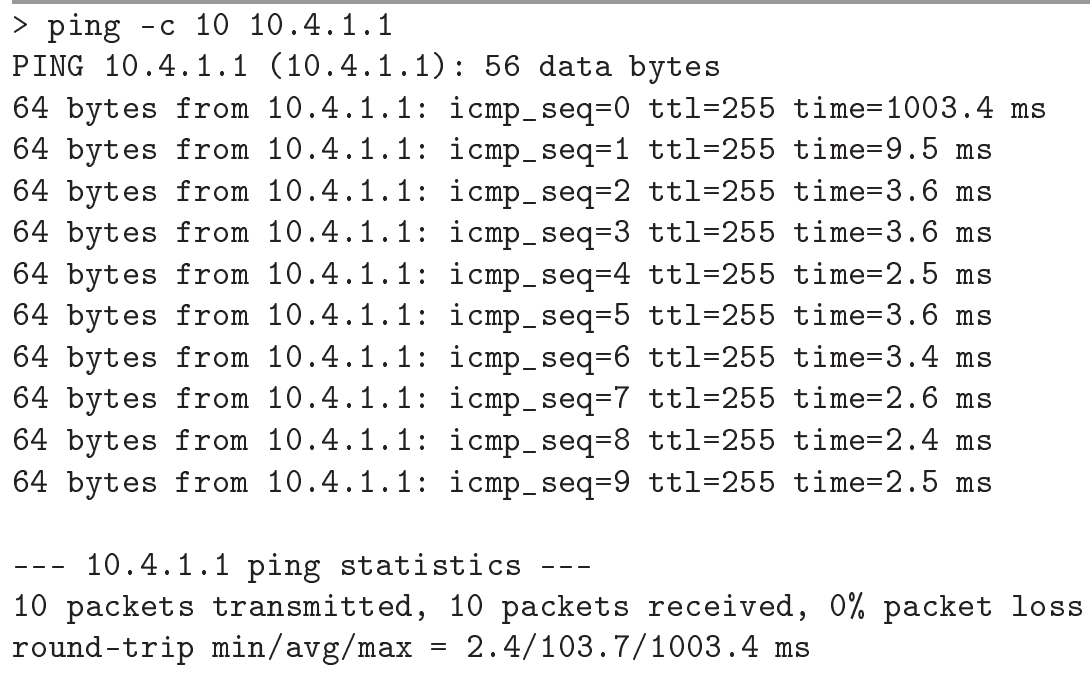

Figura 5.6: Saída do aplicativo ping de uma máquina para a chave ATM sobre LANE.

os demais, conforme mostrado na figura 5.7. O primeiro pacote tem uma latência um pouco maior pois da primeira vez é necessário fazer uma requisição ARP na rede Ethernet para a obtenção do endereço MAC do destinatário. Fica evidente que os tempos obtidos com Fast Ethernet são melhores que os obtidos com LANE e mesmo com CLIP, apesar do throughput nominal ser menor. Vale a pena notar também que não existe flutuação na latência do segundo pacote em diante, como havia com CLIP e em maior intensidade com LANE.

\subsection{Latência de aplicativo a aplicativo com sockets}

Foram desenvolvidos programas baseados no modelo cliente-servidor, onde o servidor em certo ponto da execução fica bloqueado aguardando que um cliente envie mensagens a ele [Ste90a]. O objetivo é registrar o instante em que uma mensagem é enviada pelo aplicativo cliente e o momento em que a mensagem chega ao aplicativo 


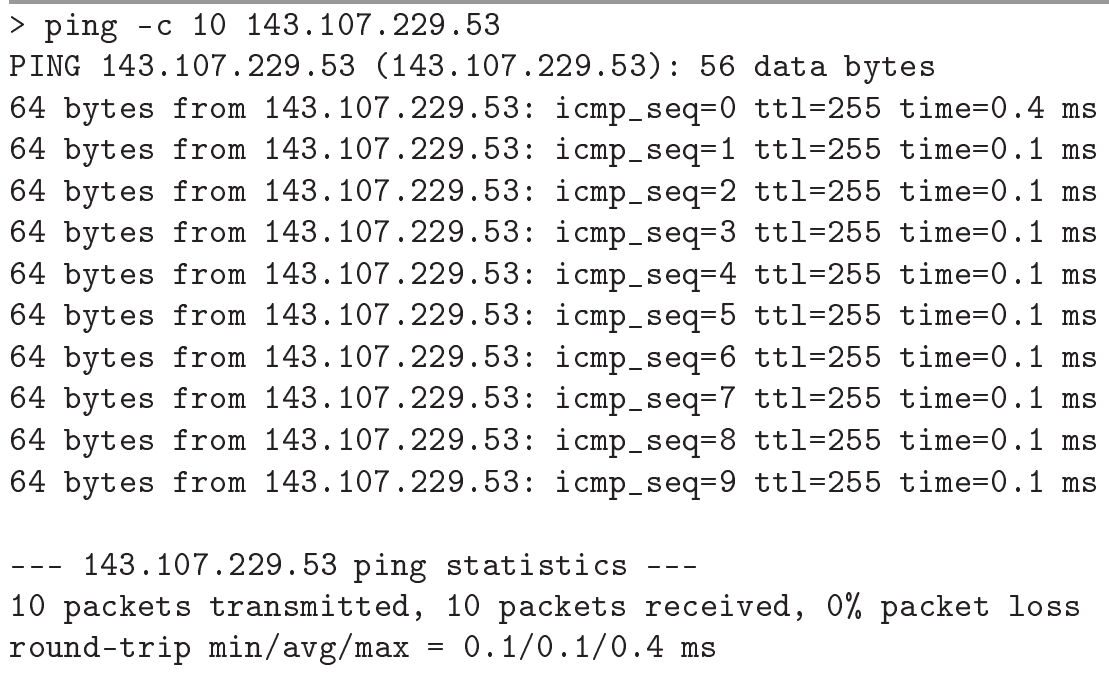

Figura 5.7: Saída do aplicativo ping de uma máquina a outra sobre Fast Ethernet.

servidor, com o uso das placas MultiKron operando com o relógio central, conforme mostrado na figura 3.2, e assim determinar a latência da comunicação entre os aplicativos em máquinas distintas. A comunicação entre os processos é feita através de sockets, que oferecem uma interface muito fácil de usar, semelhante à abstração de arquivos, em que o cliente realiza operações de escrita e o servidor operações de leitura sobre um descritor de socket (como se faz com um descritor de arquivo) [Ste90b]. Foi feita uma versão que usa o protocolo UDP, que é não-orientado à conexão, e outra que usa o protocolo TCP, que é orientado à conexão, totalizando quatro aplicativos (dois servidores e dois clientes).

Entre o envio de uma mensagem e outra foram aguardados $100 \mathrm{~ms}$ através do uso da chamada de sistema usleep( ), não havendo consumo de CPU pelo programa durante a espera, para que o resultado das medidas não fosse afetado por uma alta taxa de transmissão ou uma alta taxa de utilização de CPU. Isto pode não corresponder totalmente a uma situação real mas é uma forma de padronizar as 


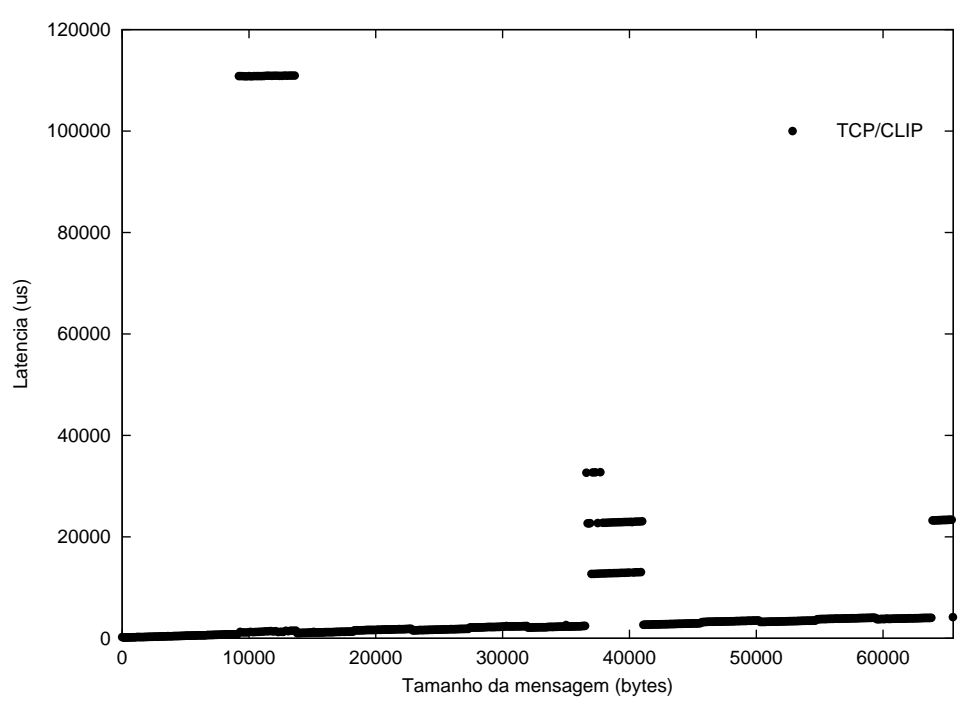

Figura 5.8: Latência de aplicativo a aplicativo em função do tamanho da mensagem utilizando sockets TCP sobre CLIP.

medidas.

\subsubsection{Latência do TCP sobre CLIP}

Na figura 5.8 é apresentada a latência de comunicação de aplicativo a aplicativo em função do tamanho da mensagem para TCP sobre CLIP para mensagens de 1 a 64 Kbytes. O mesmo gráfico é mostrado na figura 5.9 com uma escala vertical ampliada. Observando a figura 5.8 nota-se que para mensagens por volta de 11000 bytes houve um grande jitter, pois para algumas mensagens o tempo de resposta foi de $1,5 \mathrm{~ms}$ e para outras de tamanho muito próximo ele foi de aproximadamente $110 \mathrm{~ms}$. Algo parecido ocorreu para mensagens por volta de 40000 e 65000 bytes, provavelmente causado pelos mecanismos de controle do TCP. 


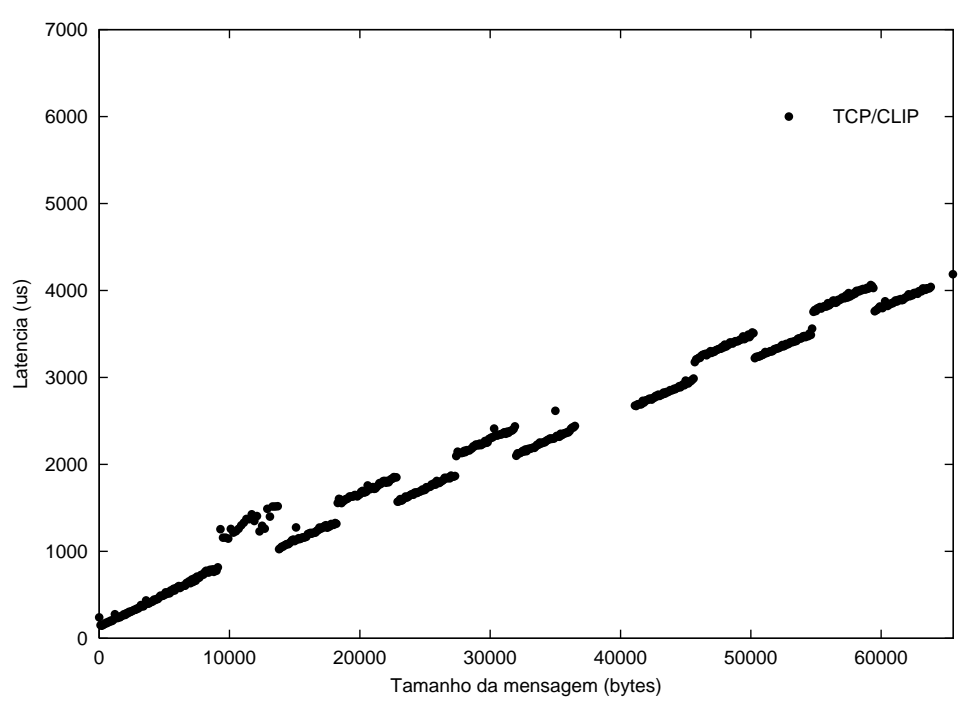

Figura 5.9: Latência de aplicativo a aplicativo em função do tamanho da mensagem utilizando sockets TCP sobre CLIP com escala reduzida no eixo vertical.

\subsubsection{Latência do UDP sobre CLIP}

A latência de comunicação de aplicativo a aplicativo em função do tamanho da mensagem para UDP sobre CLIP para mensagens de 1 a 64 Kbytes é mostrada na figura 5.10, apresentando um comportamento bastante linear com jitter desprezivel. Não foram detectadas perdas de pacotes, provavelmente devido à baixa taxa de transmissão utilizada.

\subsubsection{Latência do TCP sobre LANE}

Nas figuras 5.11 e 5.12 é ilustrada a latência de comunicação de aplicação a aplicação para TCP sobre LANE. O throughput não se mostra tão comportado como era de se desejar, apresentando um jitter considerável ao longo de toda a faixa de 1 a 64 Kbytes, provavelmente causado pelos mecanismos de controle do TCP. 


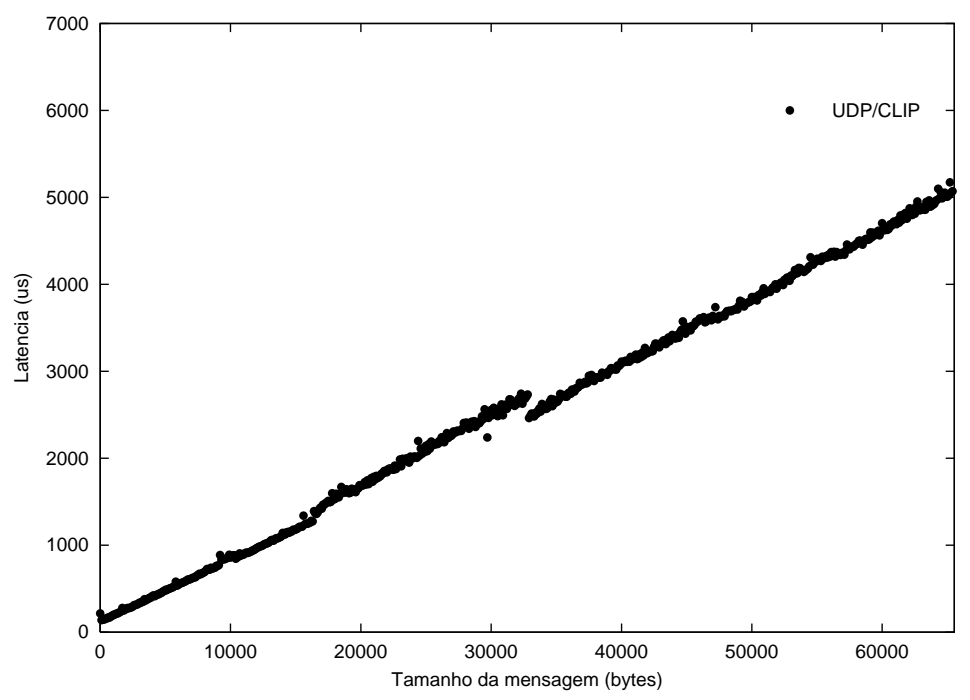

Figura 5.10: Latência de aplicativo a aplicativo em função do tamanho da mensagem utilizando sockets UDP sobre CLIP.

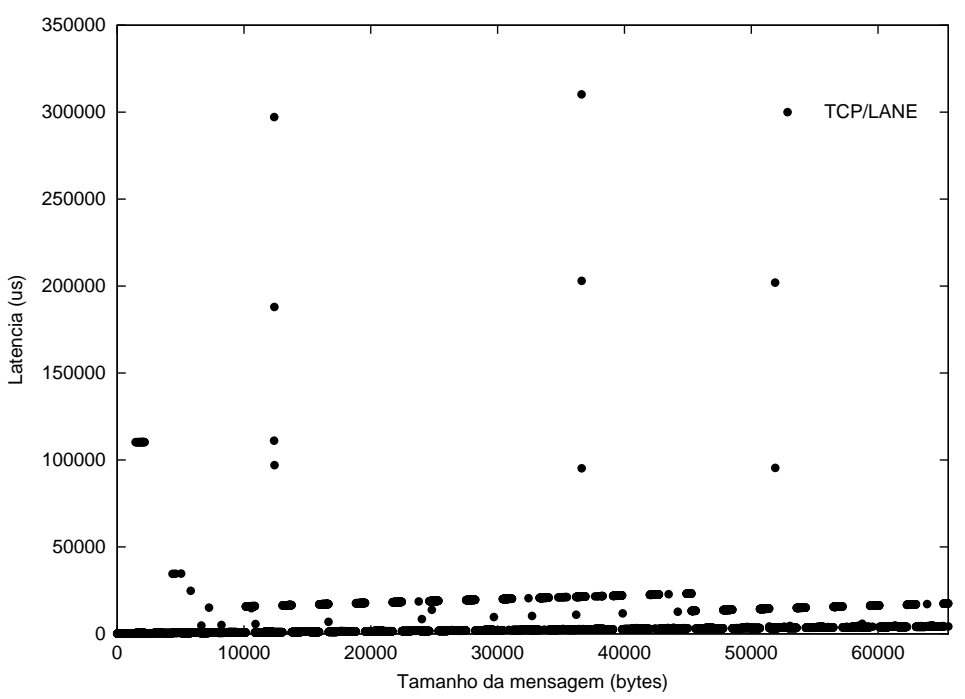

Figura 5.11: Latência de aplicativo a aplicativo em função do tamanho da mensagem utilizando sockets TCP sobre LANE. 


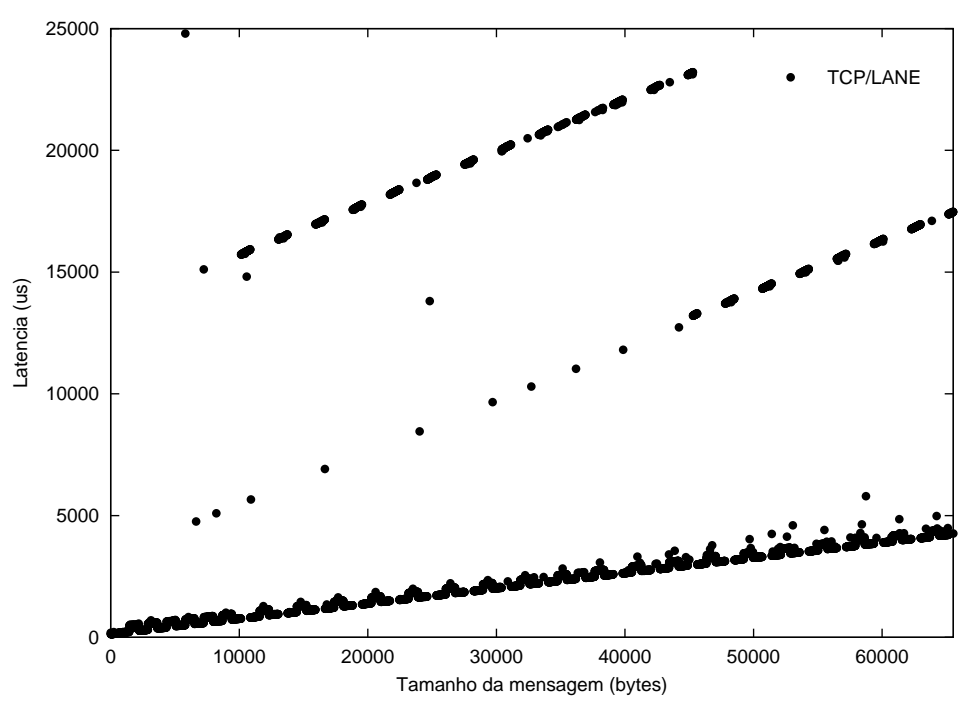

Figura 5.12: Latência de aplicativo a aplicativo em função do tamanho da mensagem utilizando sockets TCP sobre LANE com escala reduzida no eixo vertical.

\subsubsection{Latência do UDP sobre LANE}

Na figura 5.13 é mostrada a latência de comunicação de aplicação a aplicação para UDP sobre LANE. Mensagens maiores que 23670 bytes não conseguiram atravessar a rede LANE/ATM. Testes com pings desta ordem de grandeza também não obtiveram sucesso com LANE, enquanto que sobre CLIP e Fast Ethernet funcionaram corretamente.

\subsubsection{Latência do TCP sobre Fast Ethernet}

Para servir de comparação foram realizados testes similares aos mostrados anteriormente com Fast Ethernet. Na figura 5.14 é mostrada a latência de comunicação de aplicação a aplicação com Fast Ethernet, sendo que o mesmo gráfico é mostrado na figura 5.15 com uma escala mais adequada à análise dos valores obtidos. Novamente observamos jitter nas transmissões de mensagens em toda 


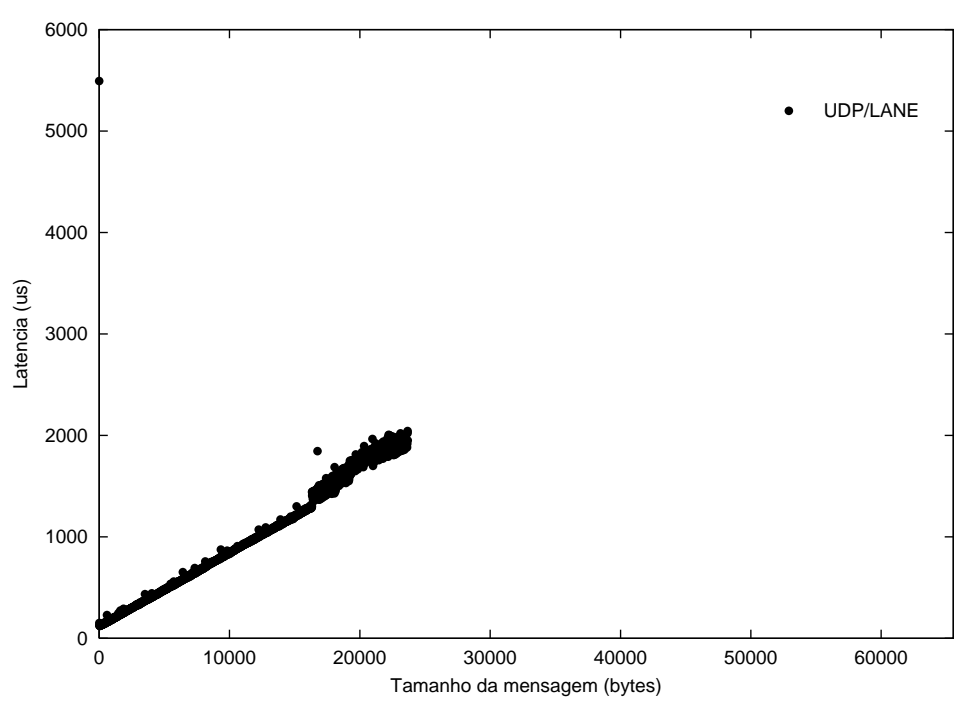

Figura 5.13: Latência de aplicativo a aplicativo em função do tamanho da mensagem utilizando sockets UDP sobre LANE.

a faixa de 1 a $64 K B$.

\subsubsection{Latência do UDP sobre Fast Ethernet}

Por fim, a latência de comunicação de aplicação a aplicação para UDP sobre Fast Ethernet é apresentada na figura 5.16. O mesmo gráfico está ilustrado na figura 5.17 com escala adequada à visualização do comportamento da latência das mensagens pequenas. Pode ser observado que o gráfico que parecia ter um comportamento bem linear na figura 5.16, apresenta na verdade ondulações que começam a surgir para mensagens maiores que 1500 bytes. Isto se deve pelo fato do MTU do Fast Ethernet ser alcançado e mais de um frame Ethernet ter de ser utilizado. Porém, a tecnologia Fast Ethernet não permite que sejam enviados frames menores que 640 bytes. É feito um padding então, surgindo um incremento considerável na latência apenas para mensagens maiores que 622 bytes (considerando um overhead de 18 bytes devido ao frame Ethernet 


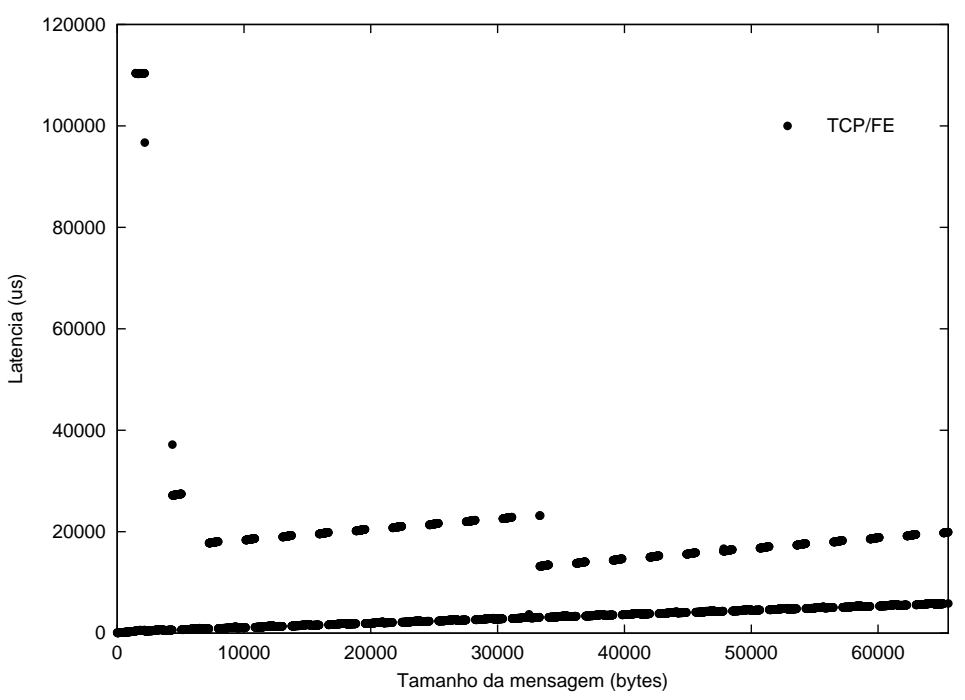

Figura 5.14: Latência de aplicativo a aplicativo em função do tamanho da mensagem utilizando sockets TCP sobre Fast Ethernet.

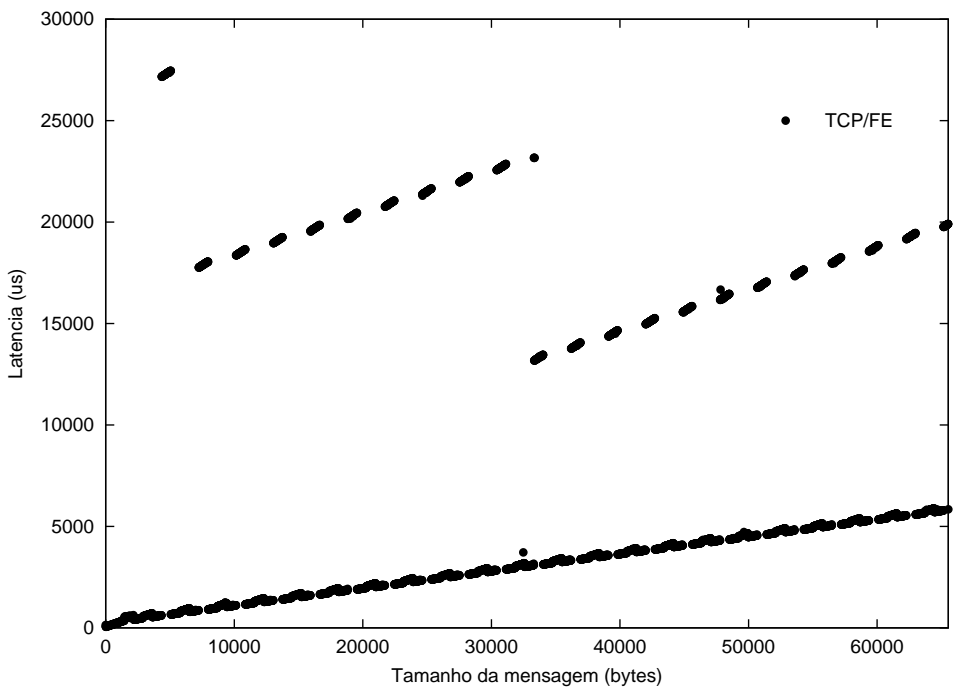

Figura 5.15: Latência de aplicativo a aplicativo em função do tamanho da mensagem utilizando sockets TCP sobre Fast Ethernet com escala reduzida no eixo vertical. 


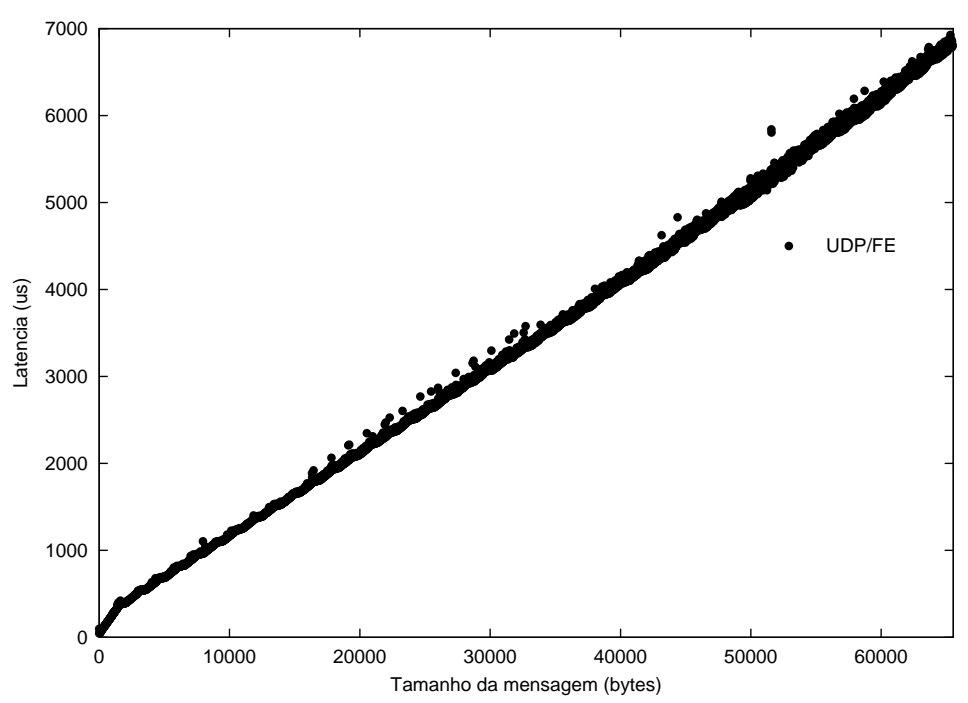

Figura 5.16: Latência de aplicativo a aplicativo em função do tamanho da mensagem utilizando sockets UDP sobre Fast Ethernet.

[Tan92a]). Pode ainda ser verificado que o throughput mais baixo com relação ao CLIP, por exemplo, faz com que a latência seja significamente maior para mensagens grandes. Tomando mensagens de 64 Kbytes como exemplo, notamos que para Fast Ethernet a latência medida foi de $7 \mathrm{~ms}$, enquanto que para CLIP foi de $5 \mathrm{~ms}$.

\subsection{Latência de aplicativo a driver e latência no meio físico}

Para a realização de medidas de tempo no driver da placa de rede, foi necessário estudar-se o uso das interfaces MultiKron dentro do kernel do Linux. Os estudos desenvolvidos estão detalhados nas seções seguintes. 


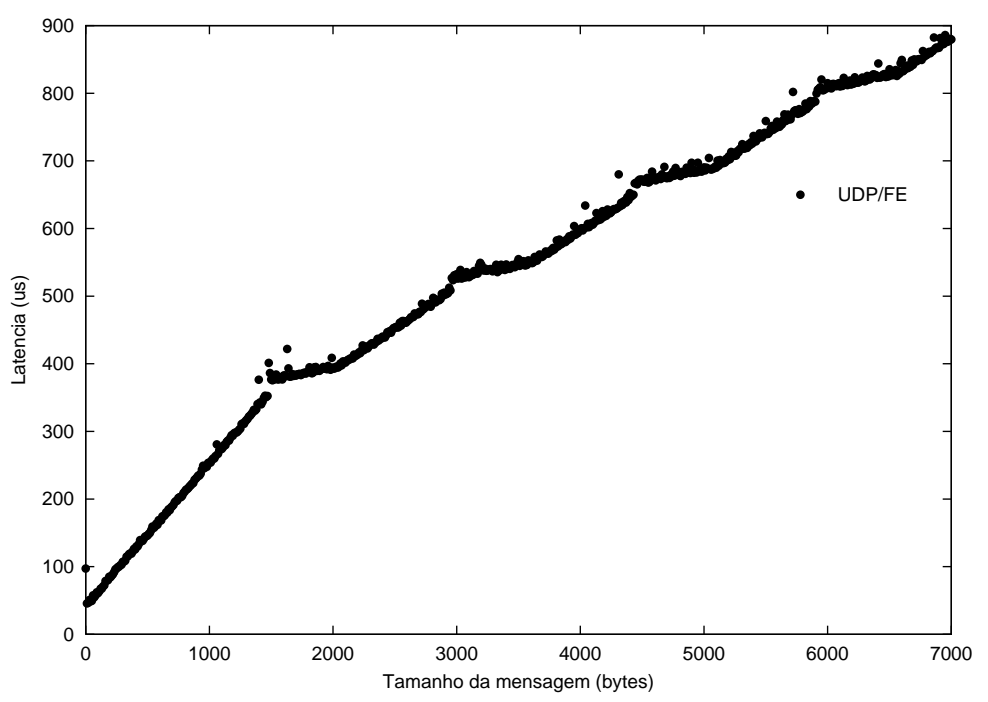

Figura 5.17: Latência de aplicativo a aplicativo em função do tamanho da mensagem para mensagens pequenas utilizando sockets UDP sobre Fast Ethernet.

\subsubsection{Uso das interfaces MultiKron no kernel}

Dificuldades surgiram ao se tentar usar a MultiKron no kernel, pois os programas que se utilizam da MultiKron até aqui mencionados fazem uso de uma rotina de inicialização da MultiKron (parte integrante do software que acompanha o produto), que inicializa o endereço base para programas de usuário acessarem os registradores da placa. Esta rotina opcionalmente também altera o estado dos registradores de controle de operação da interface dependendo dos parâmetros passados. A primeira ação desta rotina é abrir o arquivo /dev/mk0 associado à placa. Para um programa que roda no espaço do usuário isto não oferece problema algum, pois basta no início do programa adicionar a linha \#include $\langle$ f cntl. h $\rangle$ e o compilador gcc já se encarrega de incluir a biblioteca que contém a função open( ) na geração do programa executável. Porém, ao compilar um kernel ou um módulo do kernel não é possível utilizar as bibliotecas do sistema, pois elas pertencem ao nível do usuário, 
e não ao espaço do kernel. Sabendo que a biblioteca nada mais faz senão colocar alguns valores nos registradores certos e fazer uma chamada de sistema para passar o controle ao kernel [Tan92b], que é quem realmente implementa a função open( ), procurou-se no código fonte do kernel a função que é chamada ao se causar a interrupção correspondente à função open( ). A primeira tentativa foi construir um módulo de kernel cuja rotina de inicialização fosse similar aos programas até então utilizados, mas que fizesse uso direto da função que implementa open( ) dentro do kernel, cujo nome é sys_open( ). Seu protótipo é int sys_open(const char $*$ filename, int flags, int mode), muito similar ao protótipo da função comumente utilizada. Esta tentativa fracassou pois a abertura do arquivo não era bem sucedida, com a função sys_open( ) retornando -14 , cujo significado é Bad Address. Descobriu-se que a função tentava copiar a string correspondente ao nome do arquivo do espaço do usuário para o espaço do kernel, através da função getname( ), o que é absolutamente correto para programas que rodam no espaço de usuário, pois estas strings também ficam armazenadas no mesmo espaço, mas não era correto no caso do nosso módulo, pois ele já estava no espaço do kernel. A função da chamada de sistema só poderia ser chamada a partir do espaço do usuário, como tinha de ser, já que este é o método empregado para prover uma máquina virtual ao programador em nível de usuário [Tan92c]. A solução proposta foi escrever uma outra função para a abertura do arquivo, sem a cópia da string, o que funcionou.

Após a abertura do arquivo, a rotina de inicialização da placa MultiKron tenta mapear o dispositivo na memória virtual do processo através do uso da função mmap( ). Esta função, analogamente à função open( ), faz parte das bibliotecas do sistema, sendo imple- 
mentada no kernel e chamada através de uma chamada ao sistema. Tentou-se então utilizar o mesmo procedimento utilizado anteriormente. A função no kernel foi identificada por do_mmap( ), cujo protótipo é unsigned long do_mmap(struct file * file, unsigned long addr, unsigned long len, unsigned long prot, unsigned long flags, unsigned long off), que é sensivelmente diferente do protótipo utilizado pelas bibliotecas: void $*$ mmap(void $*$ start, size_t length, int prot, int flags, int $f d$, off_t offset). Uma etapa intermediária foi necessária então para obter um ponteiro para struct file a partir do descritor de arquivo. Cada erro de programação ou acesso inválido à alguma região de memória trazia graves consequências. No melhor dos casos o kernel percebia que o módulo tinha feito algo que não devia e não o deixava mais executar. Nos casos mais graves o sistema todo ficava inoperante e nada restava a não ser reiniciar a máquina. Durante o boot inevitavelmente tinha de ser feito uma checagem em todo o sistema de arquivos, pois a máquina não tinha sido desligada de maneira correta. O processo de checagem do sistema de arquivos acarretava em uma grande fragmentação de memória no espaço de kernel impedindo que o driver da placa ATM conseguisse alocar espaço contínuo suficiente para os buffers necessários à sua operação. Um novo reboot tornava-se necessário para eliminar este problema. Tornou-se por fim possível fazer medidas de tempo a partir da MultiKron no interior de um módulo. A rotina de inicialização da placa foi então reescrita fazendo uso destas funções alteradas para que programas em espaço de kernel pudessem utilizá-la, enquanto que programas em nível de usuário continuaram utlizando a rotina original, que faz uso das bibliotecas do sistema.

Decidiu-se então chamar a rotina especial de inicialização das 
placas MultiKron dentro da rotina de inicialização das placas ATM, cujo driver também estava sendo compilado como módulo, e colocar instruções de coleta de tempo dentro do driver ATM, especialmente na rotina que sinaliza ao chip IDT 77211 que ele tem um datagrama a transmitir e na rotina de tratamento de interrupção da placa ATM quando verificado que a interrupção é causada pela chegada de um datagrama [IDT97]. Seria assim possivel determinar a latência da comunicação através do meio físico (com o atraso imposto pela chave) e da latência imposta pelos diversos protocolos entre o aplicativo e o ponto mais baixo no qual poderíamos fazer alguma medida de tempo.

Para o correto funcionamento do sistema ATM, é necessário que estejam rodando alguns daemons no sistema, como o ilmid, que fornece um mecanismo automático de configuração de endereços, o atmsigd, que implementa o protocolo de sinalização UNI e o atmarpd, que implementa o protocolo ATMARP como especificado no RFC 2225 [LH98]. Isto faz com que alguns pacotes trafeguem pela rede mesmo que não haja nenhum aplicativo de usuário transmitindo dados.

Com a inserção das chamadas para a MultiKron dentro do driver ATM o sistema como um todo começou a se comportar de maneira muito errática. Foi possível observar a correta inicialização da placa MultiKron com a inserção de um comando printk( ) no interior da rotina especial de inicialização, mas os daemons morriam em sequência assim que eram chamados, sugerindo que eles deveriam ter permissão de acesso à memória utilizada pela MultiKron. Foi então inserida em cada daemon uma chamada para a rotina original de inicialização, já que eles rodam no espaço de usuário, que fizesse o mapeamento da memória da MultiKron em seu espaço virtual 
de memória. Isto funcionou por alguns minutos, sendo possível registrar eventos na MultiKron tanto a partir do driver ATM como dos daemons ATM. Decorrido algum tempo, aparentemente sem motivo, algum daemon morria ou o sistema todo ficava inoperante devido a um Kernel Panic. Devido à complexidade do sistema a ser analisado (interação entre kernel, módulos, vários daemons que dependem um do outro, aplicativos em nível de usuário, canais ATM sendo criados e destruídos pelo próprio sistema) e à própria dificuldade que o sistema apresentava à análise da sequência de eventos que levavam ao Kernel Panic, optou-se por outra alternativa: usar a função gettimeofday ( ) do sistema e registrar o tempo com printk( ), como explicado na seção seguinte. Além disso, não conseguimos registrar com sucesso nenhum evento com a MultiKron no interior da rotina de tratamento de interrupção. É sabido também que os processadores atuais têm diferentes modos de execução, restringindo os tipos de operações permitidas em determinados trechos do kernel, possivelmente restringindo nossas medidas nestas regiões [Col01]. Também não obtivemos sucesso no registro de tempos dentro do próprio kernel, somente em módulos. Isto restringiria as possibilidades de medida já que toda a pilha TCP/IP é implementada dentro do kernel sem a possibilidade de se compilar este conjunto como módulo, motivo que reforça a alternativa escolhida.

\subsubsection{Uso de gettimeofday（ ） para medida de latência no ker- nel}

Processadores que executam instruções da arquitetura x86 da geração do Pentium em diante (como é também o caso do AMD K6 III que utilizamos neste trabalho) possuem um contador de 64 bits que é incrementado a cada ciclo de clock da máquina. A instrução de 
máquina rdtsc (do inglês, Read-Time Stamp Counter) retorna os 32 bits de alta ordem no registrador $e d x$, e os 32 bits de baixa ordem em eax [Int01]. Conhecendo a frequência do clock da máquina fica portanto fácil determinar o tempo decorrido, com alta precisão.

A proposta alternativa é obter o tempo instantâneo com o uso da função do_gettimeofday( ), que fornece uma precisão de $1 \mu \mathrm{s}$, e registrar este tempo com printk( ). A função do_gettimeofday( ) tem duas formas diferentes de implementação no kernel do Linux:

- uma implementação genérica que pode ser utilizada em qualquer arquitetura, mas que é razoavelmente lenta por ter que fazer muitas operações, como verificar se o Advanced Power Management está ligado (pois isto pode acarretar em um desvio de tempo), se o chipset é o Neptune (pois ele tem um bug que precisa ser contornado), sem mencionar que algumas interrupções do timer podem ter sido perdidas, acarretando em desvio de tempo.

- uma implementação mais rápida e específica que faz uso da instrução rdtsc anteriormente citada.

Ao compilar o kernel o sistema sabe se a arquitetura a ser utilizada dispõe da instrução rdtsc e caso afirmativo passa a utilizar a implementação de do_gettimeofday( ) que a utiliza, já que ela é melhor.

Para ter certeza que o overhead dessa alternativa não seria muito grande criamos um módulo cuja rotina de inicialização continha um loop que era executado mil vezes. O interior do loop continha o seguinte trecho de código:

do_gettimeofday (\&tv); 
ltime $=$ tv.tv_sec $* 1000000+t v \cdot t v \_u s e c ;$

printk("ns_sen:\%lu\n", ltime);

Convém mencionar que uma rotina de inicialização de um módulo não é interrompida por interrupções, permitindo assim uma boa determinação do tempo gasto pela inserção deste código no pontos onde queremos determinar o tempo. Chegou-se a um valor médio de $2,5 \mu$ s quando o argumento de printk( ) tem o formato como mostrado, com um rótulo de identificação de seis letras, além dos dois pontos e do long int que se segue, não representando portanto uma interferência muito grande no sistema, já que este tempo é muito menor que os tempos que estamos a determinar, como já foi posssível visualizar até aqui.

Como os relógios dos dois micros não são sincronizados, ainda dependemos da MultiKron para estabelecer este sincronismo. A técnica adotada foi executar um programa (em nível de usuário mesmo) que a cada $150 \mathrm{~ms}$ registra um evento na MultiKron, cujo rótulo identificador é o valor calculado a partir do resultado da função gettimeofday( ), exatamente como mostrado no trecho de código acima para a variável ltime. Assim é possível corresponder cada instante obtido com gettimeofday( ) com o clock central da MultiKron. Com o auxílio deste aplicativo é gerada uma tabela em que uma coluna contém os valores calculados com gettimeofday( ) e a outra os valores dos time stamps obtidos a partir do relógio central. Com essa tabela e o aplicativo GNUPlot é feita uma regressão linear que permite a conversão de qualquer gettimeofday( ) para MultiKron clock. Este aplicativo deve ficar executando enquanto são realizadas as medidas de tempo de interesse para que pontos válidos sejam gerados no mesmo período. 


\subsubsection{Obtenção dos dados experimentais}

Existe no Linux o Kernel $\log$ Daemon, referenciado daqui para a frente como klogd, que entre outras facilidades é capaz de capturar tudo o que é escrito com printk( ) e gravar em um arquivo de log através do uso de uma chave apropriada [Rub98]. Todas as medidas realizadas no kernel ou nos módulos do kernel aparecem então neste arquivo, entre as outras várias mensagens do próprio sistema, enquanto que as medidas realizadas nos aplicativos de comunicação são feitas diretamente com a MultiKron.

A sequência de procedimentos para a obtenção dos resultados começa em rodar o klogd em ambos os micros. A seguir é verificado se a unidade de clock central está ligada e ajustada para a frequência de operação desejada. Depois o aplicativo de geração da tabela de conversão de gettimeofday para MultiKron time é colocado para rodar em background em ambas as máquinas. O aplicativo de comunicação é iniciado, sendo que o servidor em uma máquina e o cliente em outra. No início da execução dos aplicativos, eles pedem que o clock central seja reiniciado. Inicia-se a seguir o processo de comunicação entre eles.

O aplicativo cliente foi desenvolvido de maneira a enviar mensagens para o aplicativo servidor, em séries de cinco mensagens, separadas entre si por aproximadamente $100 \mu \mathrm{s}$. O tempo de espera entre cada série começa em $10 \mathrm{~s}$ e vai dobrando a cada etapa, até atingir um tempo máximo especificado pelo usuário, conforme mostrado na figura 5.18. Isto foi feito com o intuito de verificar o comportamento da rede com longos tempos de espera, para verificar a influência do fechamento e posterior abertura dos canais ATM utilizados por sockets que continuam abertos durante este período. 


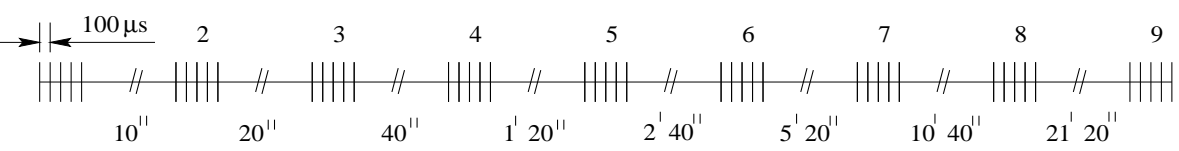

Figura 5.18: Espaçamento temporal das mensagens enviadas do aplicativo cliente para o servidor utilizadas para determinação da latência de comunicação no kernel. As mensagens são transmitidas em séries de cinco, com $100 \mu s$ entre elas. O tempo aguardado entre as séries é inicialmente $10 \mathrm{~s}$, sendo dobrado a cada nova série.

\subsubsection{Latência no kernel com TCP sobre CLIP}

Antes que possa ser feita a transmissão de uma mensagem de um aplicativo a outro através de TCP é necessário estabelecer uma conexão TCP. A abertura da conexão é feita através da chamada de sistema connect(), e levou aproximadamente $33 \mathrm{~ms}$ com CLIP. Isto ocorreu devido à necessidade do CLIP abrir um canal ATM para a outra máquina. Só quando a conexão ATM está completa é que o TCP pode estabelecer a sua conexão. Observa-se que este valor é da mesma ordem de grandeza do valor encontrado com ping através de CLIP, o que se justifica uma vez que o fator predominante na duração do estabelecimento da conexão do socket é a demora do CLIP na abertura do canal ATM.

Uma vez estabelecida a conexão TCP, mensagens de 1000 bytes levaram em geral entre $221 \mu \mathrm{s}$ e $506 \mu \mathrm{s}$ para serem transmitidas de um aplicativo a outro. Deste tempo, cerca de $150 \mu \mathrm{s}$ foram gastos na transferência pela rede, incluindo o atraso imposto pela chave ATM. A primeira mensagem de cada série tendeu a levar mais tempo que as demais para ser transmitida do aplicativo até o driver, no lado transmissor, e da rotina de tratamento de interrupção ao aplicativo no lado receptor. Nas séries de 1 a 8 , a primeira mensagem de cada série levou aproximadamente $53 \mu s$ para ser transmitida do aplicativo até o driver, no lado transmissor, e $280 \mu \mathrm{s}$ da rotina de tra- 
tamento de interrupção ao aplicativo no lado receptor, sendo que as mensagens subsequentes levaram aproximadamente de $30 \mu s$ e $230 \mu s$, respectivamente.

Entre as séries 8 e 9 há uma espera de 21 min e $20 s$, que corresponde a um tempo superior ao tempo máximo que um canal CLIP/ATM fica aberto sem utilização, levando ao fechamento do canal ATM. Porém, como a conexão TCP não é desfeita por nenhuma das pontas, o aplicativo pode iniciar uma transmissão sem ter que estabelecer uma nova conexão TCP. Isto faz com que ao ser enviada a primeira mensagem da série 9, um novo canal ATM tenha que ser aberto. Isto levou a uma latência de $23 m s$ para a primeira mensagem ser transmitida do aplicativo ao driver e $14 \mathrm{~ms}$ para as demais, provavelmente porque o aplicativo as enviava ao socket quase uma seguida da outra (100 $\mu$ s após a anterior, para ser mais exato), não havendo tempo suficiente para o canal ATM estar aberto. No lado receptor a primeira mensagem levou $1.4 \mathrm{~ms}$ para ser transmitida do driver ao aplicativo, sendo que as demais levaram de 38 a $94 \mu s$.

\subsubsection{Latência no kernel com UDP sobre CLIP}

Quando é feita transmissão de mensagens através de UDP não é necessária a abertura de uma conexão. É só enviar e esperar que o destinatário receba a transmissão. É no momento do envio da primeira mensagem então que o sistema percebe que precisa abrir um canal ATM para a outra máquina a fim de transmitir a mensagem. Para mensagens de 1000 bytes isto introduziu uma latência de $43 \mathrm{~ms}$ de aplicativo a aplicativo para a primeira mensagem, sendo que a latência medida em situações normais de funcionamento (com o canal ATM aberto) foi por volta de $460 \mu \mathrm{s}$.

Da segunda série em diante, quando o canal ATM já estava de- 
vidamente preparado para a transmissão de mensagens, a primeira mensagem levou aproximadamente $38 \mu \mathrm{s}$ para ser transmitida do aplicativo ao driver no lado transmissor e $245 \mu \mathrm{s}$ do driver ao aplicativo no lado receptor, sendo que as demais levaram aproximadamente 22 e $280 \mu s$, respectivamente. O tempo gasto no meio físico foi sempre por volta de $150 \mu s$.

\subsubsection{Latência no kernel com UDP sobre LANE}

Em situação de funcionamento pleno, os tempos obtidos com UDP sobre LANE foram muito semelhantes ao caso do UDP sobre CLIP, porém, é claramente diferente no envio da primeira série de mensagens. Na primeira série, a primeira mensagem é enviada de maneira transparente pelo BUS, tendo uma latência de 3 a $6 \mathrm{~ms}$ de aplicativo a aplicativo. As mensagens seguintes já não são enviadas pelo BUS, e por isso a segunda mensagem tem uma latência de 20 a $40 \mathrm{~ms}$. Esta situação se repete quando o canal fica inutilizado por mais de 5 minutos, sendo visualizado nas séries 7 em diante.

Tornou-se no caso do UDP sobre LANE bastante difícil o reconhecimento de qual registro de tempo era relativo à passagem da mensagem em questão, tanto no lado transmissor quanto no lado receptor. Isto porque, apesar de ser possivel estabelecer uma ordem cronológica com os registros feitos nos aplicativos ${ }^{1}$, eram realizados vários registros de tempo no driver quando o canal ATM ainda não estava criado. Parte dos registros era causada pelos daemons, com a sinalização necessária para criar o novo canal, outro registro era causado pelo envio da mensagem ao BUS e as demais pelo envio

\footnotetext{
${ }^{1}$ Não seria possível, por exemplo, atribuir um registro de envio no driver a uma mensagem que ainda não foi enviada pelo aplicativo, assim como um registro de recebimento na rotina de tratamento de interrupção no lado receptor para uma mensagem que já foi anteriormente recebida pelo aplicativo.
} 
das mensagens através do canal. Não era porém possivel saber qual era a causa de cada registro específico. Foram feitas então pequenas alterações adicionais no driver da interface ATM para registrar com printk() o valor do par VPI/VCI associado a cada registro de tempo. Isto serviu para identificar todas as mensagens que foram enviadas pelo canal ATM recém criado, pois foi só localizar quatro registros próximos referentes a mensagens enviadas ou recebidas pelo mesmo VPI/VCI. Não foi suficiente para solucionar o problema da primeira mensagem nem das mensagens de sinalização.

\subsubsection{Latência no kernel com TCP sobre LANE}

Com base nos resultados dos casos anteriores e nos problemas encontrados, não se achou relevante a realização das medidas para o caso TCP sobre LANE.

\subsection{Resumo dos resultados}

O aplicativo ping permitiu verificar a influência da abertura dos canais ATM na latência de comunicação de uma máquina a outra, indicando que para CLIP há uma latência mínima de $24 \mathrm{~ms}$ para o primeiro pacote transmitido e para LANE quase $1 s$, sendo que sobre Fast Ethernet, onde não há a abertura de um canal, este tempo é de aproximadamente $0,4 \mathrm{~ms}$.

Através dos aplicativos contruídos com sockets foi possivel uma determinação mais realística da latência de aplicativo a aplicativo, uma vez que o ping no lado receptor vai apenas até a camada IP, não chegando até a camada de aplicação.

Com UDP sobre CLIP a latência cresceu linearmente com o tamanho da mensagem, sem apresentar jitter considerável ou outro 
efeito indesejado qualquer. Já o TCP sobre CLIP apresentou jitter para mensagens por volta 11000, 40000 e 65000 bytes, provavelmente causado pelos mecanismos de controle do TCP.

O UDP sobre LANE apresentou um comportamento bastante linear da latência em função do tamanho das mensagens, além de problemas para a transmissão de pacotes maiores que 23670 bytes. O TCP sobre LANE apresentou um jitter bastante considerável ao longo de toda a faixa de 1 a 64 Kbytes, provavelmente causado pelos mecanismos de controle do TCP.

O comportamento da latência do UDP sobre Fast Ethernet foi bastante linear e do TCP sobre Fast Ethernet também apresentou um jitter considerável. Notou-se que o throughput mais baixo do Fast Ethernet em relação ao CLIP aumenta significativamente a latência para mensagens grandes.

Nas medidas realizadas no kernel do Linux descobriu-se que na comunicação por TCP, grande parte da demora na comunicação ocorre no estabelecimento da conexão TCP com a chamada de sistema connect ( ). Na comunicação por UDP, a maior demora ocorre na transmissão do primeiro pacote, pois como não existe um canal virtual estabelecido, é no envio do primeiro pacote que é percebida a necessidade do estabelecimento de um canal ATM, causando o atraso no seu envio. O caso UDP sobre LANE é favorecido pelo BUS na redução da latência de transmissão da primeira mensagem, uma vez que as demais têm que aguardar a criação do canal ATM que conecta as duas máquinas diretamente. Tanto com CLIP quanto com LANE, foi no lado receptor que residiu a maior parte da latência, na transmissão da mensagem do driver até o aplicativo. 


\section{Capítulo 6}

\section{Conclusões}

O desempenho do Classical IP é bastante satisfatório sendo que a implementação de LAN Emulation no Linux ainda precisa ser mais trabalhada e optimizada para que seu uso não pareça desvantajoso quando comparado com CLIP, apesar de oferecer a clara vantagem da conectividade com outras tecnologias. O baixo desempenho do LANE obtido em algumas situações não deve ser atribuído ao protocolo em si, sendo a causa mais provável o próprio código que implementa o LANE em Linux. Não deixa de existir a possibilidade de uma diminuição no desempenho devido ao kernel do Linux ou do hardware empregado, uma vez que uma queda no throughput para mensagens pequenas foi observada também com CLIP e Fast Ethernet. Para isolar a causa seriam necessárias medidas adicionais, variando o equipamento utilizado, assim como a versão do kernel ou mesmo substituindo o sistema operacional para observar se o fenômeno se repete. Claro que isto poderia não ser muito prático uma vez que LANE não é implementado em muitos sistemas operacionais.

As medidas realizadas com FTP foram úteis para mostrar que em situações práticas as taxas máximas de transferência obtidas 
Tabela 6.1: Tabela comparativa das latências obtidas com o aplicativo ping para LANE, CLIP e Fast Ethernet.

\begin{tabular}{||c|l|c|c|c||}
\hline \hline \multicolumn{2}{|c|}{ Latência $(m s)$} & LANE & CLIP & $\begin{array}{c}\text { Fast } \\
\text { Ethernet }\end{array}$ \\
\hline \hline \multirow{2}{*}{ Entre computadores } & $1^{o}$ pacote & 995 & 24 & 0,4 \\
\cline { 2 - 5 } & pacotes subseqüentes & 0,4 & 0,4 & 0,1 \\
\hline \hline \multirow{2}{*}{$\begin{array}{c}\text { Entre computador } \\
\text { e chave }\end{array}$} & $1^{o}$ pacote & 1003 & 2,1 & - \\
\cline { 2 - 5 } & pacotes subseqüentes & 3 & 2 & - \\
\hline \hline
\end{tabular}

são bastante próximas das que se esperava obter pelas equações (2.1) e (2.4). Porém, isto não reflete o comportamento da rede para qualquer tipo de aplicação uma vez que o FTP explora o envio de pacotes grandes, sendo que aplicações muitos utilizadas como navegadores tipicamente enviam e recebem pacotes de diversos tamanhos, inclusive alguns de tamanho bastante reduzido, para os quais o overhead dos diversos protocolos torna-se bastante significativo.

O aplicativo ping, apesar de muito simples, foi útil para mostrar que a latência de transmissão do primeiro pacote através de LAN Emulation é da ordem de $1 s$, muito superior à latência obtida com CLIP ou Fast Ethernet, conforme sintetizado na tabela 6.1. Estes resultados preliminares indicam que Fast Ethernet oferece uma menor latência de transmissão para mensagens pequenas do que CLIP ou LANE, sendo que estes últimos oferecem uma latência similar em situação de uso pleno.

O aplicativo Netperf mostrou-se muito robusto e eficiente a que se propõe, sendo que seu uso ficou ainda mais amplo com a utilização de scripts tanto para automatizar o seu uso quanto para a seleção dos dados de saída de interesse. 
Um fato revelador durante o trabalho foi a grande queda de desempenho obtida em um sistema pelo uso de uma placa de vídeo onboard, fato este que motivou a confecção de um artigo a ser publicado no SBAC 2001 [MNTS01]. Conclui-se com este trabalho que a análise de desempenho de um sistema depende muito da sua configuração, incluindo o modelo das placas usadas, se são do tipo onboard ou não, o chipset da placa mãe (conforme mostrado em [MNTS01]), a versão dos softwares que estão sendo utilizados e o número de aplicativos rodando simultaneamente no sistema. A utilização de CPU por outros processos pode influenciar significativamente no desempenho dos protocolos de rede CLIP e principalmente LANE.

O desempenho do protocolo UDP foi bastante satisfatório, sendo observadas latências reduzidas com a rede em uso pleno (com canais ATM criados), especialmente para mensagens grandes, que são favorecidas pelo maior throughput da rede. O jitter observado com UDP foi desprezivel. Perdas de pacotes foram detectadas com o uso de Netperf e UDP, mas esta perda sempre ocorreu no lado receptor, uma vez que a chave não realizava nenhum descarte de células por não haver outro tipo de tráfego competindo pelos recursos. Através do uso do UDP foi possível também verificar e quantificar a dependência do desempenho do sistema com relação à configuração do equipamento utilizado, refletido principalmante pela perda de pacotes pequenos no lado receptor.

Apesar do uso do protocolo TCP/IP com ATM manter compatibilidade e conseqüente interoperabilidade com máquinas dotadas de interfaces de rede de outras tecnologias, ele não apresenta as melhores características de desempenho que se poderia esperar com a utilização de uma rede que é capaz de oferecer garantias de GoS. 
O fato do TCP/IP ter sido desenvolvido para redes do tipo sem conexão e ter sofrido incontáveis alterações e adaptações desde seu surgimento, tornando-o por demais complexo, dificulta e até mesmo impede um uso mais eficiente e racional dos recursos oferecidos pela tecnologia ATM. Uma vez que os canais ATM, pelas suas características de QoS, não apresentam muitos dos problemas presentes em redes reais de outras tecnologias, é tentadora a idéia de usar um protocolo mais simples e robusto que aproveite todas as boas características do ATM.

Sockets representam uma maneira simples e eficiente de transmissão de dados através da rede. É interessante notar que em Linux a API vem sendo estendida para o oferecimento de novos serviços com melhor utilização dos recursos que a tecnologia ATM é capaz de oferecer [Alm96]. É com ansiedade que esperamos o surgimento de aplicações desenvolvidas para executar especificamente sobre ATM.

As medidas de tempo realizadas dentro do kernel do Linux permitiram verificar que grande parte da latência de comunicação reside na máquina receptora. Tal fato já foi comentado na literatura e grande parte da culpa é atribuída à cópia adicional dos dados realizada no lado receptor, da memória no espaço do kernel para a memória no espaço do usuário. Como valores típicos podemos citar os resultados da seção 5.3.5 para UDP sobre CLIP. Constatou-se que em funcionamento pleno, foram gastos $22 \mu \mathrm{s}$ da aplicação ao driver no lado transmissor e $280 \mu s$ do driver à aplicação no lado receptor para mensagens de 1000 bytes. O tempo gasto na transmissão pelos componentes físicos da rede foi sempre por volta de $150 \mu s$ para mensagens de 1000 bytes, não causando jitter nas transmissões com UDP. Isto também vem a indicar que o jiter observado 
com TCP não é devido à rede mas sim ao protocolo em si. 


\section{Referências Bibliográficas}

[Alm95] W. Almesberger. High-speed ATM networking on low-end computer systems. EPFL, CH-1015 Lausanne, Switzerland, August 1995. Laboratoire de Réseaux de Communication (LRC), IEEE Fifteenth Annual International Phoenix Conference on Computers and Communications.

[Alm96] W. Almesberger. Linux ATM API version 0.4, July 1996. EPFL, LRC.

[Arm96] G. Armitage. Support for Multicast over UNI 3.0/3.1 based ATM Networks, November 1996. RFC2022.

[Atk94] R. Atkinson. Default IP MTU for use over ATM AAL5, May 1994. RFC1626.

[ATM95] ATM Forum. LAN Emulation Over ATM Version 1.0. ftp://ftp.atmforum.com/pub/approved-specs/ af-lane-0021.000.pdf, January 1995.

[ATM01] ATM Forum. The History of ATM, June 2001. http://www . atmforum.com/pages/aboutatmtech/atmhistory.html.

[Col01] R. Collins. Protected mode, February 2001. http://www. x86.org/articles/pmbasics/tspec_a1_doc.htm. 
[Com95a] D. E. Comer. Internetworking With TCP/IP, volume 1. Prentice-Hall, 3rd edition, 1995.

[Com95b] D. E. Comer. Internetworking With TCP/IP - Principles, Protocols, and Architecture, volume 1, chapter 7. Prentice Hall, 3rd edition, 1995.

[Cor97] Platform Architecture Labs Intel Corporation. Pci efficient use, April 1997. http://support.intel.com/support/ chipsets/PC1001. HTM.

[Fox89] R. Fox. TCP Big Window and Nak Options, June 1989. RFC1 106.

[Hei93] J. Heinanen. Multiprotocol Encapsulation over ATM Adaptation Layer 5, July 1993. RFC1483.

[IDT97] IDT, Santa Clara, California, USA. IDT77211 Nicstar User Manual, version 1.0 edition, February 1997. http://www . idt.com.

[Int01] Intel. Model specific registers and functions, February 2001. http://developer.intel.com/design/intarch/ techinfo/Pentium/mdelregs.htm\%.

[ITU93] ITU-T. B-ISDN ATM Adaptation Layer Specification, March 1993. Recommendation I.363.

[ITU96] ITU-T. B-ISDN ATM Adaptation Layer Specification: Type 5 AAL, 1996. Recommendation I.363.5.

[JBB92] V. Jacobson, R. Braden, and D. Borman. TCP Extensions for High Performance, May 1992. RFC1323. 
[JK88] Van Jacobson and Michael J. Karels. Congestion avoidance and control. In ACM SIGCOMM Conference, pages 314329, 1988.

[Jon00] R. Jones. Netperf homepage, August 2000. http://www. netperf.org.

[Lau93] M. Laubach. Classical IP and ARP over ATM. RFC 1577, January 1993.

[LH98] M. Laubach and J. Halpern. Classical IP and ARP over ATM. RFC 2225, April 1998.

[Min94] A. Mink. Operating Principles of MultiKron II Performance Instrumentation for MIMD Computers. National Institute of Standards and Technology, Gaithersburg, MD 20899, December 1994.

[Min97] A. Mink. Operating Principles of the PCI Bus MultiKron Interface Board. National Institute of Standards and Technology, Gaithersburg, MD 20899, March 1997.

[MNTS01] A. Muezerie, R. J. Nakashima, G. Travieso, and J. F. W. Slaets. Matrix Calculations with SIMD Floating Point Instructions on $\mathrm{x} 86$ Processors. In Proc. of the SBAC, 2001. a ser publicado.

[NIS99] The multikron project, 1999. http://www.multikron.nist. gov/software.html.

[RF95] A. Romanov and S. Floyd. Dynamics of tcp traffic over atm networks. IEEE JSAC, May 1995.

[Rub98] A. Rubini. Linux device drivers, pages 71-72. O'Reilly \& Associates, Inc, 1st edition, February 1998. 
[Ste90a] W. Richard Stevens. Unix Network Programming, pages 56. Prentice-Hall, N. J., 1990.

[Ste90b] W. Richard Stevens. Unix Network Programming, chapter 6. Prentice-Hall, N. J., 1990.

[Ste01] W. Stevens. TCP Slow Start, Congestion Avoidance, Fast Retransmit, and Fast Recovery Algorithms, January 2001. RFC2001.

[Tan92a] A. S. Tanenbaum. Sistemas Operacionais Modernos, page 320. Livros Técnicos e Científicos Editora S. A., 1992.

[Tan92b] A. S. Tanenbaum. Sistemas Operacionais Modernos, page 13. Livros Técnicos e Científicos Editora S. A., 1992.

[Tan92c] A. S. Tanenbaum. Sistemas Operacionais Modernos, page 5. Livros Técnicos e Científicos Editora S. A., 1992. 